Final Scientific/Technical Report

\title{
Advanced Turbo-Charging Research and Development DE-FC26-06NT42873
}

July 5, 2008

Prepared For:

The U.S. Department of Energy

By:

Honeywell International Inc.

Transportation Systems

Turbocharger Technologies (HTT)

Torrance, California 


\section{DISCLAIMER}

This report was prepared as an account of work sponsored by an agency of the United States Government. Neither the United States Government nor any agency thereof, nor any of their employees, makes any warranty, express or implied, or assumes any legal liability or responsibility for the accuracy, completeness, or usefulness of any information, apparatus, product, or process disclosed, or represents that its use would not infringe privately owned rights. Reference herein to any specific commercial product, process, or service by trade name, trademark, manufacturer, or otherwise does not necessarily constitute or imply its endorsement, recommendation, or favoring by the United States Government or any agency thereof. The views and opinions of authors expressed herein do not necessarily state or reflect those of the United States Government or any agency thereof. 


\section{Introduction}

This Final Report for the Advanced Turbo-Charging Research and Development is submitted by Honeywell Inc. to the Department of Energy (DOE) for work performed under Award number: DE-FC26-06NT42873. This report contains activities and expenditures for the second quarter of calendar year 2007. Specifics of the program are as follows:

Project Title:

Advanced Turbo-Charging Research and Development

Project Period:

Till December 31 2007

Date of Report:

June $30^{\text {th }}, 2008$

Recipient:

Honeywell International Inc.

Company Address:

3201 West Lomita Blvd. Torrance, CA 90505

Working Partners:

Not Applicable

Cost-Sharing Partners: Not Applicable

HTT Contact:

HTT Program Director

Reddy Vennam (310) 517-1372

vennam.raghurami.reddy@honeywell.com

HTT Contract Manager

Mark Hall (310) 791-9108

mark.hall@honeywell.com

DOE Managers:

DOE Project Officer

Mr. Samuel Taylor (304) 285-4681

samuel.taylor@netl.doe.gov

DOE Contract Officer

Ms Janet Laukaitis (412) 386-5173

Janet.laukaitis@neti.doe.gov 


\section{PROJECT 1 - SERIES SEQUENTIAL TURBOCHARGING FOR LIGHT-DUTY DIESEL ENGINES}

The objective of this project is to conduct analysis, design, procurement and test of a high pressure ratio, wide flow range, and high EGR system with two stages of turbocharging. The system needs to meet the stringent 2010MY emissions regulations at $20 \%+$ better fuel economy than its nearest gasoline competitor while allowing equivalent vehicle launch characteristics and higher torque capability than its nearest gasoline competitor. The system will also need to meet light truck / SUV life requirements, which will require validation or development of components traditionally used only in passenger car applications. The conceived system is termed "seriessequential turbocharger" because the turbocharger system operates in series at appropriate times and also sequentially when required. This is accomplished using intelligent design and control of flow passages and valves. Components of the seriessequential system will also be applicable to parallel-sequential systems which are also expected to be in use for future light truck / SUV applications.

\section{Background}

Series sequential turbocharging systems improve vehicle launch performance without sacrificing top-end power. These objectives are accomplished by transitioning from a small to large turbochargers. Flow restriction and over-speed of the smaller (high pressure) turbocharger is prevented by means of compressor and turbine bypass valves. Chassis certified vehicles rely heavily on the high pressure variable nozzle turbocharger (VNT) to meet low load emissions targets. Note that during low-load operation, the high pressure (HP) turbocharger provides the majority of boost. 

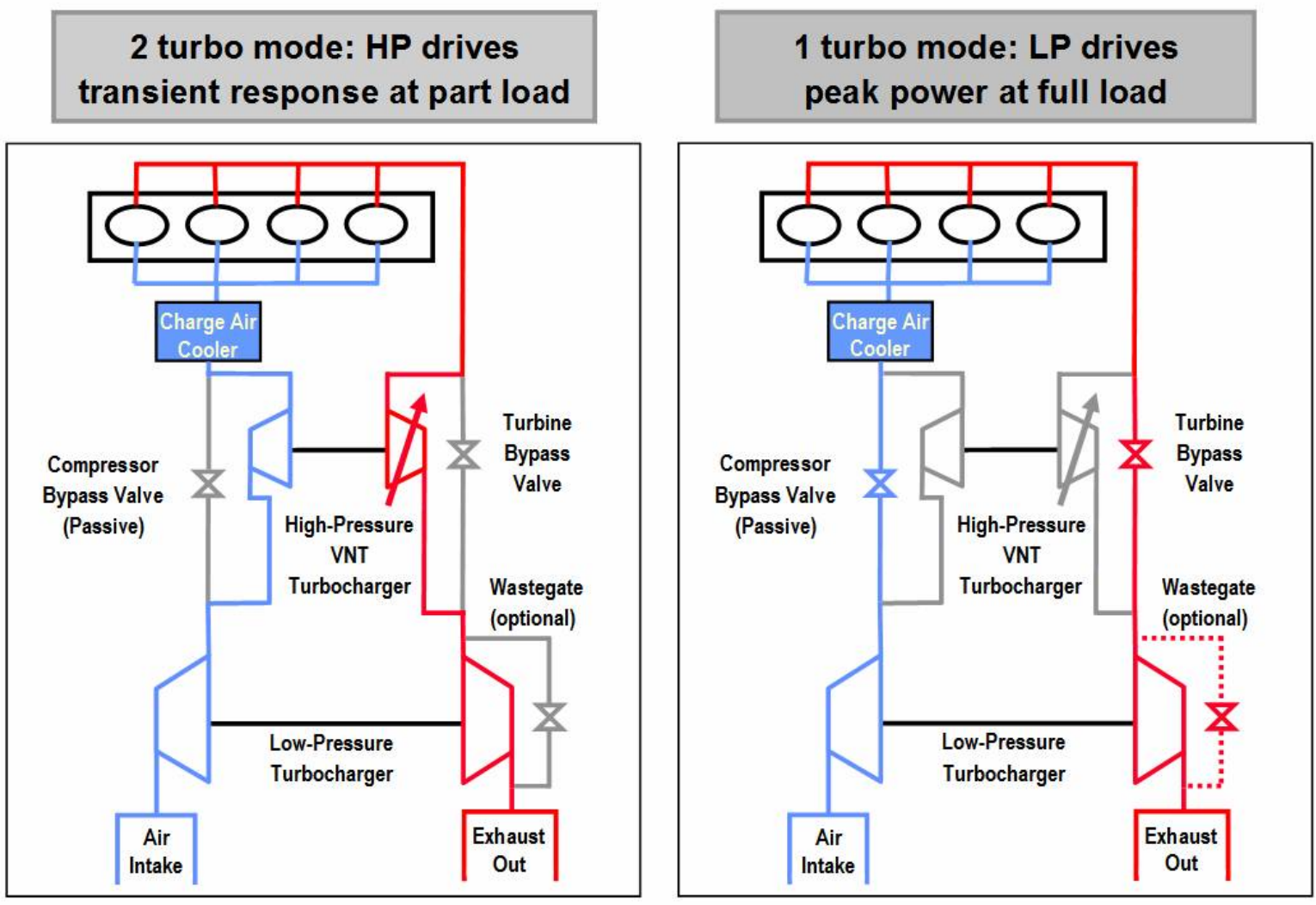

Series sequential system schematic, series operation on the left and single operation on the right.

\section{Task 1.1 - Component Life Requirements}

By utilizing existing engine data, predicted to the more stringent operating conditions for 2010MY emissions compliance, turbo system match analysis will be performed to determine where the High Pressure turbo transitions over to Low Pressure turbo operation. Based on the range requirements, this could be a significant challenge to meet the end-user performance, transition transparency and technology robustness requirements.

\section{Task 1.1 Milestones}

Technology Specifications meant to satisfy the range of anticipated applications will be generated for the following System Components:

- High Pressure Variable Nozzle Turbine (VNT) Turbocharger

- High Pressure Variable Nozzle Turbine Actuator

- Low Pressure Waste-gated Turbocharger

- Turbine Bypass Valve (TBV)

- Turbine Bypass Valve Actuator

- Compressor Bypass Valve (CBV)

- Associated ducting 


\section{Task 1.1 - Overall Progress Update}

\section{System Design Evolution}

The series sequential turbocharger system went through a number of design configurations in order to meet performance, durability, cost, and packaging requirements.

Iteration 0 and 1 systems were built as proof of concept for system performance and function. These early systems were used to refine the turbocharger matching, develop preliminary engine controllers, and demonstrate emissions at key operating points.

Iteration 2 and 3 systems were the first attempt to create a vehicle packagable system. A significant drop in LP turbine performance and consequently rated engine power output was observed due to flow split through the turbine bypass. This system also demonstrated failures at the gasketed joints due to a combination of inadequate gasket stiffness, vibratory loading, and transient thermal growth differences. Metallic gaskets and a secondary support for the HP turbocharger were used to allow these systems to be used for development testing.

Iteration 5 and 6 systems were designed with improved turbine bypass flow split, improved assemble-ability, and improved joint integrity. These design iterations also incorporate design changes to make the components more robust, as needed, to pass qualification tests.

\section{Summary of System Design Iterations}

\begin{tabular}{|c|c|c|}
\hline Iteration 0 & $\begin{array}{l}\text { Performance mock-up fabricated from off the shelf } \\
\text { components. }\end{array}$ & Freeze N/A \\
\hline Iteration 1 & $\begin{array}{l}\text { Performance demonstrator packaged to fit on } \\
\text { engine; Rapid prototype castings. }\end{array}$ & Freeze 06/15/06 \\
\hline Iteration 2 & $\begin{array}{l}\text { Improved performance demonstrator packaged to } \\
\text { fit in vehicle; Rapid prototype castings. }\end{array}$ & Freeze 10/20/06 \\
\hline Iteration 3 & $\begin{array}{l}\text { Performance and Durability demonstrators; Soft- } \\
\text { tooled castings. }\end{array}$ & Freeze 12/22/06 \\
\hline Iteration 4 & CANCELLED & \\
\hline Iteration 5 & $\begin{array}{l}\text { Updated with cost-down TBV and high-reliability } \\
\text { TBV actuator, position sensor, and HP turbo } \\
\text { actuator, GT20 HP stage }\end{array}$ & Freeze 06/20/07 \\
\hline Iteration 6 & $\begin{array}{l}\text { Production intended design made with production } \\
\text { intended processes, inserted TBV, pedestal mount }\end{array}$ & Freeze 10/01/07 \\
\hline
\end{tabular}




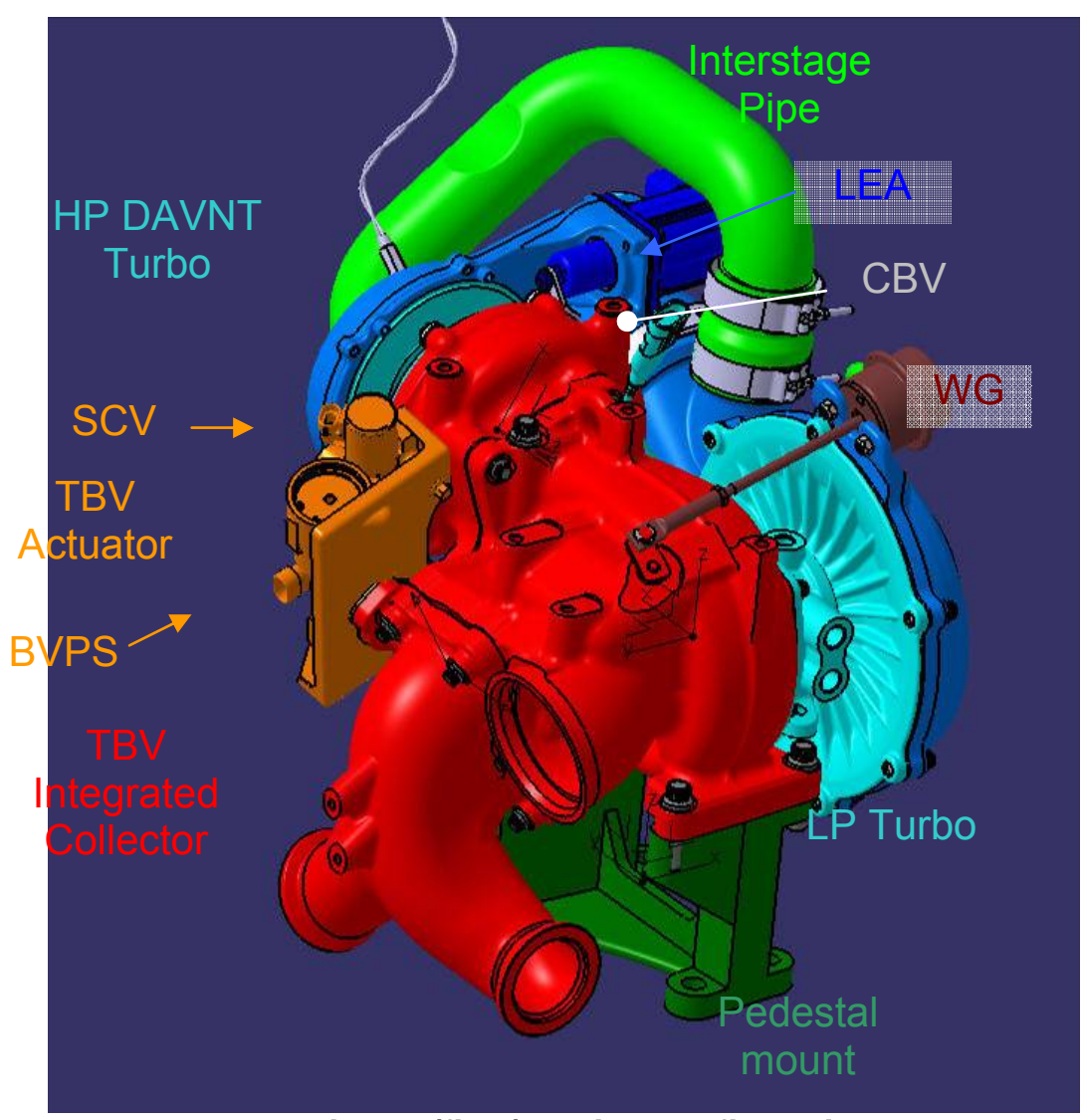

Iteration 6: (final) design configuration.

\section{System Performance}

North American Light Truck engines must deliver high horsepower and torque, good launch performance, and low fuel consumption. As stated earlier, objectives for the series sequential engine integration are $20 \%$ reduction in BFSC, equivalent vehicle launch performance compared to gasoline engines, and compliance with US 2010 vehicle emissions regulations. Demonstrating fulfillment of these objectives will not be possible until the turbocharger system is fully integrated into a production-ready vehicle. Some preliminary performance data, which does not come from a fully integrated vehicle meeting emissions regulations, is available. While this data may be useful to assess potential performance, it cannot fairly be used for comparison with current production vehicles.

1. Peak observed torque and power is favorable (802 lb-ft, $462 \mathrm{hp})$. These values were logged from an iteration 3 system installed on a $6.6 \mathrm{~L}$ diesel engine run on a dynamometer (see Table 2).

2. A $40 \%$ improvement in vehicle $0-60 \mathrm{mph}$ acceleration was observed compared to a 2008 production vehicle with a similar-displacement turbo diesel engine (not a back-to-back comparison).

3. Bulk specific fuel consumption (BSFC) as low as .214 kg/kW-h was observed on dynamometer with a 2006MY fueling table in the ECU. A lower BSFC value is 
targeted, and may be achievable with modifications to the fueling table. A BSFC value of $.256 \mathrm{~kg} / \mathrm{kW}$-h is considered low for a naturally aspirated, spark ignition gasoline engine. The demonstrated value of $.214 \mathrm{~kg} / \mathrm{kW}-\mathrm{h}$ is a $16.4 \%$ reduction. Vehicle fuel consumption improvement will likely be lower than this due to improved off-peak fuel consumption since the two efficiency peaks of the two turbochargers broaden the overall system efficiency range.

\section{Durability Specification Definition}

Preliminary duty cycles were recorded on a test vehicle with an iteration 0 turbocharger system and a table-based engine controller. The duty cycle was used as a basis for determining the details of the validation test plan. Table below summarizes the development targets used for validation testing.

2007MY NA Light Vehicle Engines (Wards Auto).

\begin{tabular}{|l|c|c|}
\hline \multicolumn{1}{|c|}{ OEM - Vehicle - Engine } & Torque (lb-ft) & Power (hp) \\
\hline GM - Silverado - 6.0L LQ4 gasoline & 365 @ 4000 rpm & $355 @ 5200 \mathrm{rpm}$ \\
\hline GM - Silverado - 6.6L LBZ turbo diesel & $660 @ 1600 \mathrm{rpm}$ & $360 @ 3200 \mathrm{rpm}$ \\
\hline Ford - F250 - 6.0L 99P turbo diesel & $570 @ 2000 \mathrm{rpm}$ & $325 @ 3200 \mathrm{rpm}$ \\
\hline Ford - F250 - 6.8L 99Y gasoline & $457 @ 3250 \mathrm{rpm}$ & $362 @ 4750 \mathrm{rpm}$ \\
\hline DC - Ram HD - 6.7L Cummins turbo diesel & $650 @ 1500 \mathrm{rpm}$ & $350 @ 3100 \mathrm{rpm}$ \\
\hline DC - Ram HD - 5.7L EZA gasoline & $375 @ 4200 \mathrm{rpm}$ & $345 @ 5400 \mathrm{rpm}$ \\
\hline Toyota - Tundra - 5.7L 3UR-FE gasoline & $427 @ 3200 \mathrm{rpm}$ & $382 @ 5800 \mathrm{rpm}$ \\
\hline Nissan - Titan - 5.6L VK56DE gasoline & $393 @$ @ 3600 rpm & $320 @ 4900 \mathrm{rpm}$ \\
\hline $\begin{array}{l}\text { Series Sequential Iteration 3 on 6.6L turbo } \\
\text { diesel engine on dyno test stand }\end{array}$ & $802 @ 2727 \mathrm{rpm}$ & $462 @ 3112 \mathrm{rpm}$ \\
\hline
\end{tabular}

${ }^{*}$ without emissions after-treatment devices and with 2006MY engine fueling tables

Two key limits are status yellow (risk production qualified solution will not be ready for program timing). Target design life is questionable due to risk of HP compressor wheel low cycle fatigue (LCF). The principal driver for HP compressor LCF is the frequency of turbine bypass valve actuation. The HP rotor speed responds quickly (up to 70,000 rpm per $100 \mathrm{~ms}$ ) when the TBV is actuated, resulting in a significant LCF event with each actuation. The frequency of TBV actuation must be limited by the engine controller, since an unstable controller or highly cyclic duty cycle will result in premature HP compressor failure.

The PPS resin compressor bypass valve is unable to withstand even momentary $(<1$ second) excursions beyond the target pressure and temperature. Engine and turbocharger gas stand control systems used for development testing have not been capable of preventing temperature and pressure excursions. Design modifications have been unsuccessful in adding robustness to creep and surface degradation. Probe testing with aluminum valves has demonstrated they exceed temperature and wear requirements when anodized. A late decision to develop aluminum valve technology puts project timing at risk. 


\section{Task 1.2 - Detailed Thermal and Mechanical Design}

Conduct thermal and mechanical analysis of the valve assembly as it is employed in the system to understand robustness to temperature and cycling. This will involve Finite Element Analysis, valve gas stand functional testing and on-engine valve testing to estimated duty cycle and life requirements.

\section{Task 1.2 Milestones}

Reports containing typical Housing Thermal and Mechanical FEA plots for various system components; list of Preliminary Component Design Risks; preliminary valve functionality test results from on-engine or gas stand bench tests.

\section{Task 1.2 - Overall Progress Update}

\section{Turbine Bypass Valve (TBV)}

The turbine bypass valve is configured as a butterfly valve with valve sealing occurring between axial (not radial) faces. The butterfly and seat-insert are comprised of stainless steels, as are the actuation shaft and bushings. The valve is integrated into a ductile iron adaptor housing, which connects to the exhaust manifolds from each bank of a $\mathrm{V}$ engine.

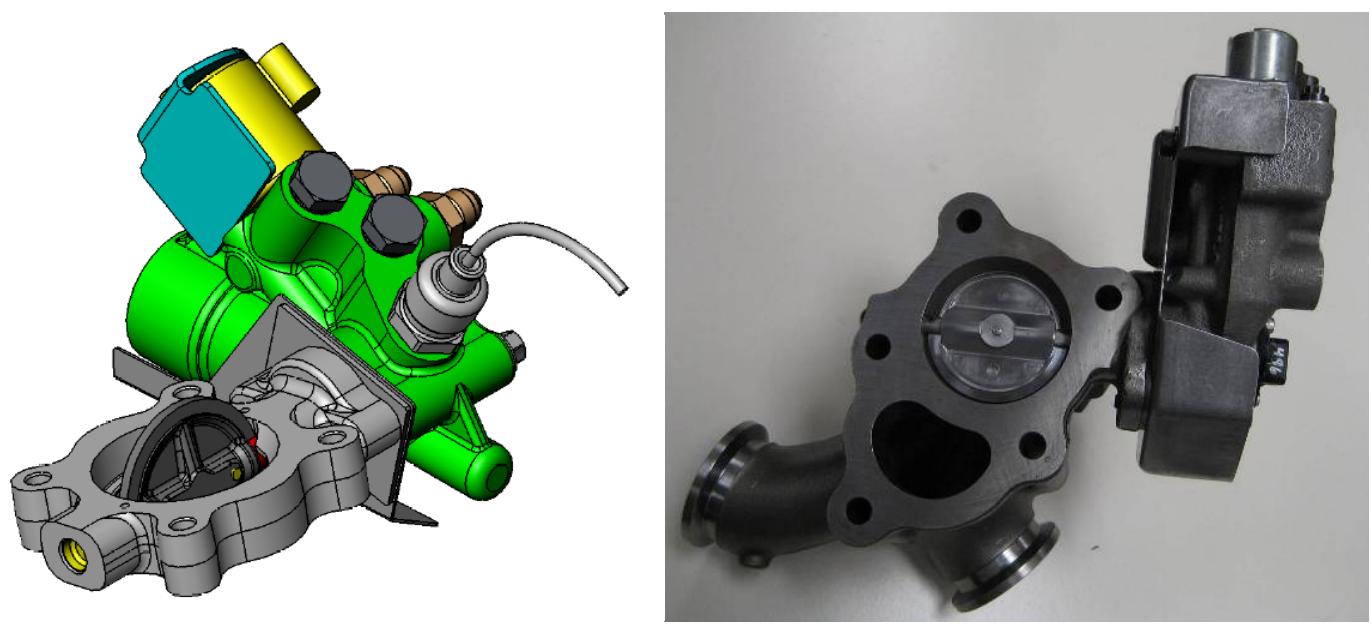

Turbine bypass valve design evolution. Iteration 1 left, Iteration 5 right.

Development of the turbine bypass valve included evaluation of multiple materials for the butterfly, valve seat, adaptor housing, shaft and bushings. System performance is sensitive to leakage through the butterfly valve and selected materials were selected to minimize leakage growth as the valve ages. Durability testing was performed to evaluate the butterfly and valve seat materials for resistance to high-temperature oxidation in diesel exhaust, and resistance to aqueous corrosion in the presence of diesel exhaust condensate.

The valve materials selected were within leakage specification after 2500 hours at the peak continuous service temperature. Please see the figure below. The shaft and 
bushing materials selected demonstrated acceptable tribological performance through 1 million cycles.

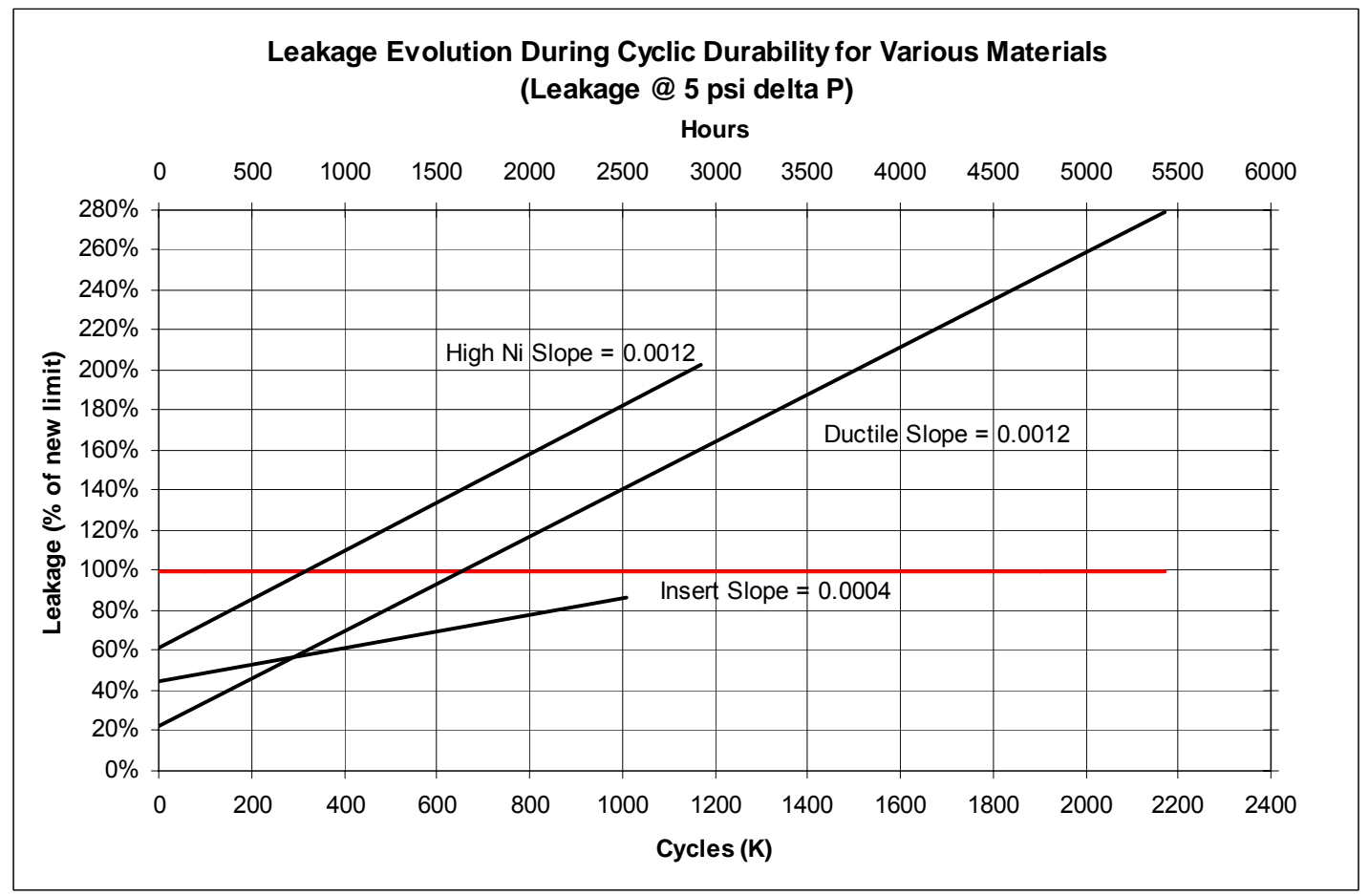

Leakage evolution of various valve seat materials.

Flow characterization of the turbine bypass valve being developed was performed, and is documented in Figure below.

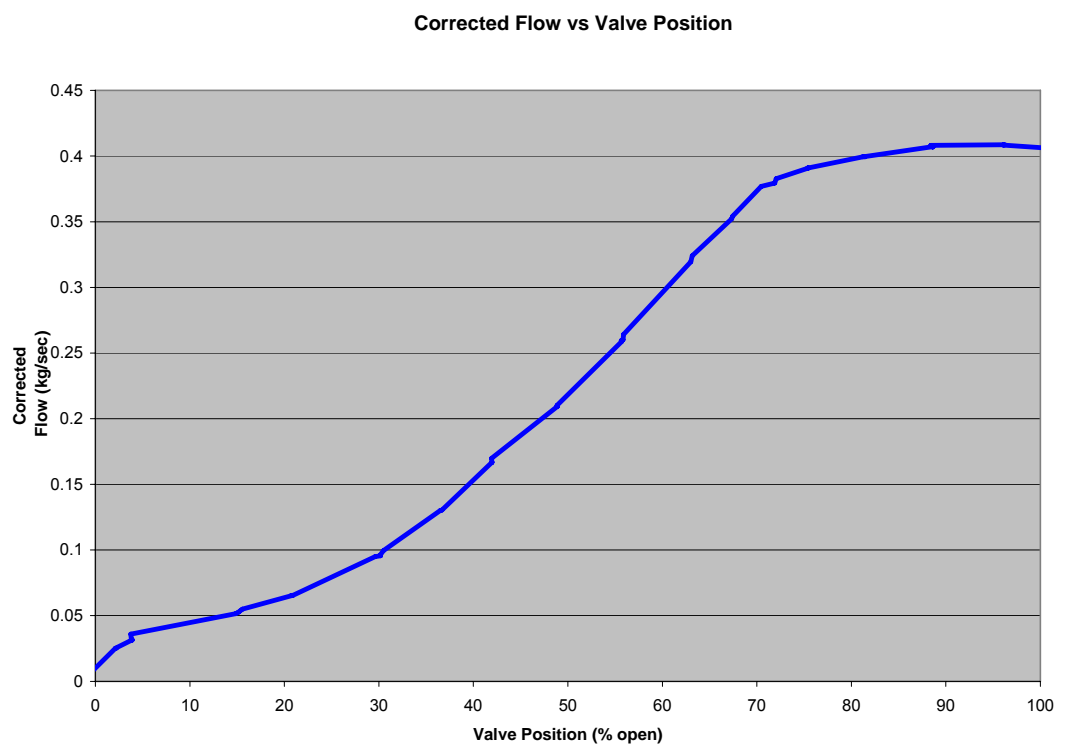

Flow characteristics of the TBV.

Finite element analysis of the TBV with inserted valve seat housed in the forked turbine inlet adapter was performed to evaluate thermal-mechanical fatigue (TMF) resistance of 
both the ductile iron adaptor-housing and stainless seat-insert. The analysis simulated deep thermal cycling from peak to idle exhaust gas temperature, and included contact stresses from the insert press-fit. Plastic-elastic analysis was performed with cumulative damage theory used to predict cycles to crack initiation.

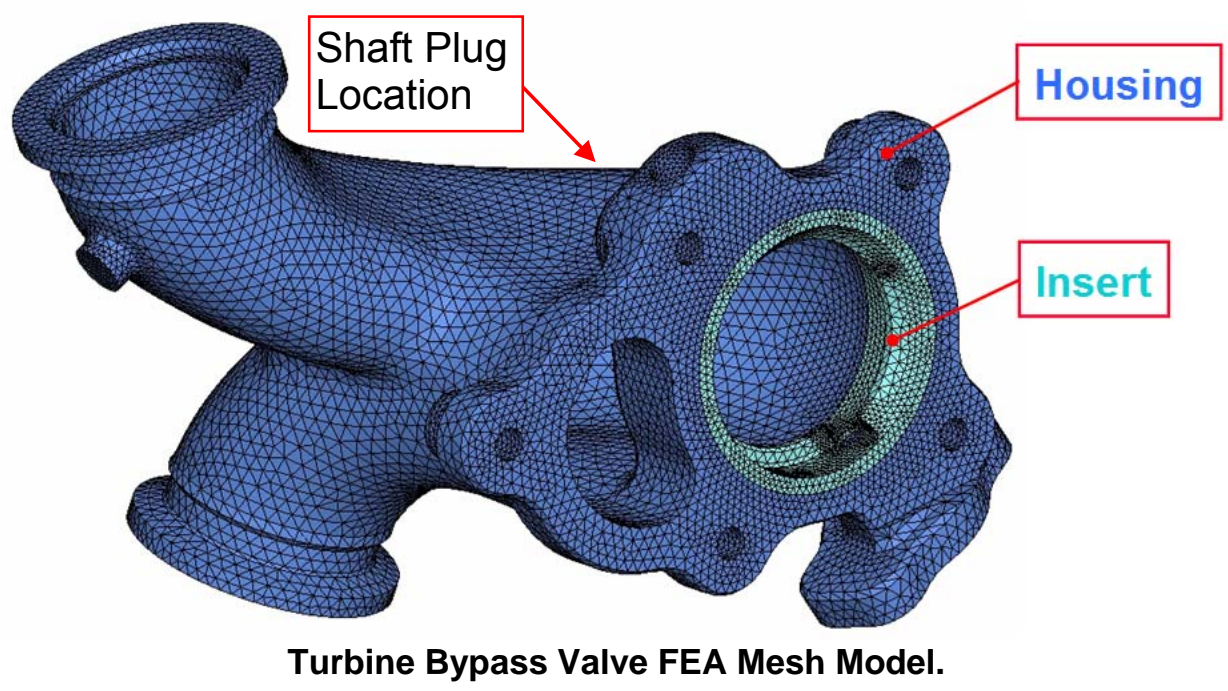

A couple additional failure modes were uncovered during iteration 3 testing, loosening of the shaft plug and leakage out of the bolted-flange joint with the LP turbine housing.

Loosening of the shaft plug occurred due to thermal expansion differences, oxidation of the plug and bore materials, and thermal deformation of the bore. The plug material, press-fit, and staking design is being optimized to address this issue. Loosening of the plug results in exhaust leakage into the engine compartment.

Bolted joint leakage occurred due to inadequate gasket design, flange deformation, bolt thermal expansion incompatibility with the flange materials, bolt preload loss with temperature, and transient heating and cooling delay between the bolt and flange. A beaded steel gasket was specified to improve sealing contact pressure, demonstrated with pressure-sensitive film. The bolt length and torque specification were optimized to improve clamping performance. FEA is in process to model joint sealing integrity during thermal transients.

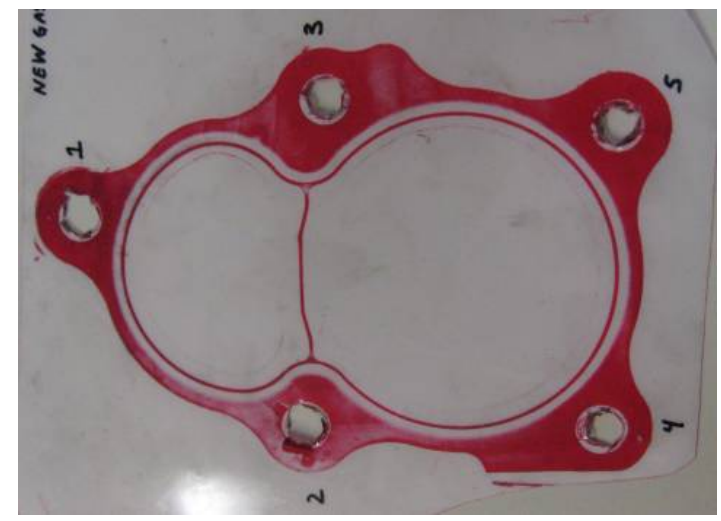

TBV to LP turbine housing gasket performance - Pressure sensitive film. 


\section{Turbine Bypass Valve Actuator}

Valve actuation is accomplished with an electro-hydraulic actuator. The actuator consists of an ECU-controlled electric solenoid valve which directs engine oil flow to either side of an actuator-piston, controlling butterfly position. The actuator incorporates a hall-effect rotary position sensor which provides valve position feedback to the engine ECU.

The actuator is being qualified to 12 million cycles durability life. It can operate with a supply of oil ranging from 34 to $900 \mathrm{kPa}$ and minimum of $0.5 \mathrm{~L} / \mathrm{min}$ flow. The solenoid valve uses a 0 to $1 \mathrm{amp}, 100 \mathrm{~Hz}$ PWM signal. Technology for the actuator was adopted from production AVNT turbochargers and Cam Phasing systems.
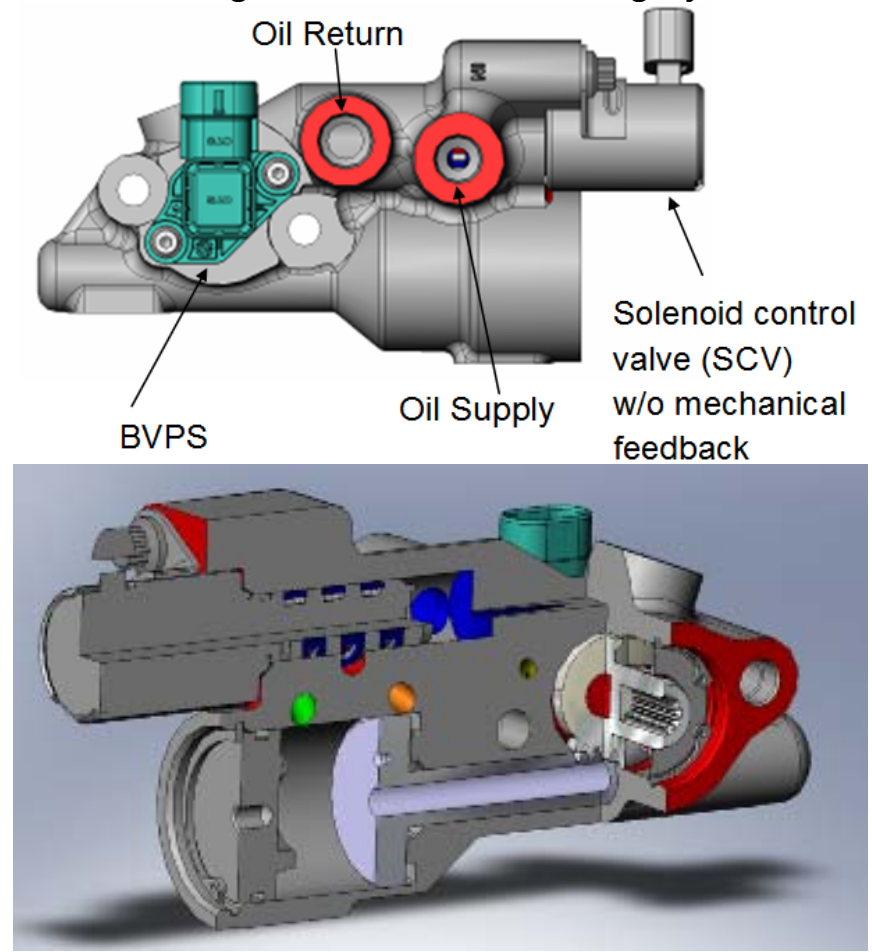

TBV Actuator Iteration 5

\section{Compressor Bypass Valve (CBV)}

The compressor bypass valve is passive (not actuated). When the TBV is opened the LP rotor increases in speed and the HP rotor sharply decreases, causing the interstage boost pressure to exceed the after-stage boost pressure, opening the valve and bypassing the $2^{\text {nd }}$ compressor stage. The valve is designed to fit in-line with flow; the double doors reduce the package space required.

The design history of the CBV includes a number of failures and subsequent design changes. Issues with spring fatigue, wear, and relaxation were resolved with modifications to the spring design. Issues with door hinge wear were resolved with material changes. Issues with creep of the plastic resin were addressed with geometry modifications (a 93\% reduction in stress and $90 \%$ reduction in deflection). 
Uncertainty in the true service temperature requirements of the valve have led to two solutions. The plastic valve shown in Figure 10 has been proven capable to the desired temperature limits, but quickly degrades with any excursion beyond the limit. Since there is risk that aftermarket performance modifications will cause excursions, an aluminum valve is being developed as well as a more robust alternative.

Initial wear problems with aluminum valve door hinges will be addressed with coatings. Two aluminum valves with coated doors were tested for over 400,000 actuation cycles with only superficial wear. Parts from production processes are being pursued on a rush schedule for final validation.

Continued development of the PPS resin valve will also be pursued as an option for applications with less demanding service temperatures. The final PPS valve design iteration has completed 800,000 wear cycles, and 60 hours of HALT vibration testing without failure. Probe tests to evaluate creep at maximum temperature and pressure was performed, as well as an evaluation of valve response during turbocharger system surge.
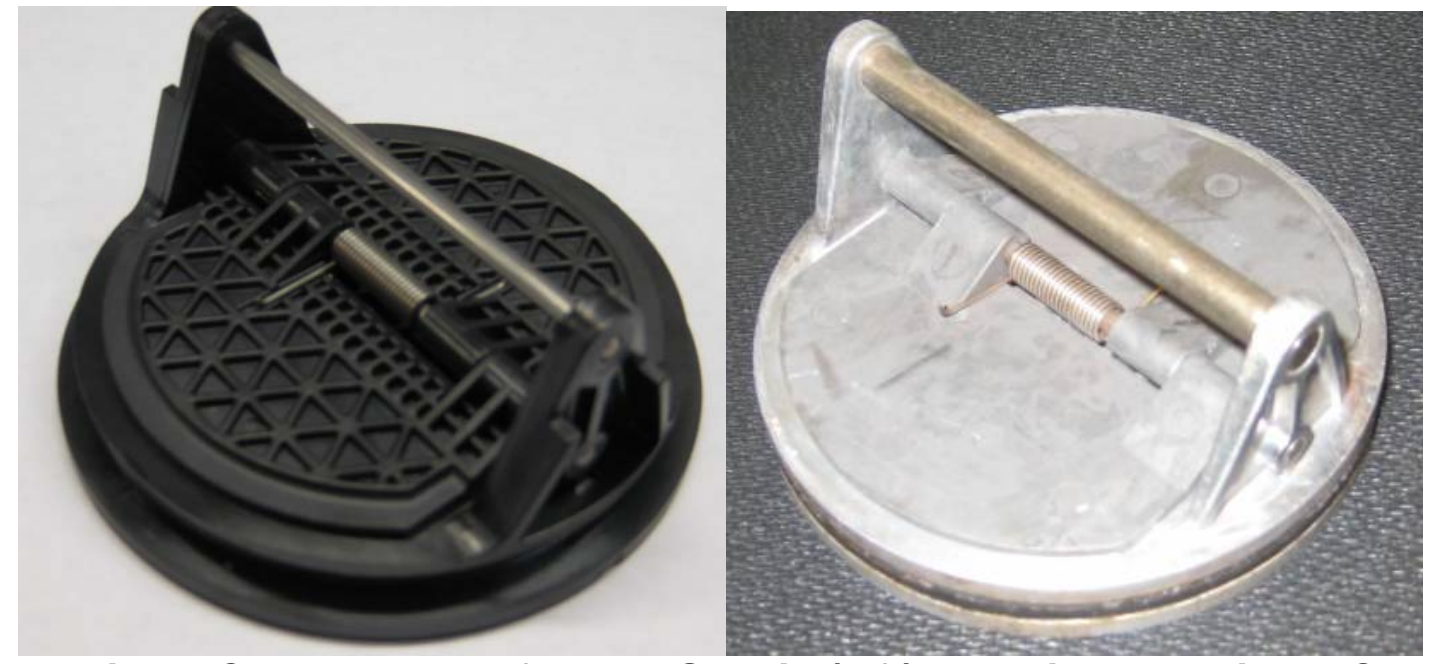

Iteration 6 CBV assembly from PPS resin (left), Anodized aluminum CBV assembly used for probe wear testing (right).

\section{Task 1.3 - System Performance Verification}

Conduct performance testing of the system including mapping of the High Pressure stage operation, transition operation when both turbochargers are functional and high load operation where only the Low Pressure turbo is functional. Leakage of the valves is especially concerning and needs to be considered. As light truck and especially SUV applications tend to require stringent noise levels, an assessment of the turbo and valve switching noise will be conducted.

\section{Task 1.3 Milestones}

Turbine Performance Maps, Compressor Performance Maps, Valve leakage sensitivity study, Noise Assessment Report. 


\section{Task 1.3 - Overall Progress Update}

\section{System Performance}

Series sequential turbo-charging systems have effectively two performance maps, one with the valve open (series operation), and another with the valve closed. The following compressor map is from iteration 3 hardware. Map performance is as expected - lower flow range and efficiency than for either single stage, but significantly increased flow range when the maps are overlaid. Lower flow range and efficiency is expected when compared with single-stage turbochargers of equivalent aerodynamics due to losses in the interstage ducting and leakage through valves.

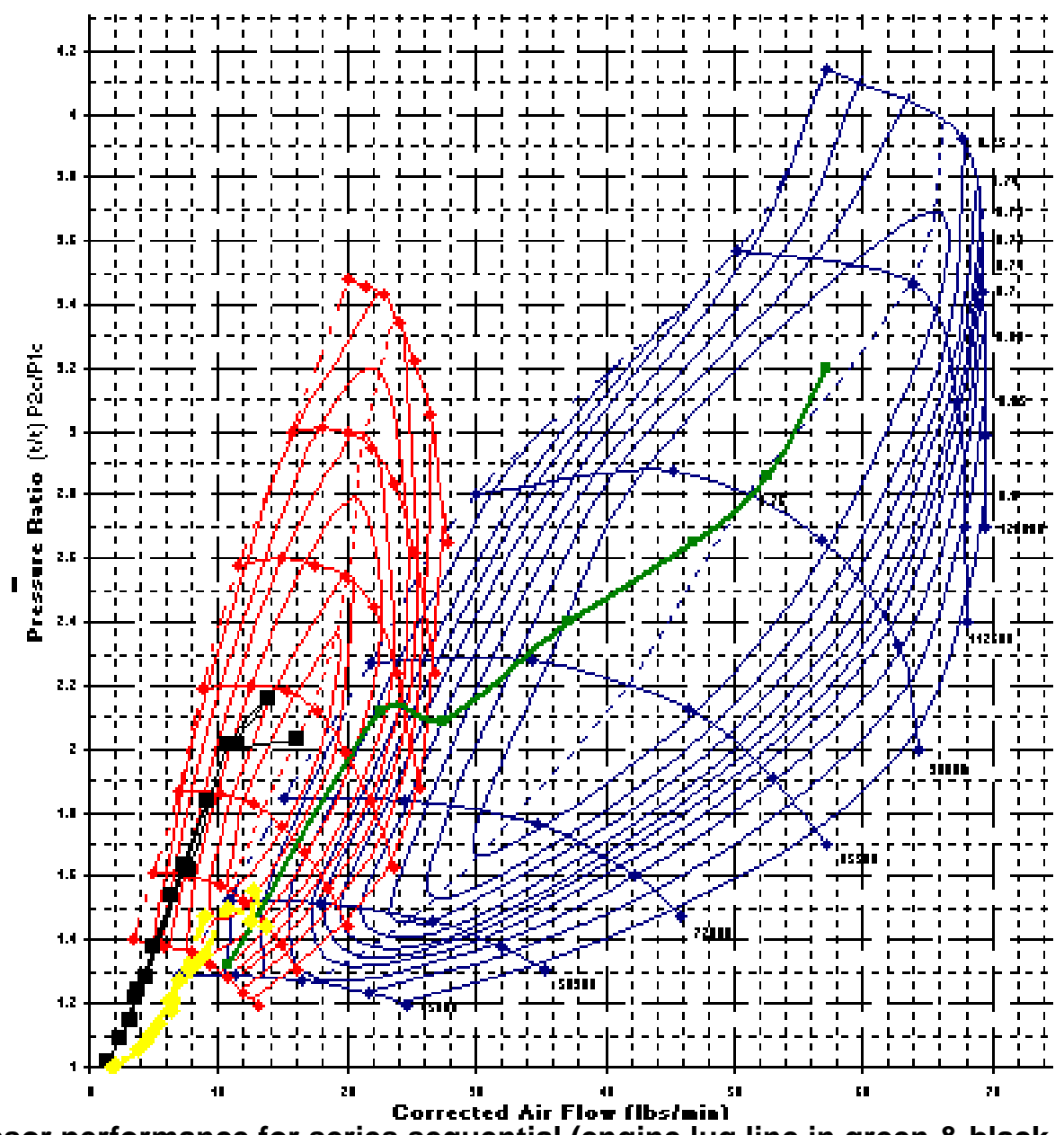

Compressor performance for series sequential (engine lug line in green \& black, part load emissions critical points in yellow).

Turbine stage CFD analysis was performed on the LP turbocharger. The objective of the analysis was to quantify the impact of various packaging related losses on LP performance. Of particular concern were flow patterns through the split inlet (through the TBV and HP turbine), as well as outlet losses stemming from poor flow in the duct itself, and the impact in the wheel performance. A significant loss was discovered in Iteration 5 hardware (see figure below), and subsequently corrected with passage geometry changes in Iteration 6. 


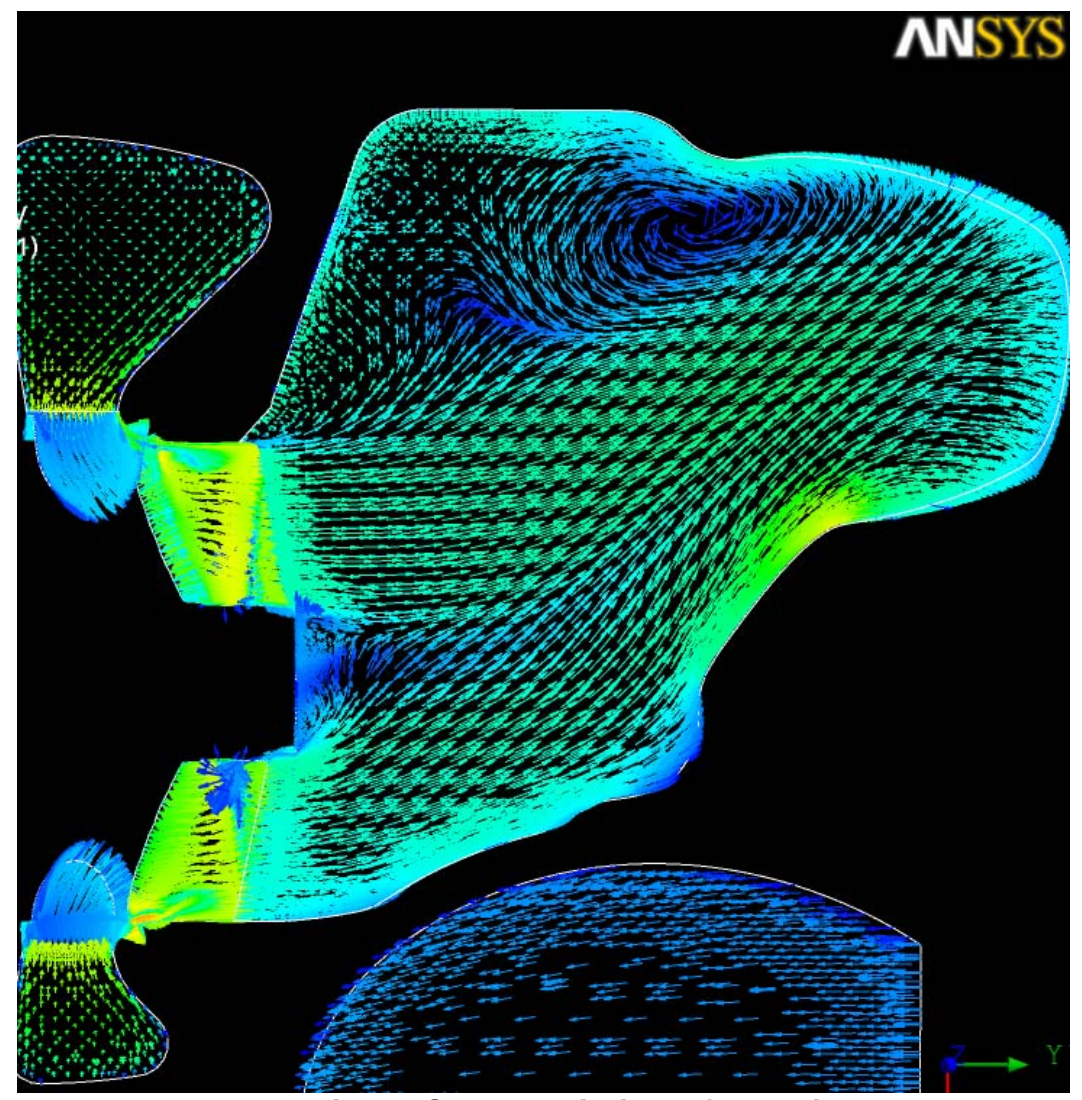

LP stage Iteration 5 CFD prediction of velocity vectors.

\section{Transition Study}

Series to single stage transition strategy was explored to understand the effects of HP turbocharger sizing and control strategy on drivability. One key test used to evaluate transition performance is a full load quasi-steady-state ramp, where the engine is run up at full throttle from idle to rated speed at a rate of 5 seconds per 100 ERPM. The engine tested used 2006MY fueling tables. The recommended match for the test engine is shown in the following figure. The transition study was performed with iteration 0 zero hardware having 3 different HP stages with different flow ranges (GT1752 76T, GT1752 84T, and GT2056), as well as an iteration 3 system having the GT2056 HP stage.

The drop in total boost pressure when the HP turbo is bypassed is reduced as the HP turbo increases in size, and as the transition point is delayed (both serving to increase the overlap of compressor flow-ranges). Minimizing the boost drop during transition is advantageous since smoothing the torque curve for good drivability will require additional fuel to compensate for the valleys in the boost curve. In extreme cases, fueling will be insufficient, and noticeable loss of power will be felt by the driver during transitions. Difficulty in developing a stable controller is another concern. 


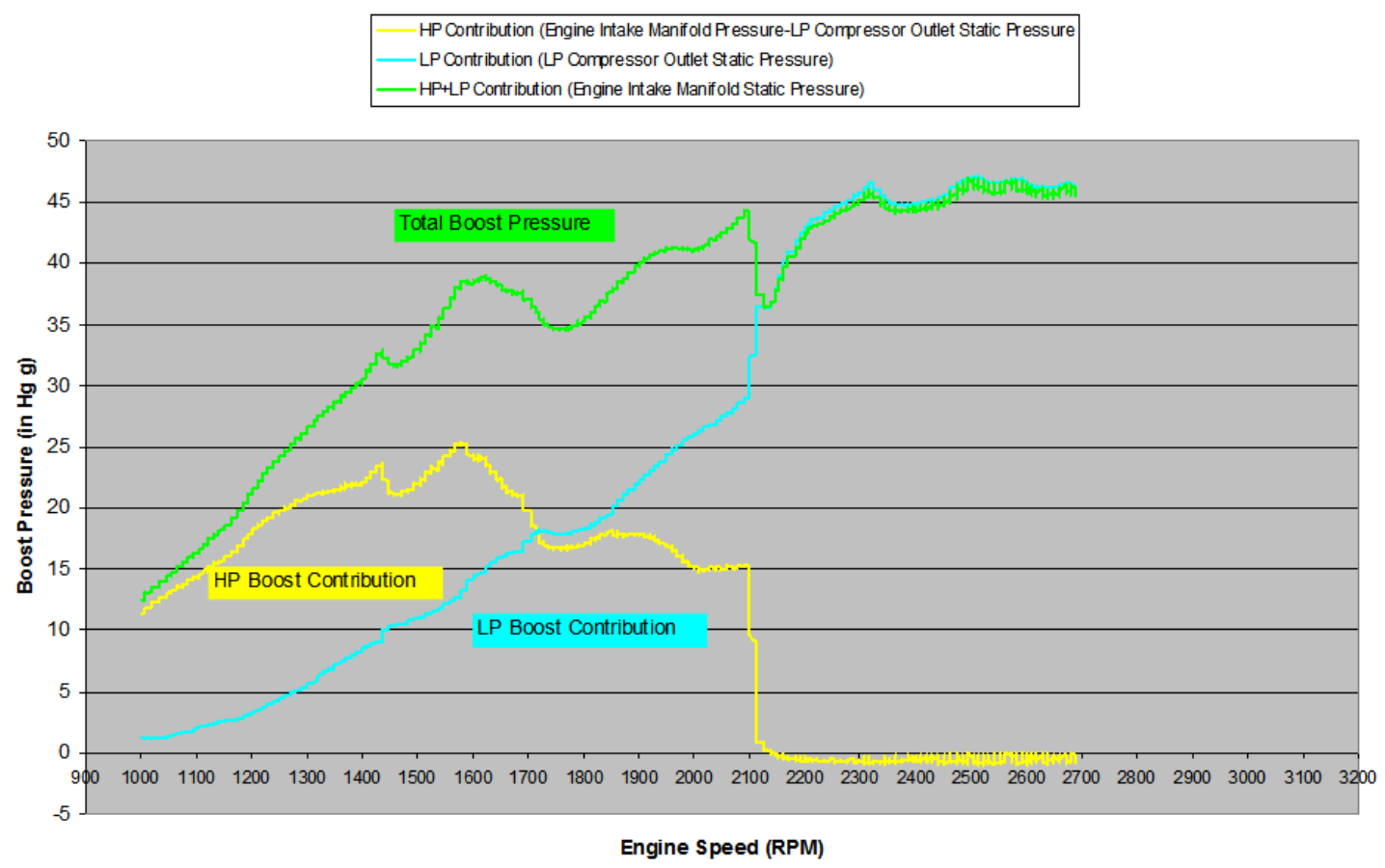

Boost transition with recommended HP and TBV control logic.

\section{Variation Study}

An analytical variation study was performed to understand the expected production variation of key clearances. Statistical process control data for the relevant part features was collected from existing suppliers on similar products. The data was then combined in a Monte Carlo analysis to determine $+/-3 \sigma$ values for critical to performance stack-up dimensions.

Turbocharger systems built to the $+/-3 \sigma$ clearance values have been procured. The systems will be used to verify emissions compliance of prototype engines being prepared for Tier 2 Bin 5 emissions compliance. The risk being assessed here is that the turbo system to turbo system variation combined with engine to engine variation will result in emissions performance dispersion larger than the shrunken compliance window of NOx and PM for 2010 regulations. It is expected that improved model based control systems and OBD2 closed loop emissions monitoring will reduce sensitivity of engine emissions to process variation of key turbocharger system tolerances.

One key performance parameter introduced with series sequential technology is turbine bypass valve leakage. Bypass leakage equates to reduced HP turbine efficiency, and has potential to be a significant driver in vehicle emissions performance. This parameter was assessed on an iteration 0 engine and system by replacing the TBV with various diameter orifice plates, and evaluating the largest orifice capable of meeting emissions targets for some key emissions points. The equivalent orifice diameter is set as the specification for TBV leakage at end of life.

\section{System Noise}

Probe tests have shown noise generated by valve transitions to be unperceivable. LP turbocharger blade pass frequency noise is a concern, but no more of a concern for 
other single-turbo engines in this class. In-vehicle noise testing is planned as MY2010 approaches and vehicles are available.

\section{Task 1.4 - System/Component Durability and Reliability Assessment}

Based on the anticipated worst case duty cycles and temperature exposure, on-engine and bench gas stand test durability tests will be developed to evaluate the robustness of such a system. This testing will involve detailed risk assessment using system and component Design Failure Modes \& Effects Analysis (DFMEA) as well as a detailed Design Validation Plan \& Report. This will result in the development of system and component test standards that would be used for series sequential technology going forward to prove out later design changes.

\section{Task 1.4 Milestones:}

Following are the key milestones.

- Reliability Documentation

- Reliability and Robustness Checklist

- External Functional Analysis

- Internal Functional Analysis

- Fault Tree Analysis

- System and Component DFMEA

- System and Component DVP\&R.

\section{Task 1.4 - Overall Progress Update}

\section{Reliability Process}

Series sequential turbo-charging requires significantly more components in the bill of materials than a single-stage turbocharger. As a result, more potential modes of failure exist in the system. A systematic approach to reliability modeling was used to ensure failure rates on production systems are lower than current experienced with single turbo systems. The reliability process outlined in the following figure shows the process used. The result of systematic reliability tool usage is a well developed qualification test plan, which considers multiple failure modes, and the contribution of noise factors. 


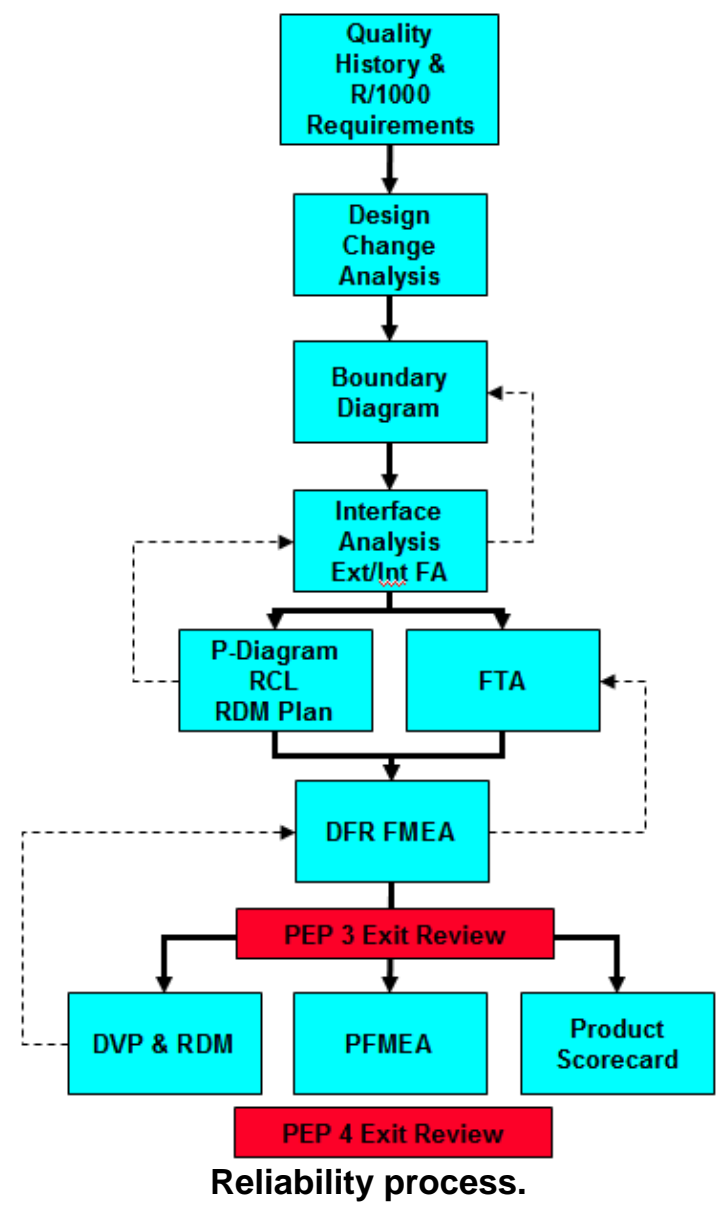

Iteration 5 System Durability Tests

Durability testing for iteration 5 prototypes is well underway. Thermal cycle, Vibration, and gas-stand performance tests were completed, and on-engine durability testing has started. Steady state and soakback temperatures at key locations were also recorded at worst case thermal loading.

System thermal cycle testing resulted in failures of the TBV ball plug and gasketed joint, which are discussed in section 1.2. Cracking of the LP turbine housing was predicted with FEA in multiple locations. One crack was identified in this housing after the test. This crack occurred in the tongue of the volute, and is self-arresting.

System vibration testing was performed, both resonance search sweeps and endurance sweeps were performed. The first modal frequency occurs at $180 \mathrm{~Hz}$. No structural failures occurred during the test, but a few component failures occurred. The cantilevered (unloaded) portion of a worm-drive v-band strap fractured from fatigue. A more-robust clamp will be specified. Wear occurred on the pivot joints of the LEA 4-bar linkage, however fault was found to be an incorrectly specified coating. The dust shield on the LEA fractured due to fatigue as well. The LEA is being redesigned to incorporate a shorter (stiffer) shield. 


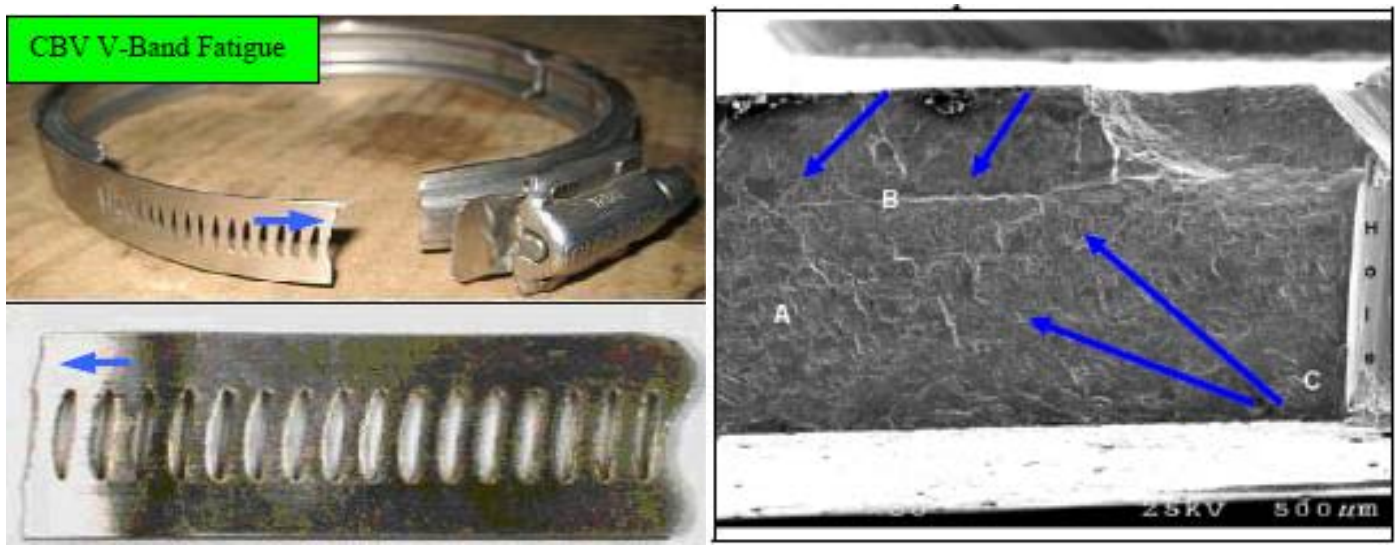

V-band failure on vibration test.

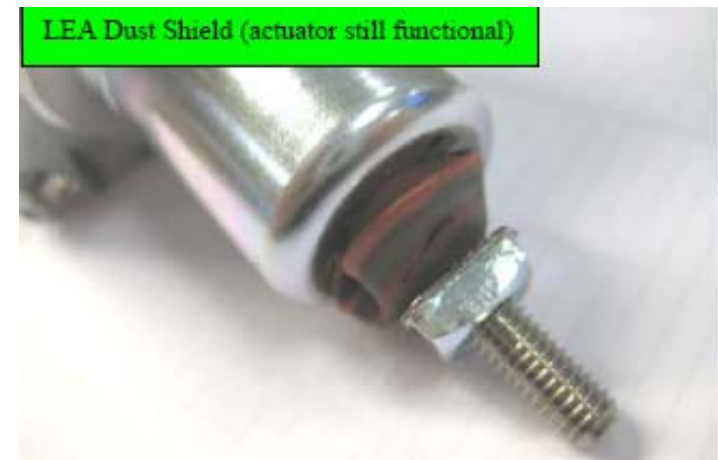

LEA dust shield fracture.

Gas-stand performance testing on iteration 5 systems demonstrated lower than desired LP turbine stage efficiency. CFD was employed to improve performance through redesigning the outlet duct geometry (see section 1.3). Leakage between the gasketed joints and LP center to turbine housing joints also occurred during the gas stand test. Leakage was more pronounced during the thermal cycle test. Fuji-film pressure analysis and FEA was employed to arrive at an improved design (as discussed in section 1.2).

An on-engine durability test cycle was developed specifically for the series sequential system. The test cycle consists of multiple sub-cycles, each of which incurs multiple damage events in various failure mechanisms, including:

- Thermal shock (mechanical fatigue, oxidation, HP Turbine HCF)

- Extended high temperature dwell (creep \& oxidation)

- Vane cycling (wear)

- Valve cycling (wear, HP compressor LCF)

- Shutdowns (heat-soak back, oil coking)

- Sweeps (vibration)

The test will be correlated to duty cycle information through cycle counting to confirm durability life of the system.

A thermo-coupled iteration 3 system was run on a hot test in a simulated vehicle to assess steady state and shutdown temperatures. Under-hood electronics stayed below the target of $150^{\circ} \mathrm{C}$, the $\mathrm{CBV}$ stayed below the $230^{\circ} \mathrm{C}$ target, and turbine inlet 
temperatures spiked momentarily above the $780^{\circ} \mathrm{C}$ target, reaching $834^{\circ} \mathrm{C}$. Turbine inlet temperatures will be monitored closely in the application to verify the calibration prevents them from routinely exceeding qualified limits.

\section{Task 1.4 Planned work in future}

- Qualification tests on Iteration 6 systems (thermal cycle endurance, on-engine performance, vibratory endurance, heat soak-back assessment, corrosion resistance, general on-engine durability).

- Continued technology refinement.

\section{Inventions/Patents}

All inventions, patents and associated publications related to this project are being reviewed for applicability and will be submitted under separate cover. 


\section{PROJECT 2 - SINGLE SEQUENTIAL TURBOCHARGER (SST)}

The objective of this task is to develop the concept of SST for use in SUV and Medium Duty Diesel Engines in the 4.5 to 7 liter size. The design is aimed at providing fuel efficiency, performance, transient response, packaging, and cost advantages to customers challenged to meet US'10 emissions regulations. Note, the tasks listed below may be performed in series or in parallel over a 2 year period pending hardware availability.

\section{BACKGROUND}

Turbocharging is critical for reducing fuel consumption in internal combustion engines. This is true for diesel, gasoline, and alternate fuel engines for passenger cars as well as commercial vehicle applications. In order to adapt and fully utilize the benefit that turbocharging can provide for US applications, further advances are required.

The SST (Single Sequential Turbocharger) concept is intended for use in SUV and Medium Duty Diesel Engines in the 4.5 to 7 liter size. The SST design is aimed at providing advantages to customers challenged to meet US' 10 emissions regulations

- Fuel efficiency

- Performance

- Transient response

- Packaging

- Cost

The SST concept will improve turbine efficiency by improving the compressor/turbine match. The SST takes advantage of exhaust restriction (catalysts/particulate filters) to permit downsizing the turbine. And since the flow range is greatly increased, compressor backward curvature can be reduced in the compressor wheel, increasing the pressure ratio capability of the stage.

The following tasks describe the work breakdown structure (WBS) and associated program status.

\section{Task 2.1 - Conduct Fundamental Investigation into the Phenomenon of Surge at the Fringe of Compressor Operating Range}

Surge phenomenon characterization is outlined in the following figures. Work to date has shown that SST compressor surge is highly influenced by inlet piping aerodynamic design, effect of individual wheel stage geometry, and the effect and impact of surge on one side of the wheel will have on the opposite side. Work continues to understand this interaction and performance sensitivity. 


\section{SST Compressor Surge}

Surge Phenomenon characterized by:

- One compressor wheel stalling causing dip in pressure ratios (shaded regions of the map) Second wheel still functional

- Unusable region with high temperatures and poor efficiency

- Usable region with poor efficiency

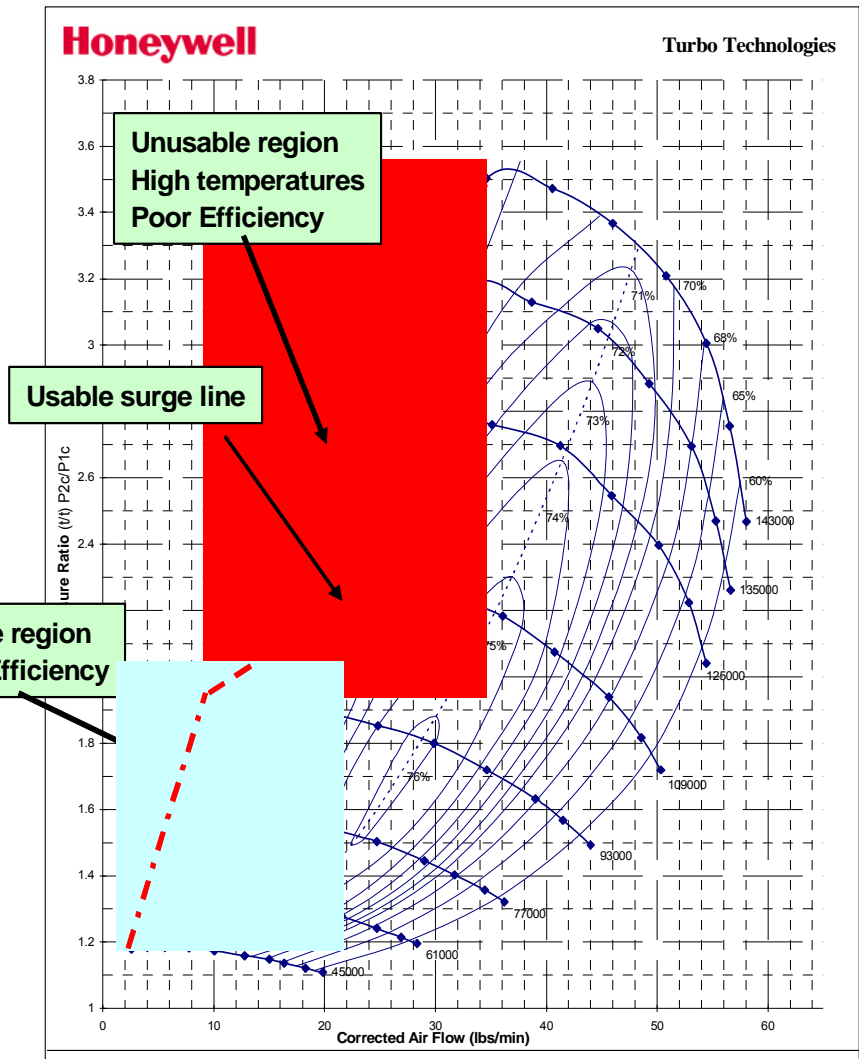

\section{SST Compressor Surge}

Simultaneous wheel stall

- Certain wheel geometrical parameters trigger simultaneous wheel stall in sections of the map

- Conventional surge line with good efficiencies close to surge

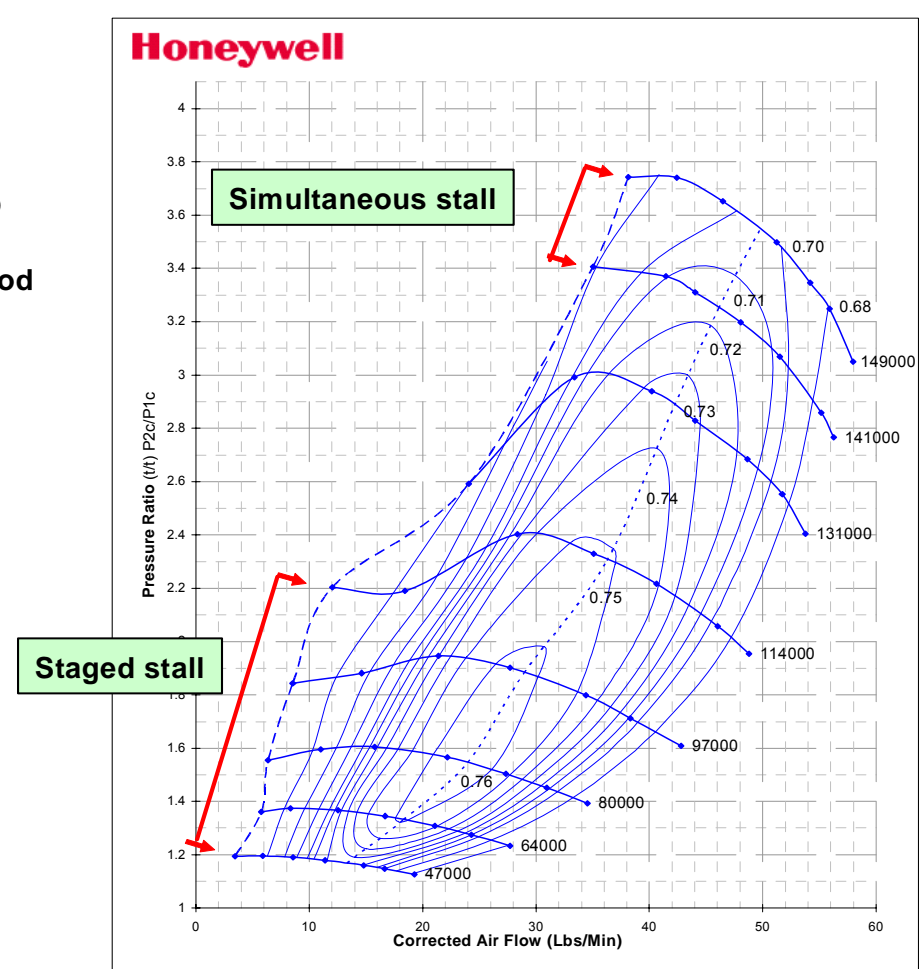




\section{SST Compressor Surge- Packaging Considerations}

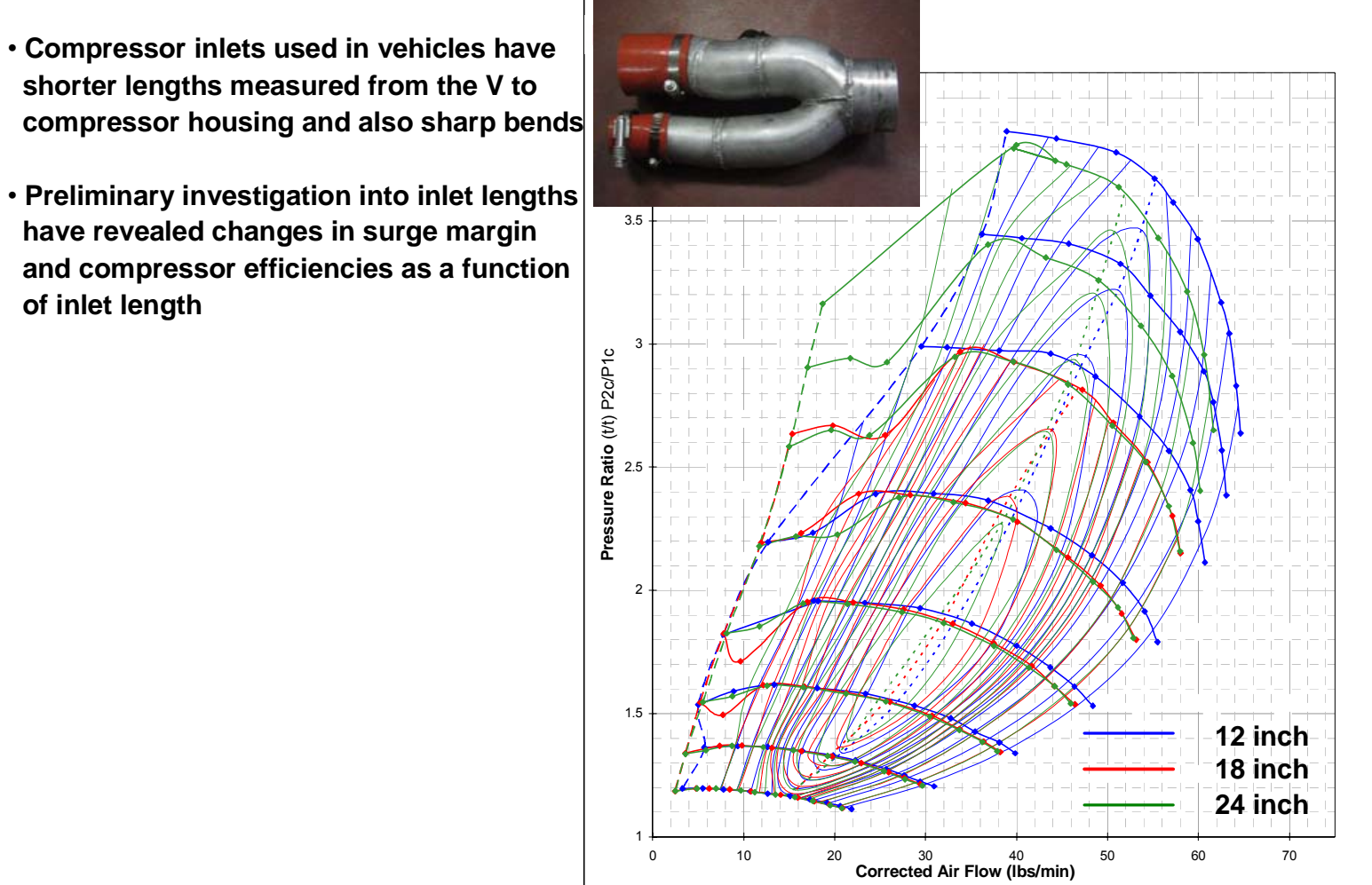

\section{Task 2.1 Overall Progress Update}

\section{Surge Variation from Pre-Production to Production Intent Hardware Investigation.}

Differences between pre-production and production ready hardware have been observed and CFD modeling was started to evaluate the impact of the changes. The initial CFD model was not able to identify the surge margin differences; a more complex model is required and has been started.

Performance Gas Stand testing with the production intent inlet piping was completed and showed equivalent performance to the standard gas stand inlet. 


\section{Task 2.2 - Develop Shaft Motion Control Technology/Design}

The highly overhung rotor group presents rotor dynamics challenges requiring development and complete qualification to ensure dynamic stability. Two bearing systems configurations have been evaluated for the SST35 frame size; ball bearing and dual film journal bearing. Initial indications are that conventional journal bearing configurations requires significant additional development.

Shaft motion measurement results:

- SST turbocharger tested with ball bearing cartridge

- Nominal clearenced SST equipped with a ball bearing cartridge satisfies Honeywell's shaft motion qualification speculation

- SST equipped with ball bearing cartridge satisfies shaft motion at varying oil delivery pressures

- Shaft motion performance must be evaluated at tolerance limits of center housing, bearing, shaft and rotor balance conditions

- SST turbocharger with conventional journal bearing system

- Nominal clearenced SST fitted with conventional production journal bearings does not satisfy qualification specifications for any oil pressure delivery condition

- SST with conventional dual film journal bearings requires additional; development to meet shaft motion specifications

- Conventional journal bearing development must include additional thrust bearing development to ensure stability

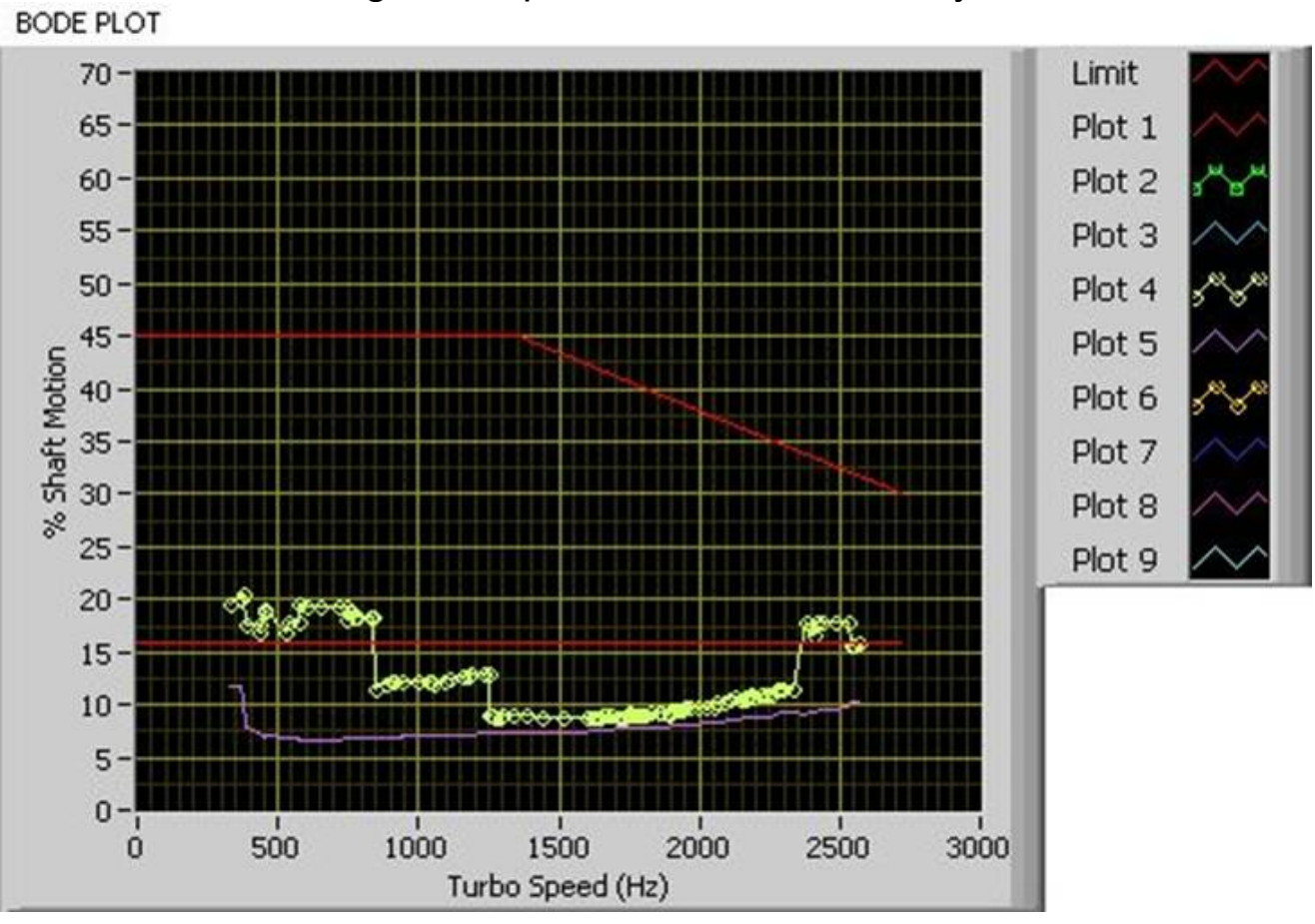

Ball bearing shaft motion sweep (nominal hardware sizing) provides good control 


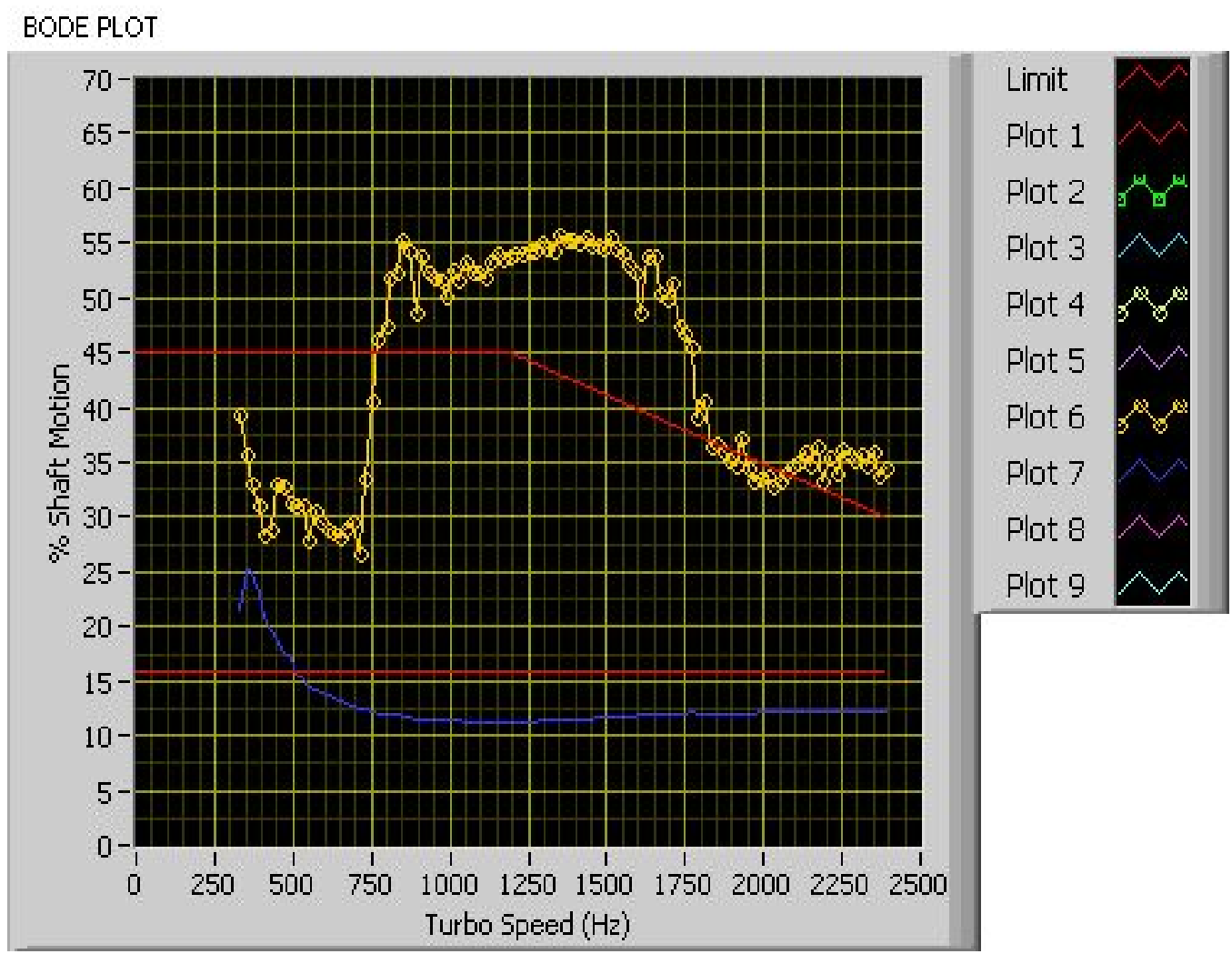

\section{Journal bearing configured bearing system must be optimized to meet Honeywell qualification requirements}

\section{Task 2.2 Overall Progress Update}

SST35 rotor motion stability data was collected during the second quarter. Hardware was prepared in accordance with Honeywell rotor motion criteria for component balance condition, assembly, and minimum and maximum bearing-to-housing clearance. Two turbocharger assemblies were built; one to minimum bearing to housing fit, and a second turbocharger to maximum bearing to housing fit. The ball bearings were not modified to extremes of internal tolerances. They were selected as 'off the shelf'. This is typical of procedure for rotor motion qualification for ball bearings.

Oil pressure for qualification purposes is varied to simulate pressure extremes that the bearing assembly could experience across a wide variety of engine applications. Oil pressures of $20 \mathrm{psi}, 30 \mathrm{psi}$, and $60 \mathrm{psi}$ were used for each test turbo. Oil temperature is held constant at $100^{\circ} \mathrm{C}$.

Recorded motion of the turbocharger shaft, defined as a percent of maximum available excursion (based on the bearing and housing assembly clearances), is shown plotted against turbo speed in Hertz. Acceptable rotor motion falls within the red boundary lines. Plots are labeled accordingly. Shaft motion is well controlled with geometry tested. 


\section{Minimum bearing-to-center housing-clearance results}

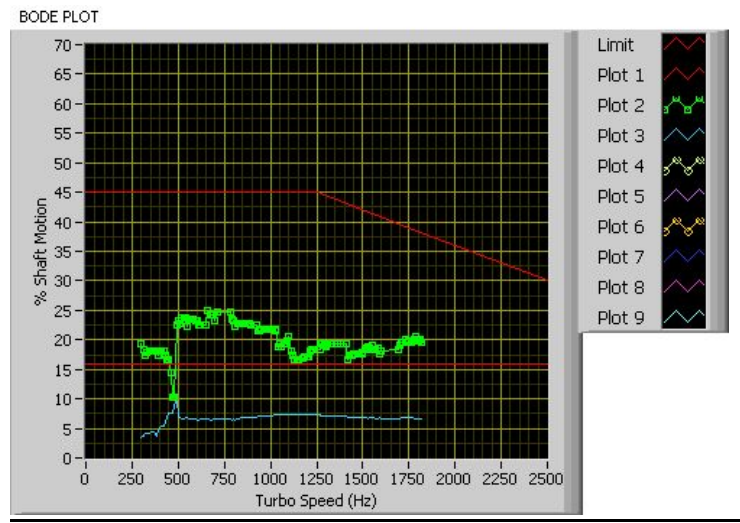

Oil Pressure- 20PSI

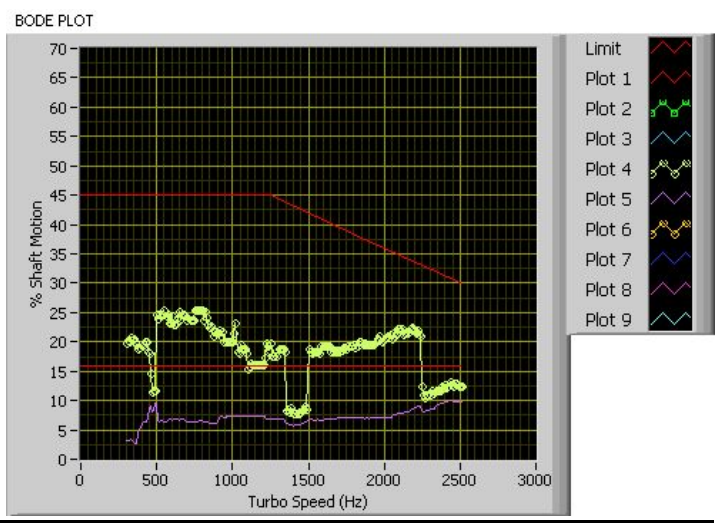

Oil Pressure- 30PSI
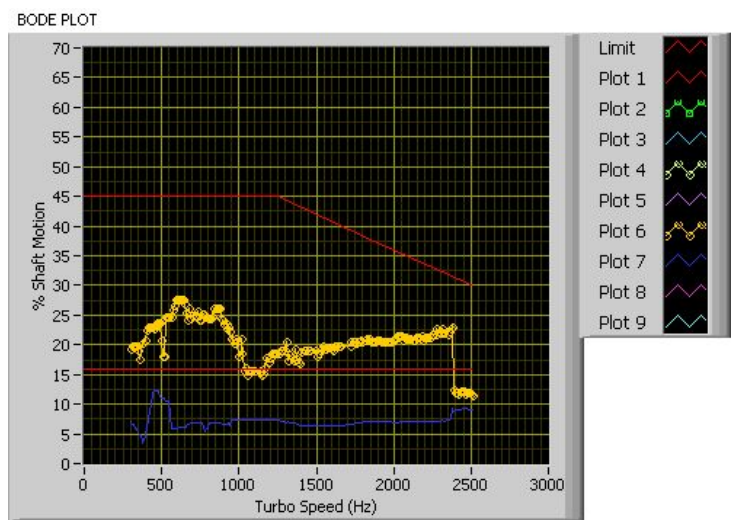

Oil Pressure- 60PSI

\section{Maximum bearing-to-center housing-clearance results}

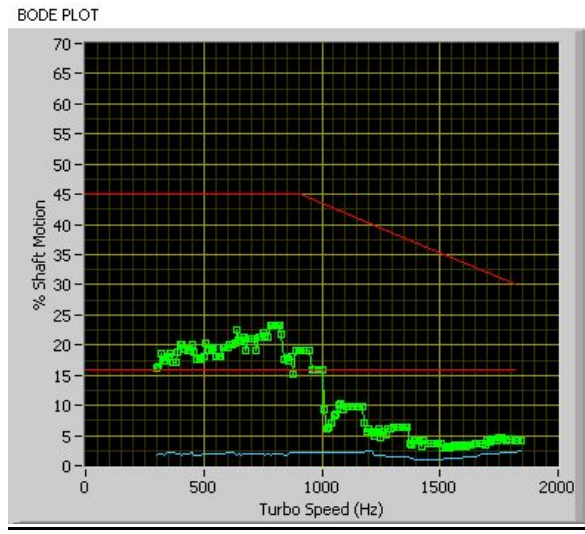

Oil Pressure- 20PSI

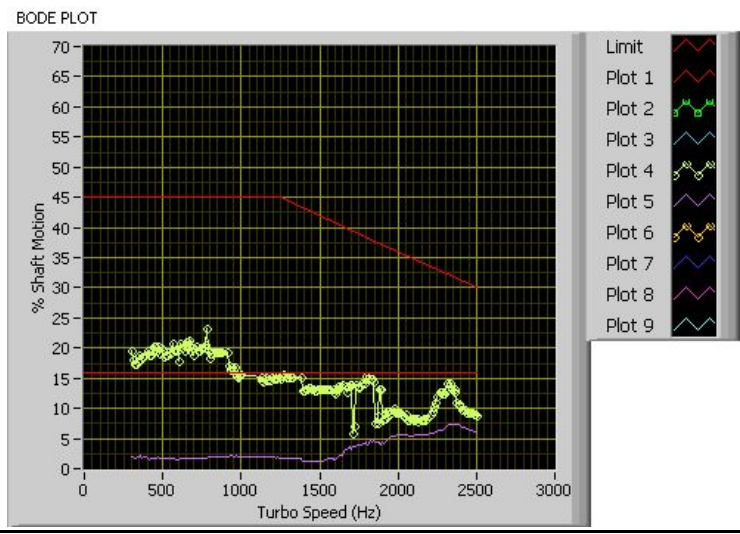

Oil Pressure-30PSI 


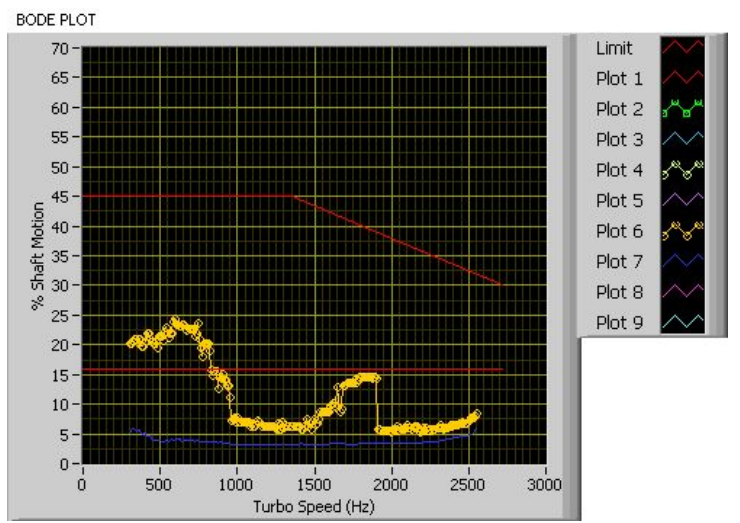

Oil Pressure- 60PSI

Recorded SST35 shaft motion is well controlled with the $10 \mathrm{~mm}$ ID cartridge bearing assembly and $69 \mathrm{~mm}$ compressor wheel and $68 \mathrm{~mm}$ turbine wheel.

\section{Develop Shaft Motion Control Technology/Design}

A turbine wheel configuration change was made to the SST32 frame size prompting an analysis of impact on rotor dynamics. The new turbine wheel is more than $10 \%$ heavier than its predecessor. A larger compressor seal/spacer combination is also changed during Q4, as has the compressor wheel method of attachment to the shaft. Initial and current SST32 rotor systems are illustrated for comparison.

Prediction of rotor group critical speeds suggests similarity, but remains to be confirmed by qualification test. The heavier turbine wheel, and new SST32 compressor wheel attachment method act to move the rotor group center of gravity in the direction of the turbine wheel, offsetting the overhang created by the length requirement of the back-toback compressor wheel. This has a positive impact on rotor dynamic response.

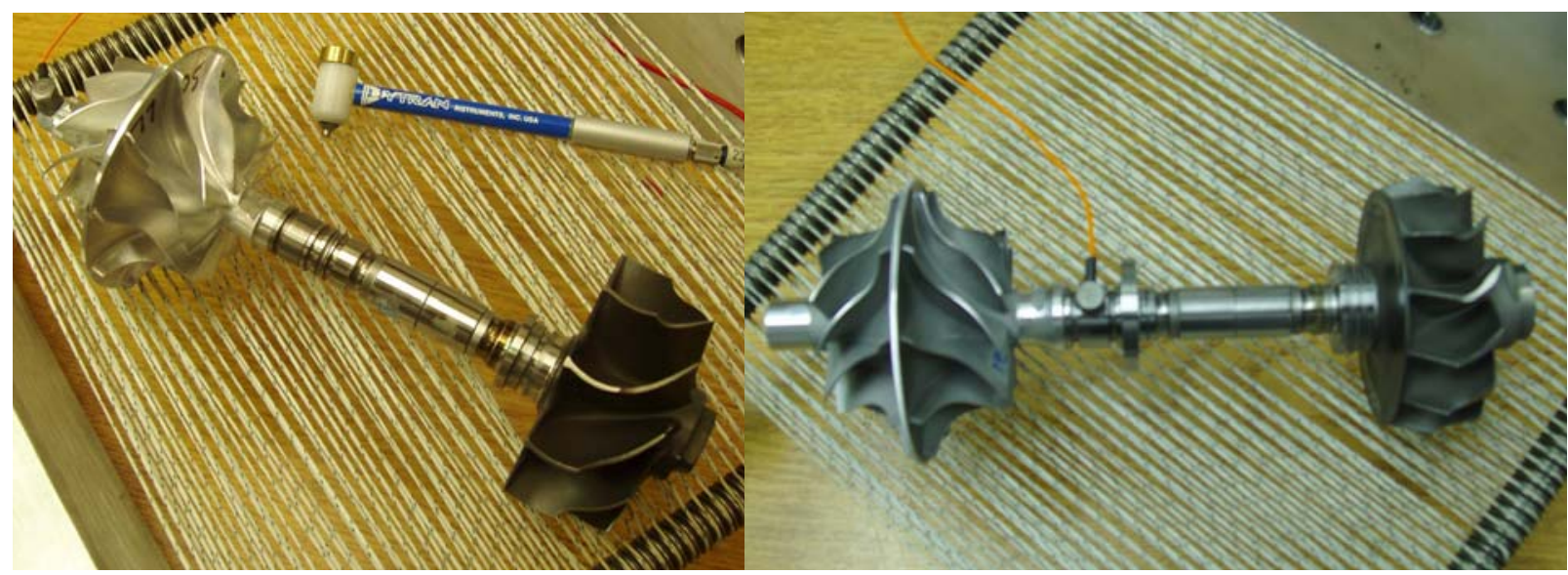


The predicted un-damped critical speed map for the new configuration SST32 rotor group produces a first bending mode near the turbocharger speed limit, not unlike the prediction for the SST32 original rotor group. Actual recorded shaft motion for the SST32 original rotor group was reported in an earlier quarterly report. The effect of the predicted bending critical speed was not seen in those results.

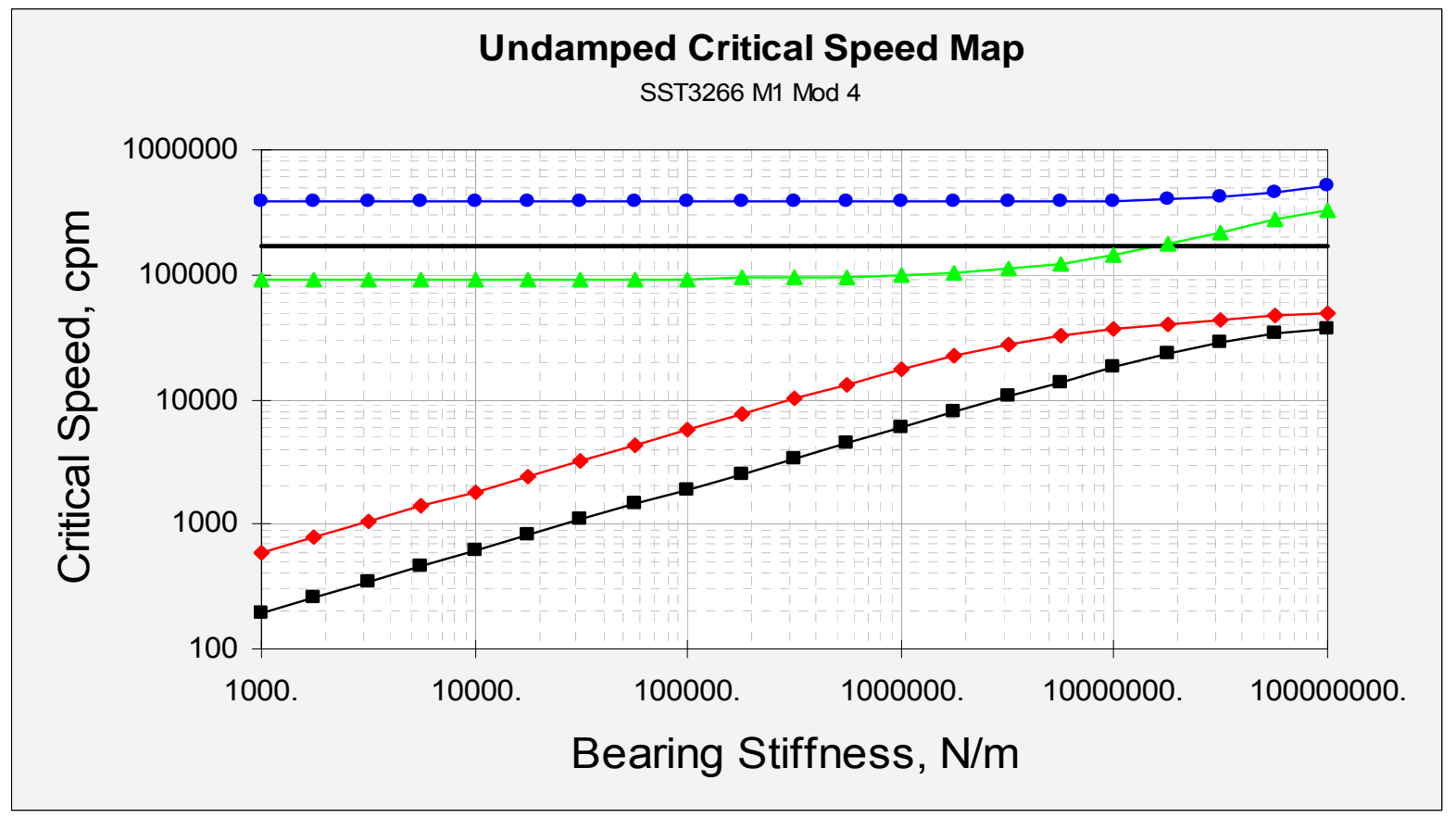

\section{Upgraded SST32 Rotor Group Critical Speed Prediction}

New SST32 hardware with upgraded rotor group for shaft motion testing and qualification is in-process. This test work will be completed outside of the DOE contract period.

\section{Task 2.3 - Develop Compressor Oil Seal Technology Uniquely Required for the SST}

A new seal system configuration, illustrated below, was designed for the unique SST compressor set geometry and pressure conditions. Hardware orders have been placed. 


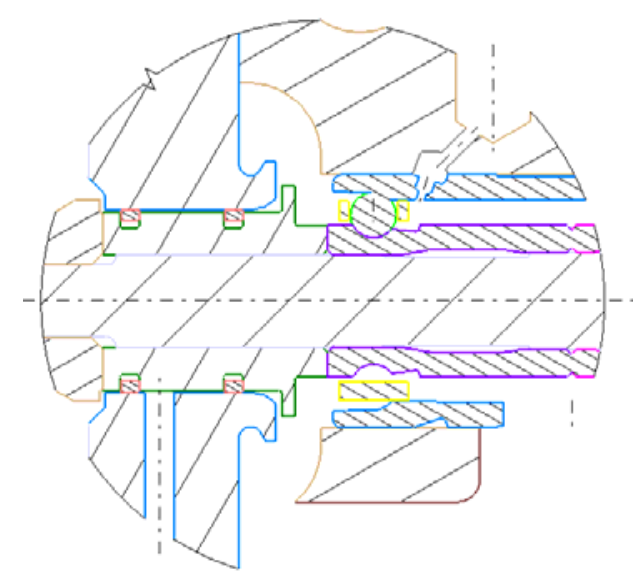

SST Dynamic Compressor Seal System

\section{Task 2.3 Overall Progress Update}

\section{Compressor Seal Development Activity}

On-engine pressure data has been collected to better understand the behavior of the pressurized compressor seal. Pressure measurements were taken in the center housing, between the compressor piston rings and at the compressor wheel inlet. A compressor seal qualification test was defined based on the pressure data to evaluate the new seal design. The original design did not pass the qualification testing and the seal area circled in red above was redesigned. The redesigned seal did not allow oil to leak into the compressor stage at the worst case condition for the application and passed the qualification test. This seal design is sensitive to bleed port oil blockage and work is on-going to minimize the amount of oil in the compressor stage.

\section{Task 2.4 - Thrust Load Measurement}

Thrust load measurement data have been collected for an SST35 turbocharger with variable nozzle turbine stage operating in dual mode (both compressors contributing equally) via an instrumented pin fitted to a ball bearing cartridge.

- Thrust load through the full operational speed range of the turbocharger was always in the direction of the turbine

- Thrust load direction with the selected turbine nozzle vane positions was always in the direction of the turbine

- Magnitude of the thrust load toward the turbine could be changed by the turbine vane opening position

- Thrust load will increase with the turbine wheel back-disk configuration, i.e. a full turbine back-disk will produce greater thrust than a scalloped turbine wheel configuration. 
Thrust Loads vs Rotational Speeds for Varying Vane Configurations From Maximum Load Characteristics

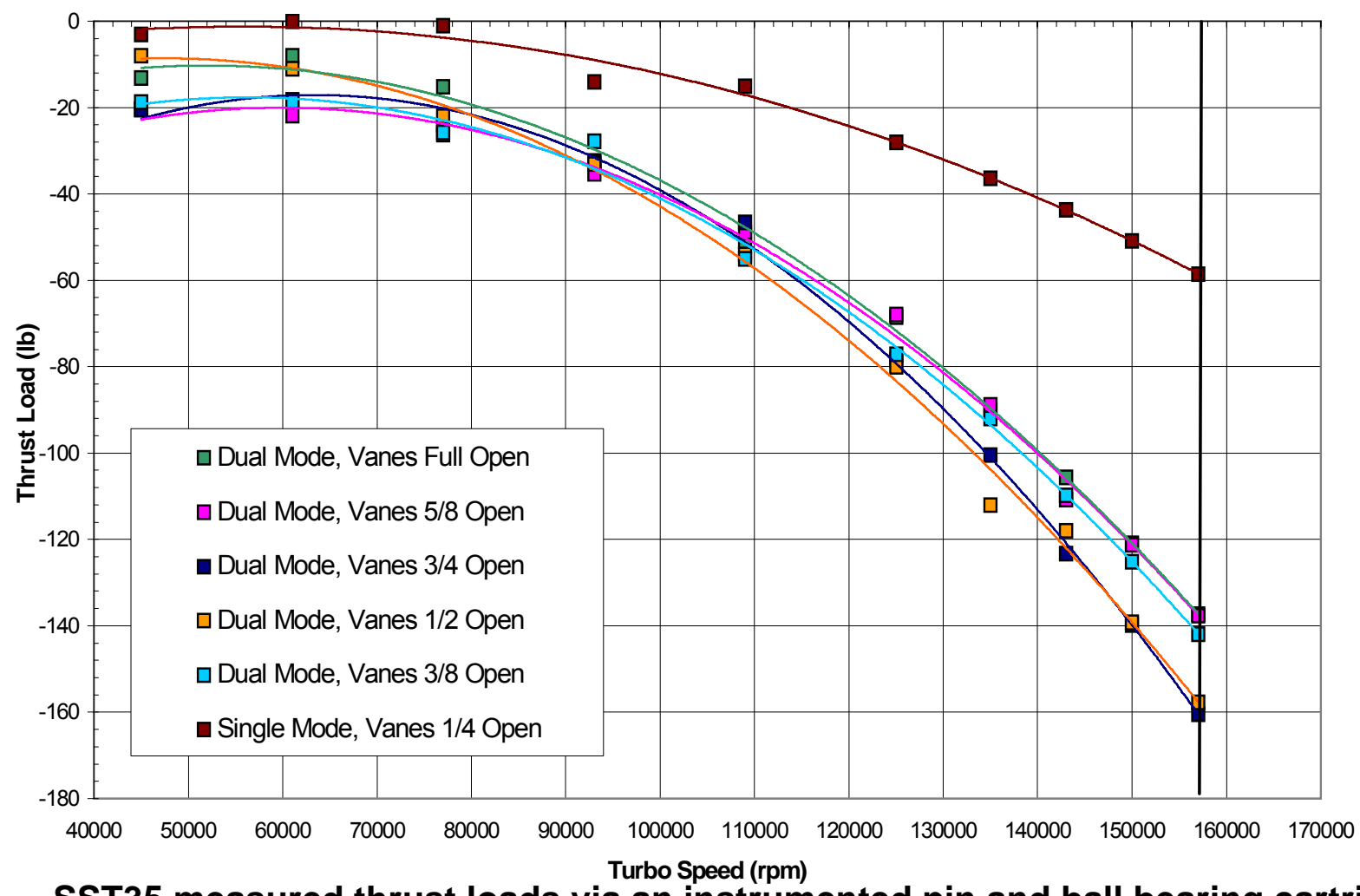

SST35 measured thrust loads via an instrumented pin and ball bearing cartridge

\section{Task 2.4 Overall Progress Update}

Thrust load measurements were recorded for an instrumented SST32 turbocharger mounted to the vibration sorting rig (VSR). In this setup cold air drives the fixture rotor assembly to speeds approaching $2100 \mathrm{hz}$ for the SST32 frame size. The following graph plots measured axial load in pounds force vs. rotor speed. The direction of the force is uniformly toward the turbine. These data represent the first measurement of axial thrust load for the SST32 frame size with $66 \mathrm{~mm}$ diameter compressor wheel and $64 \mathrm{~mm}$ turbine wheel. Hot, operational loads will be measured with similar rotor group. 


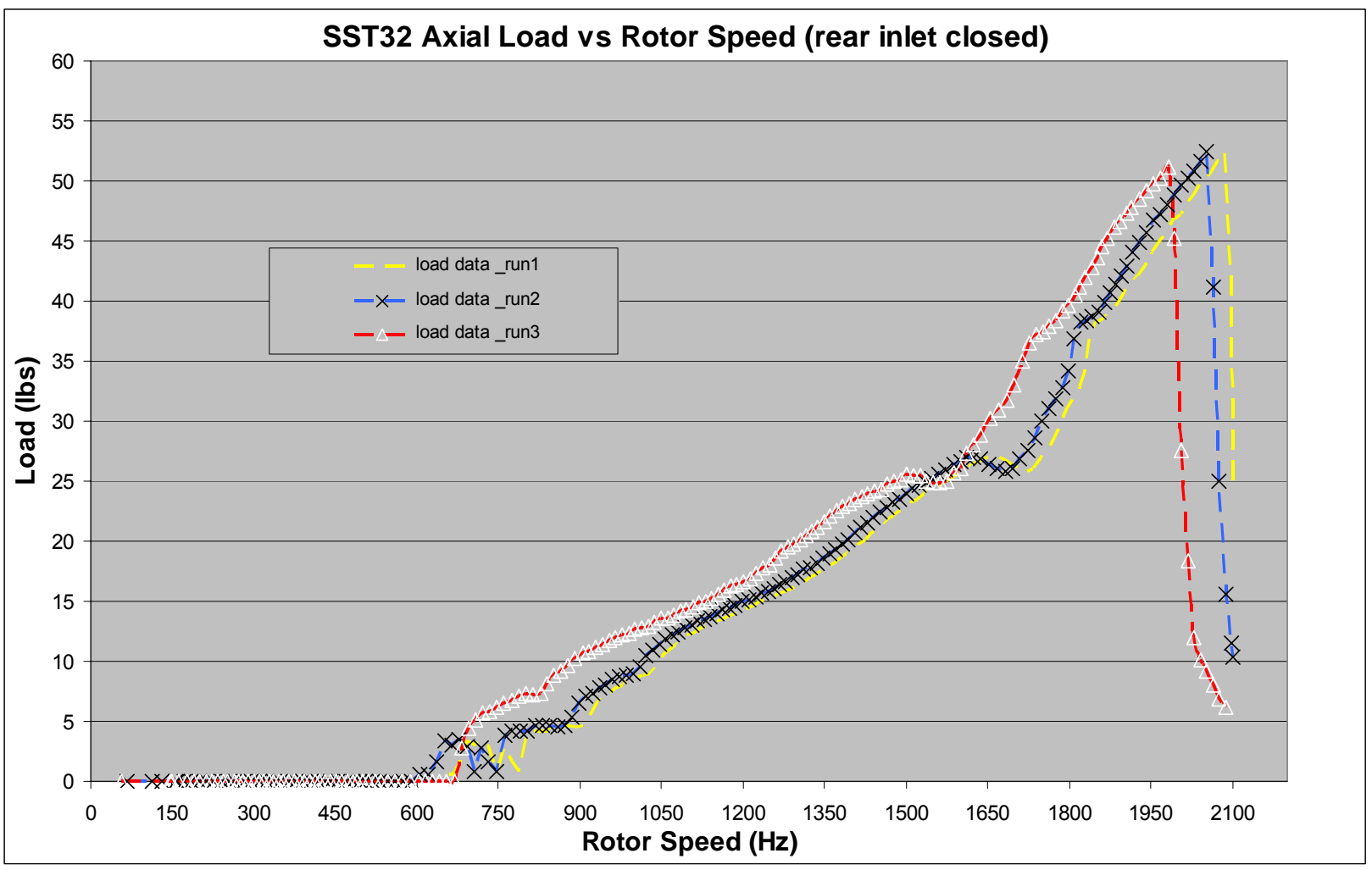

SST32 Axial Load Measurement on VSR Test Stand

Axial load comparison between SST32 and SST35 frame sizes can now be made. The following graph over plots axial loads measured (on the same VSR stand) with the larger SST35 rotor group. The SST35 rotor group combines larger $69 \mathrm{~mm}$ diameter compressor wheel and $68 \mathrm{~mm}$ tip diameter turbine. Comparing axial load at a common $1500 \mathrm{hz}$ value (the SST35 VSR test speed limit), the SST32 rotor group produces about $71 \%$ the axial load of the larger SST35. Given that the SST35 has had 'hot' axial load data measured during a compressor performance test, and those hot operational maximum measured loads approximated $150 \mathrm{lbs}$ force, the SST32 should produce steady state maximum operational axial loading of $110 \mathrm{lbs}$ force. These data are useful in bearing loading/durability studies for the smaller SST32 ball element bearing cartridge. The thrust loading and duty cycle for the SST32 has been evaluated by the ball bearing supplier and has found it to have acceptable durability. 


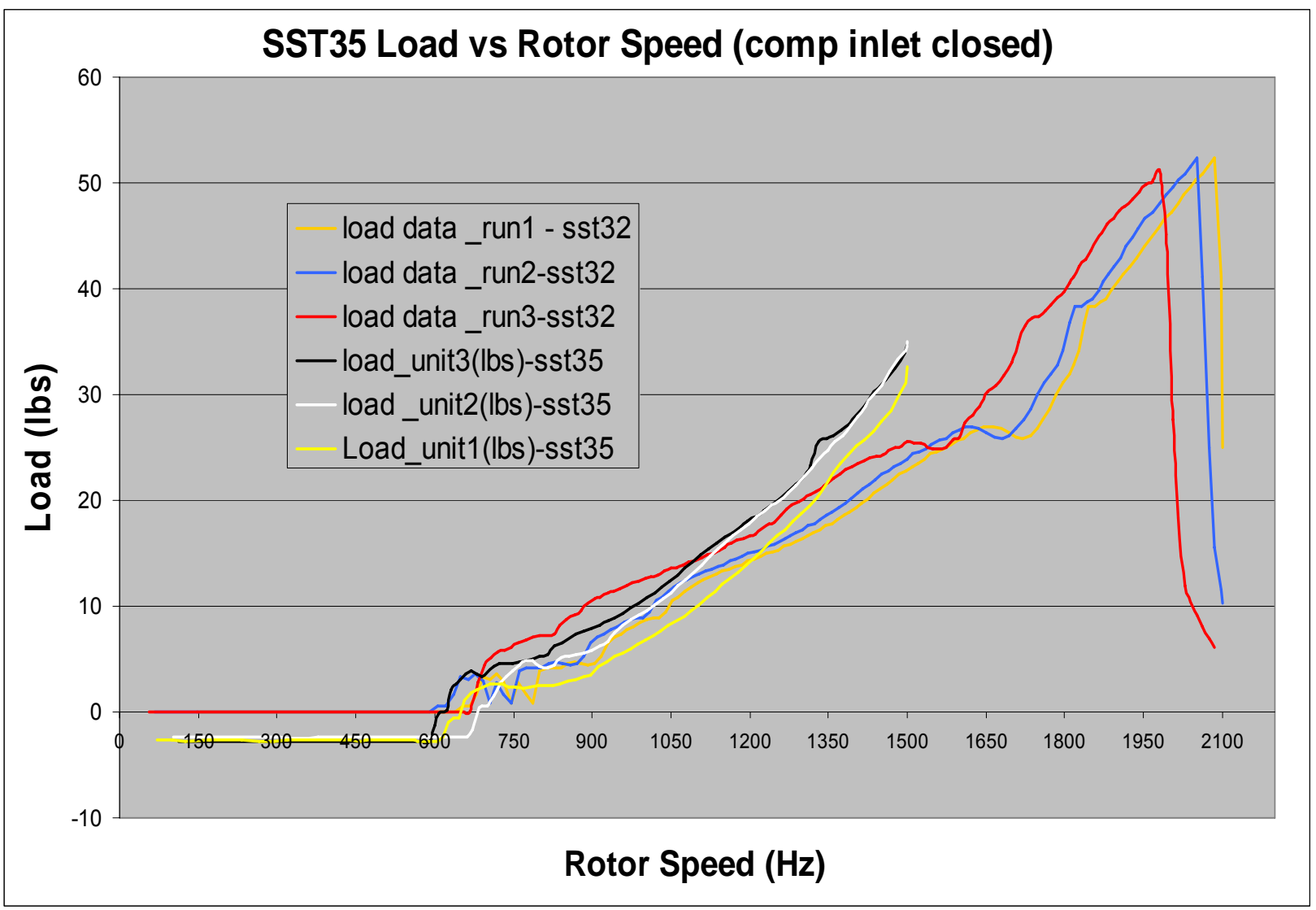

SST32 vs SST35 Axial Load Measurement on VSR Test Stand

\section{Task 2.5 - Develop Compressor Wheel Manufacturing Method}

Casting tools for three SST wheel diameter sizes have been commissioned. Detail development has focused on $66 \mathrm{~mm}$ and $69 \mathrm{~mm}$ diameters in a similar blade count and camber sheet configuration. The wheel model illustrates the unique double backed wheel design. Several casting melts have been made in the reporting period, raising concerns that have initiated subsequent development in controlled casting cooling rates, mold matching design, chill plate design, and casting balance material location. Machining fixtures for prototype wheel machining have been procured and tested. 


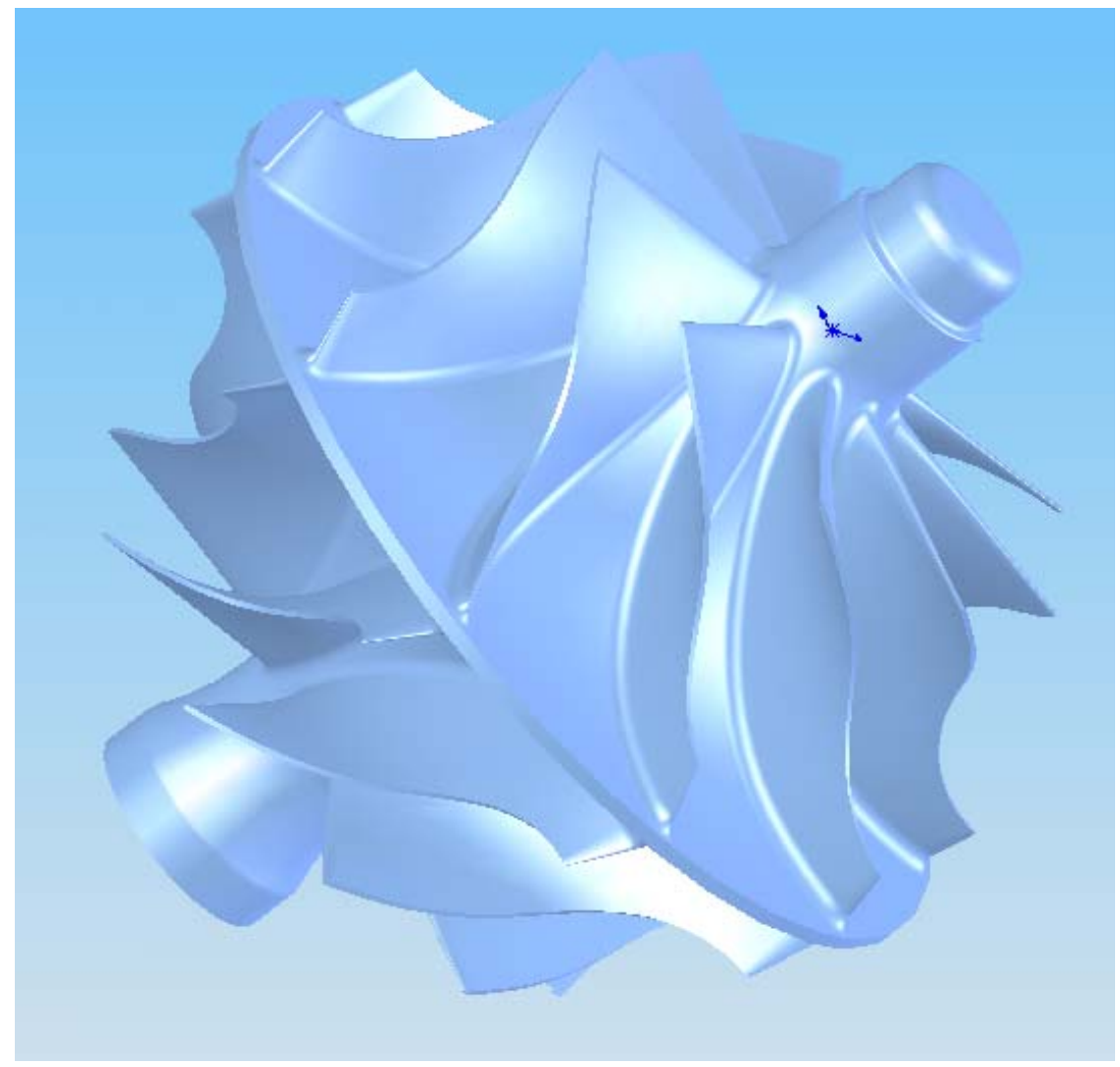

\section{SST Double Backed Compressor Wheel Casting Model}

\section{Task 2.5 Overall Progress Update}

The root cause of casting shrinkage defects discovered early in the project was identified with careful selection and control of mould, metal and pouring funnel temperatures, in addition to mould vacuum setting. Mechanical qualification of the improved wheel castings was re-started with acceptable castings. See Task 2.9.

Development progress is centered with reducing casting process rejects. The following Pareto chart reflects those foundry results for the period. The reduction in reject rate for 'Inspection' scrap cause reflects the reduction in shrinkage defects. Dimensional and Mould scrap cause rates have improved less in this period; corrective action plans and trials are in place to address these causes. 


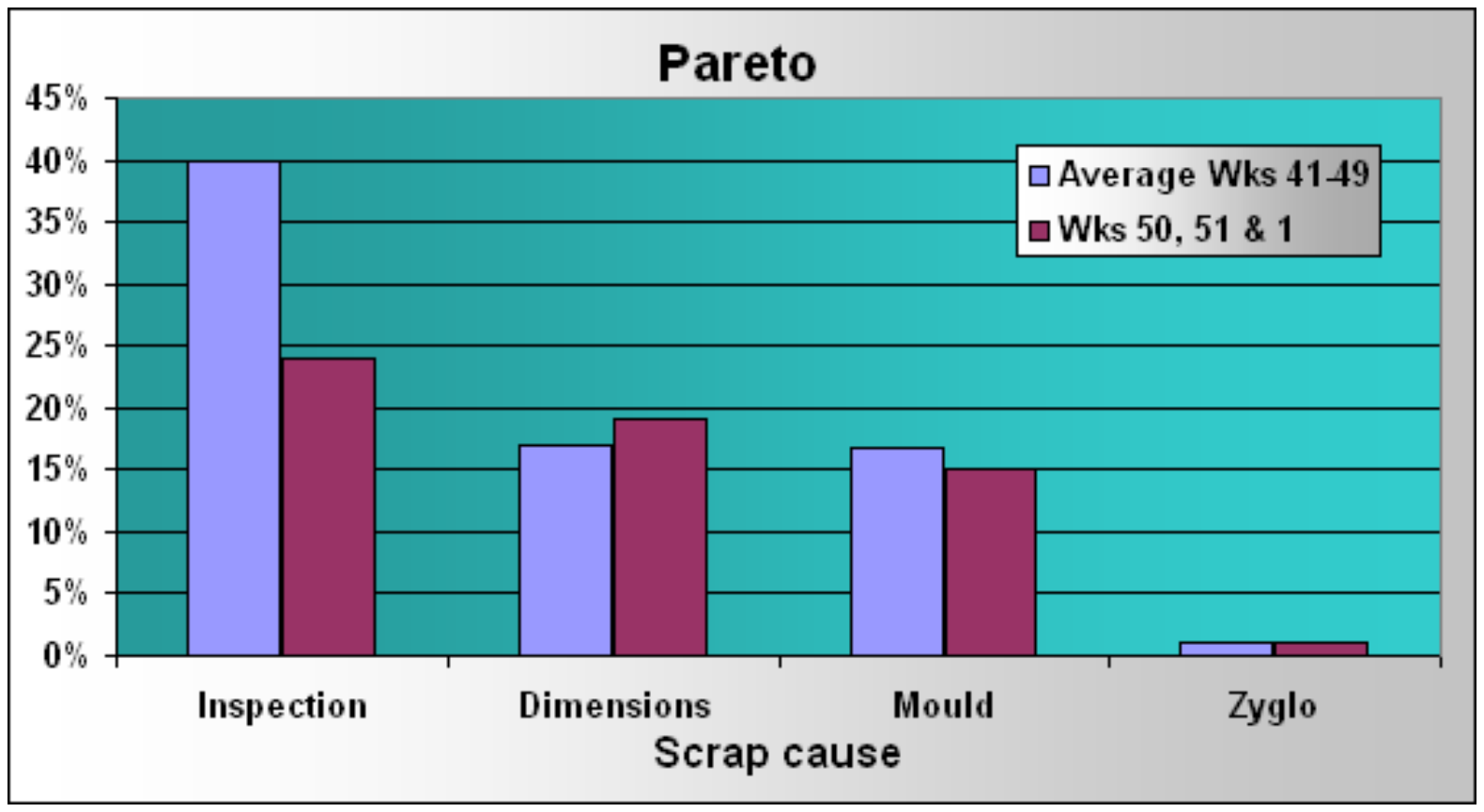

SST Compressor Wheel Casting Pareto Chart

Parallel high volume casting process development continues to show promise, although its priority has taken a lower level based on resource availability. This activity was driven as a very high volume casting alternative method. Mould and chill assembly complexity represent difficult individual assemblies for accepted foundry casting methods. Progress has been made in a method of delivering hot metal to multiple moulds, however, by the end of the contract period, high volume SST casting demonstration remains an action item.

\section{Task 2.6 - Create Design-for-Reliability Design-Failure-Modes-and- Effects-Analysis (DFR-DFMEA)}

Detail DFR-DFMEA documents for the SST turbine stage and ball bearing cartridge were initiated during this reporting period. A DVP\&R plan was initiated to include action items from SST compressor, bearing and turbine DFR-DFMEA's.

\section{Task 2.6 Overall Progress Update}

DFR/DFMEA is a living document. This document is being updated frequently to reflect the new product issues such as turbine blade pass noise. The preliminary DFR/DFMEA has been updated to include the latest learning from failures and results of testing and analysis. Some of the high risk items identified through the DFR/DFMEA were compressor sealing, compressor wheel LCF, turbine wheel HCF and unbalance generated noise. 
Task 2.7 - Using the results of the fundamental investigations is Tasks 2.1 through 2.6, design a dual compressor wheel VNT turbocharger (SST) for a 3 liter turbo-diesel engine meeting U.S. Tier 2 Bin 5 emissions

Design of a passenger vehicle sized SST is complete. The new design size is designated SST20 based on wheel diameter sizing. The solid model image below represents the outline of the smaller SST20 turbocharger.

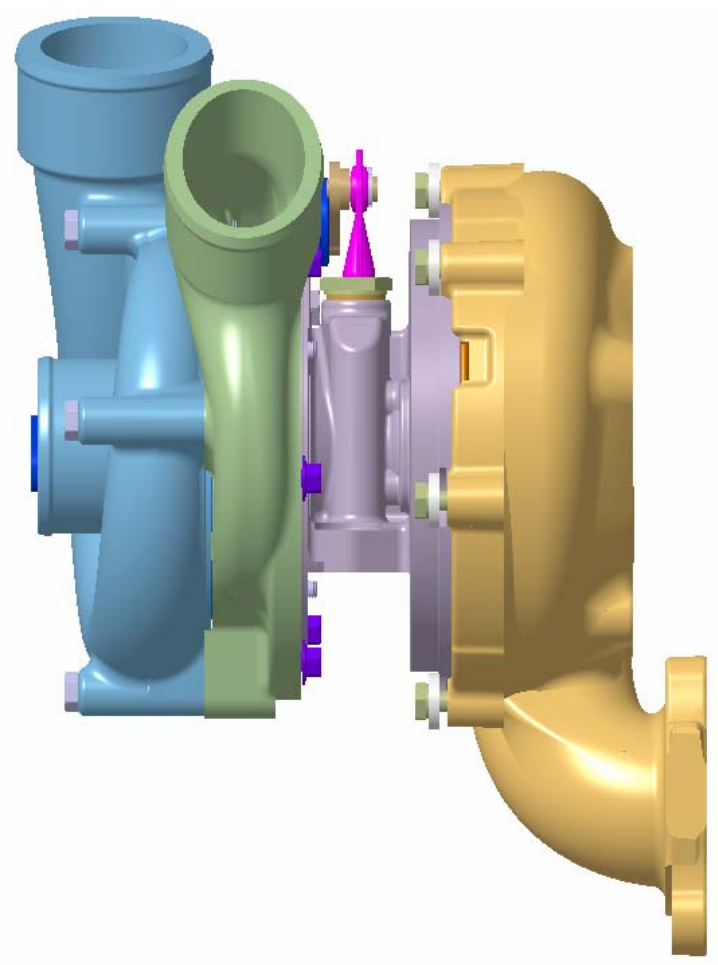

SST20 Passenger Vehicle Turbocharger Model

The first design of a SST20 (matched for a 3 liter engine) was completed. Rapid prototype compressor housings, rear inlets and shrouds were procured. Three different compressors were investigated in terms of satisfying the operating requirements of a 3 liter engine. Compressor performance of the C226, C232 and C253 compressor wheels were evaluated on a gas stand. Based on the gas stand results a C232 compressor was deemed to be the best match for the operating requirements for the engine. Two turbine wheels T232 and T246 were investigated. The first generation SST20 was packaged into a 3 liter Diamler Chrysler engine calibrated to mimic operation necessary to satisfy the emission requirements for 2010. Engine test results with EGR indicated that the compressor efficiency needed further improvement. The turbine efficiency also needed to be improved at rated operation. A typical SST20 compressor map is attached for reference. 




SST20 Compressor Map

\section{Task 2.7 Overall Progress Update}

An SST20 turbocharger was prepared with the scalloped $51 \mathrm{~mm}$ diameter C226 type compressor and rotor system. This prototype included new ball bearing, bearing housing, compressor housing, insert, and compressor wheel.

Multiple performance tests produced compressor maps with consistent peak efficiencies down $4 \%$ to $5 \%$ compared to previous SST20 compressors with conventional blade hubs extending beyond the (blade) tip diameter $(51 \mathrm{~mm})$. The root cause of the reduced compressor efficiency was not obvious based on initial baseline testing. Later, turbocharger failure was experienced during extended performance mapping. The root cause of the failure was found to be exceeded ball bearing thrust load capacity at rotor 
speeds approaching $200 \mathrm{Krpm}$. The low compressor efficiency was impacted by a poor static seal between the compressor diffuser and rear wheel inlet air path. The poor seal will permit compressed air to leak back to the rear wheel inlet air passage (which operates at sub-atmospheric pressure). Retest of the scalloped compressor wheel performance is scheduled for early 2008.

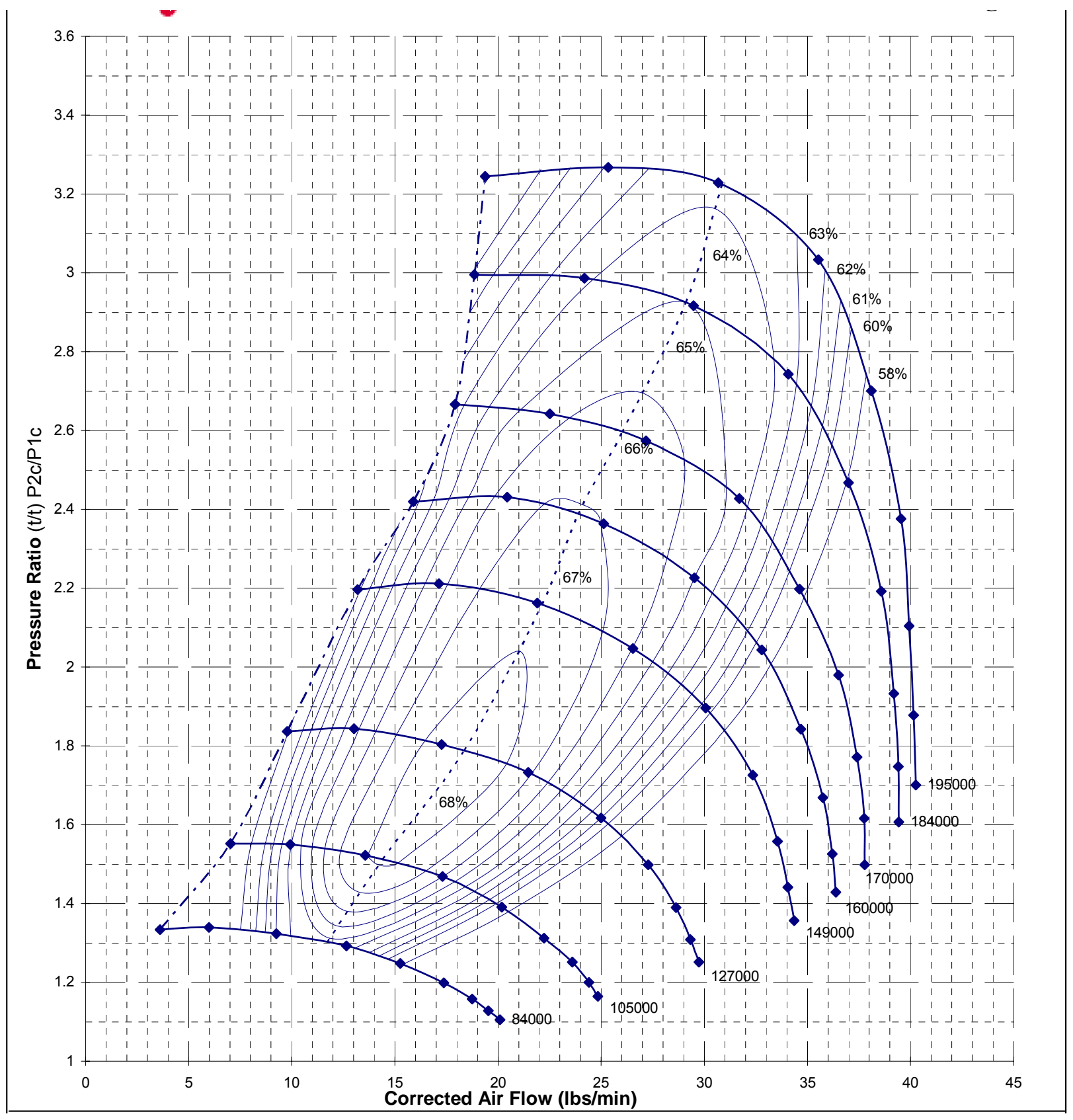

SST20 Scalloped Compressor Wheel Performance with Internal Leak 
The SST20 compressor rear inlet air flow passage was also identified as an element compromising stage efficiency.

A 3D CFD analysis was conducted on the current rear inlet design. The results show that there is severe flow separation leading to high loss in total pressure. Below, the left illustration models the area of flow separation near the inlet of the rear compressor. Improved geometry, illustrated at right in 2D, shows that separation at the wheel inlet can nearly be eliminated. The pressure loss prediction through the duct to the rear compressor wheel inlet suggests that more than $50 \%$ reduction will be experienced. Redesign of the SST20 rear inlet is a new action item.
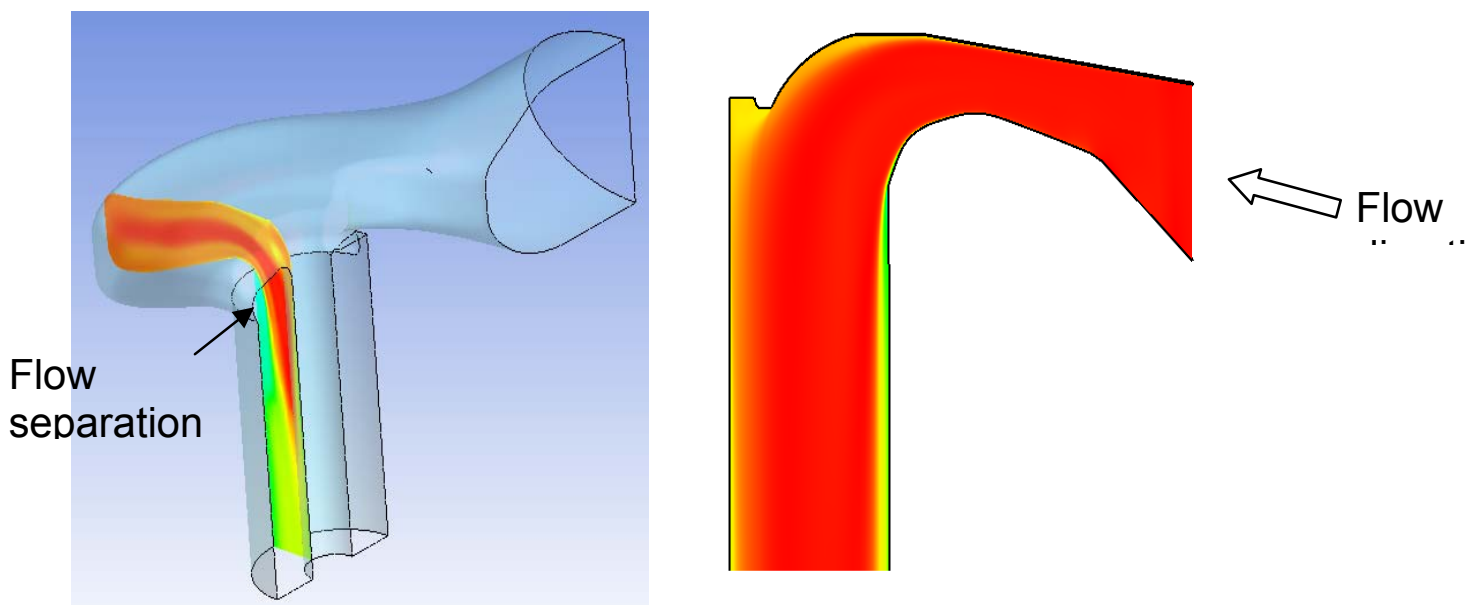

\section{$\underline{\text { SST20 Rear Inlet Air Flow Separation Improved Rear Inlet Air Flow Geometry }}$}

A new generation ball bearing cartridge assembly and bearing housing have been ordered in $4 \mathrm{Q} 07$. The ball bearing is more robust design with higher thrust capacity, however, these components represent a non-interchangeable change requiring a new bearing housing, and re-configured turbine wheel assembly. The new prototype SST20 parts will arrive in late 1Q08. Shaft motion testing and compressor stage performance are key follow-on action items.

\section{Task 2.8 - Optimize the Aerodynamic Performance}

Compressor aerodynamic performance in three SST 66mm tip diameter wheels was mapped. Compressor wheel types are designated by Cxxx nomenclature protocol; in this period C226, C117 and C250 type wheels in selected aerodynamic trims were tested. Significant effort in optimizing wheel trim/diffuser geometry, re-circulation port effects, and wheel type impact was conducted. Effect of twin compressor inlet duct geometry (see Task 2.1) is very closely tied to map width, performance, and wheel surge onset. 
Turbine performance was mapped with a new T235 turbine wheel design, in a trim size complimenting high flow, high pressure ratio operation for medium duty diesel applications. This wheel demonstrated preferred characteristics, however, during gas stand and on-engine tests, a turbine high cycle fatigue (HCF) condition within the operational speed range, resulted in exducer blade tip separation failure. Additional test work is underway to identify the operating regime responsible for the high blade strain. A cartridge concept, desirable for durability of the turbine stage at elevated temperature, has been designed, and hardware procured. An illustration of the concept is shown below.

The turbine insert impact on performance indicated that stage efficiency was down compared to non-insert equipped stages. Analysis of the insert/turbine housing/center housing joint uncovered an area near the vane actuation lever in which direct (to atmosphere) leakage would occur. A new joint design correcting the leak path was implemented. Stage performance re-test is planned. 


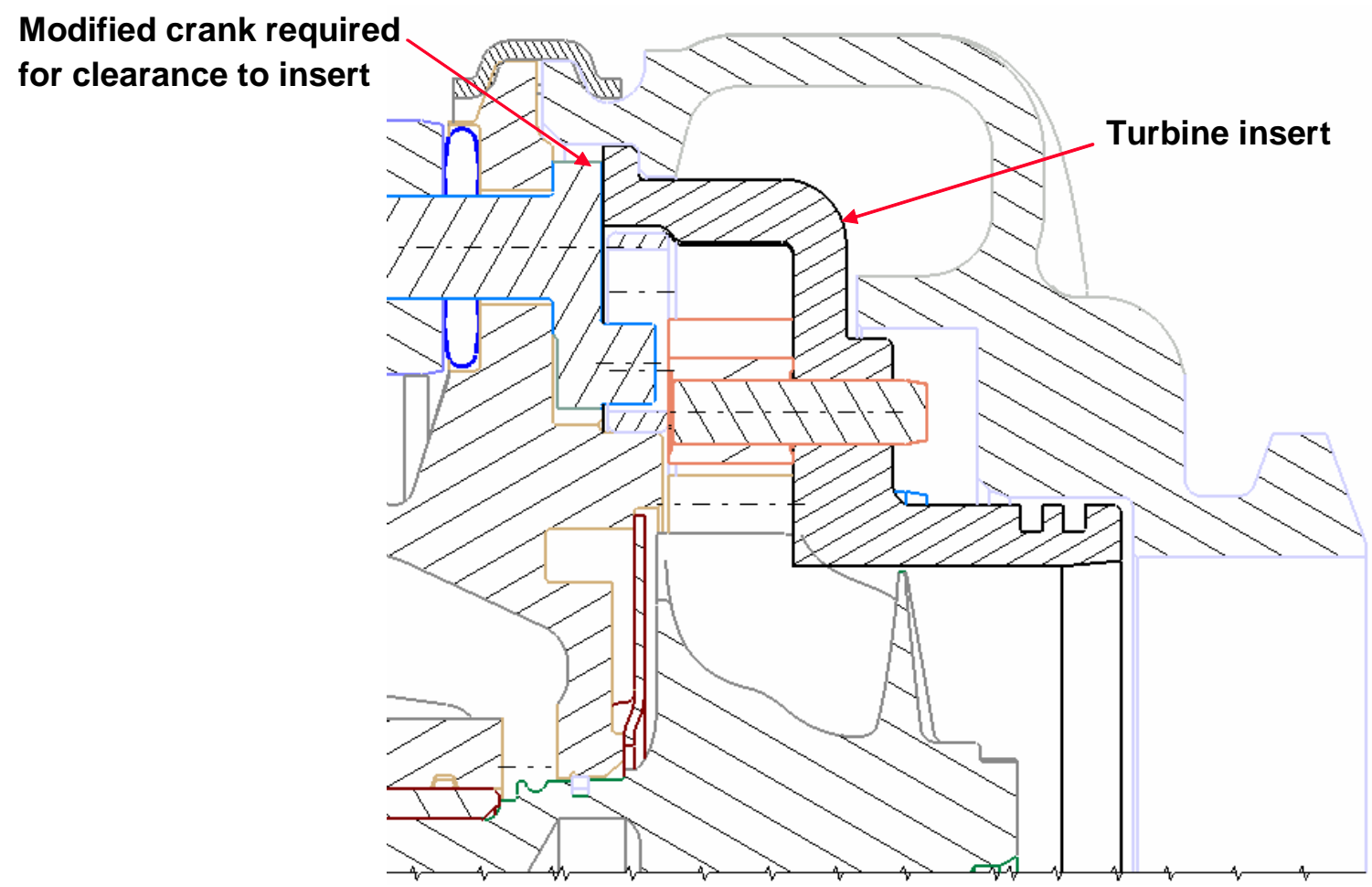

\section{SST Turbine Cartridge Insert Configuration}

\section{Task 2.8 Overall Progress Update}

Prototype thinned 66mm SST32 frame size C226 (designated C226A) and new design C257 compressor wheels were procured and tested in the third quarter. Both compressor wheels were tested in 44 trim size, initially configured to compare directly to the target SST32 C226 44 trim variant with wheel inducer/exducer area (EI) ratio, and diffuser exit (DE) area ratio set to 48 and 1.41 respectively. Both wheel designs were also tested in 44 trims with modified El and DE geometry ratios as follows-

- $\mathrm{C} 226 \mathrm{~A}, 44$ trim, $55 \mathrm{EI}, 1.35 \mathrm{DE}$

- $\mathrm{C} 257,44$ trim, $55 \mathrm{El}, 1.35 \mathrm{DE}$ and 44 trim, $48 \mathrm{EI}, 1.65 \mathrm{DE}$

Three performance plots are included, labeled Map 1, 2, and 3. In map plots 1 and 2 respectively, performance of like trim C226A, and new design C257 wheels are plotted against the baseline $\mathrm{C} 226$ stage. Both new wheel designs provide the predicted $(5 \%)$ flow increase, however, only the C257 wheel design yielded increased peak stage performance. The peak island efficiency was $1 \%$ higher than the baseline at $76 \%$. Clearly, the new wheel designs could be de-trimmed to better match the baseline map, perhaps providing enhanced surge performance. This should be investigated further.

In map plot 3, best C226(A) performance, derived from a change in trim inducer/exducer area (EI) ratio, and diffuser exit (DE) area ratio $(55 \mathrm{EI}, 1.35 \mathrm{DE})$, bests 
the baseline peak efficiency by $1 \%$, and raises the islands also. The C226(A) surge line, despite the excessive trim size is better as well. A de-trimmed C226(A) could be higher efficiency in a wider range map. This, as with the C257 design, needs further testing.

\section{Honeywell}

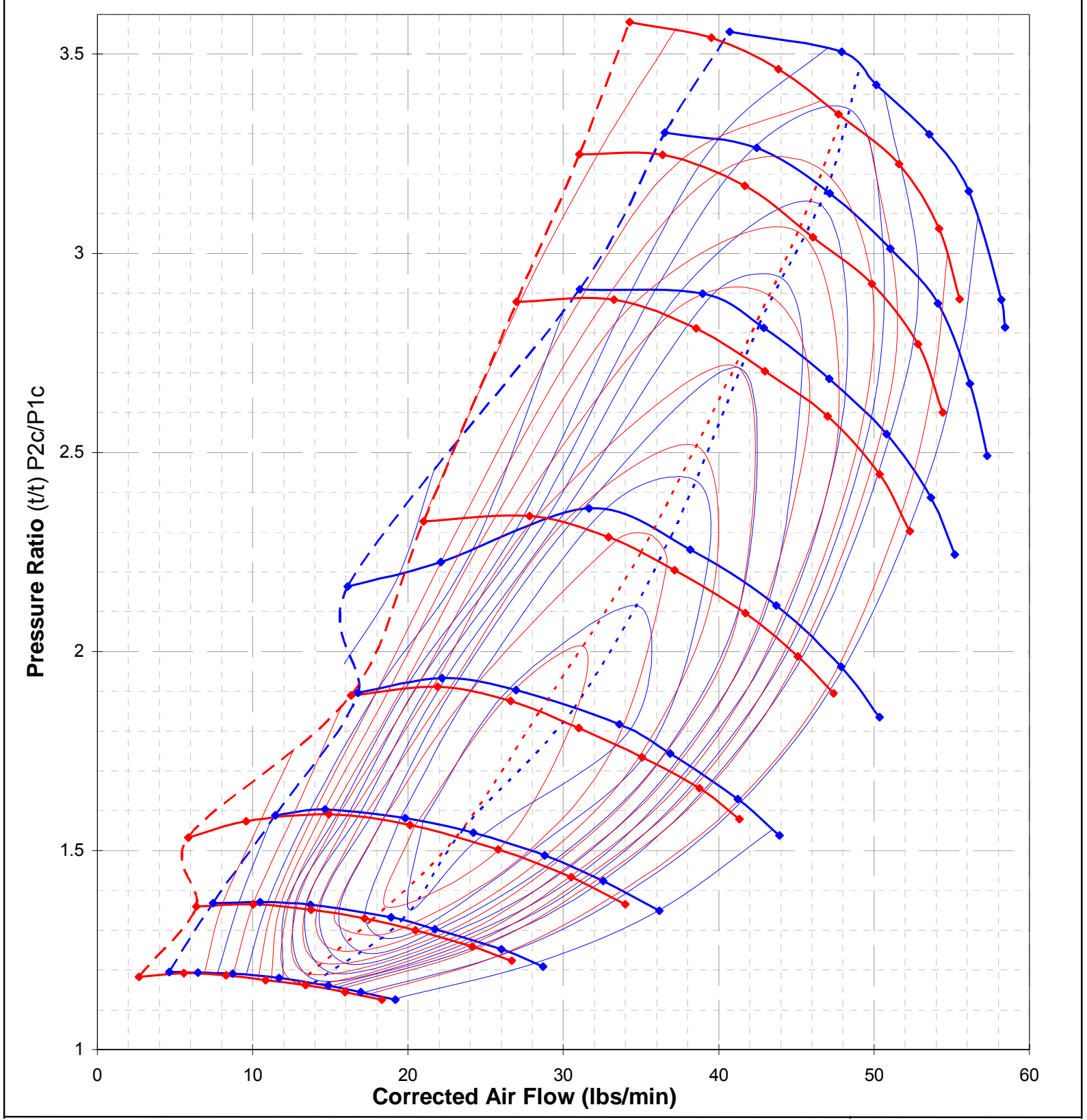

Map 1- Baseline C226 44 trim (red) vs. C226(A) 44 Trim Performance (blue) 


\section{Honeywell}

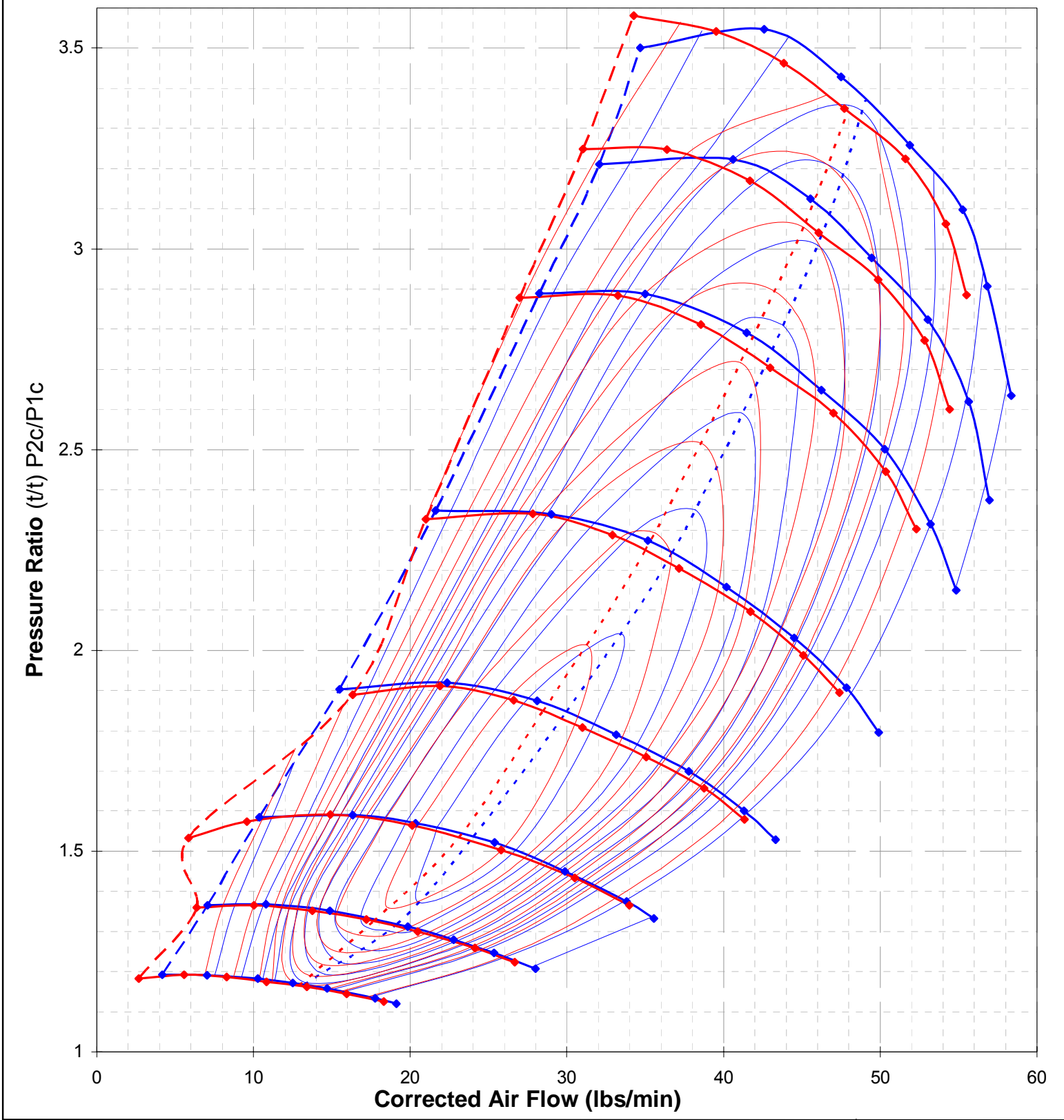

Map 2 - Baseline C226 44 trim (red) vs. C257 44 Trim Performance (blue) 


\section{Honeywell}

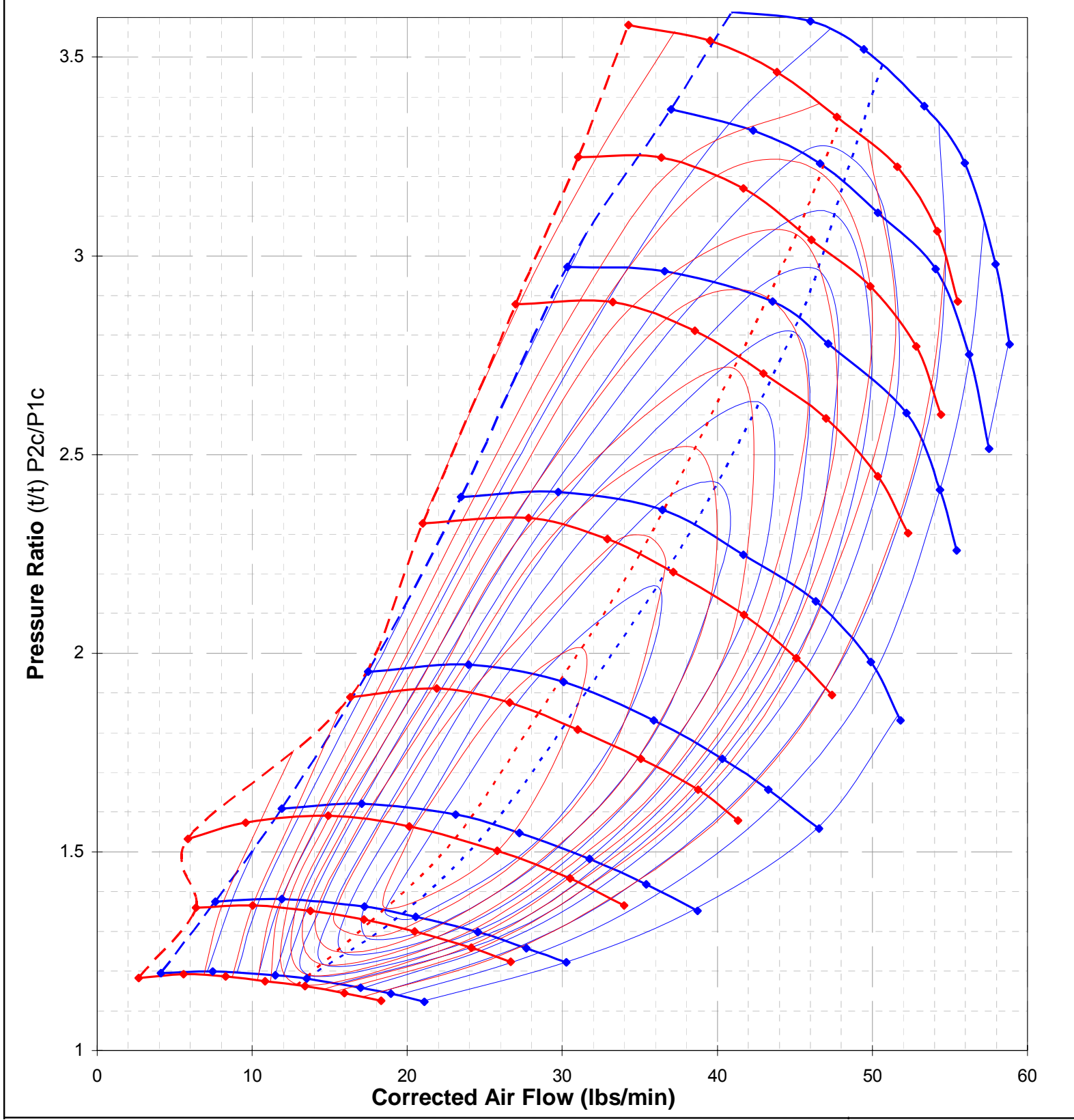

Map 3 - Baseline C226 44 trim (red) vs. Best C226(A) 44 Trim Performance (blue) 


\section{Task 2.9 - Complete (low cycle fatigue) LCF Testing of the Compressor Stage}

Prototype SST hardware was assembled and delivered to the test lab for LCF fixture fabrication and testing. Testing on a twin turbo endurance stand is scheduled to begin the week of January 29, 2007. The compressor wheel configuration will be C226, 69mm tip diameter. Test wheels are configured with a boreless turbine wheel attachment.

\section{Task 2.9 Overall Progress Update}

The wheel casting improvement process consumed the third quarter. Sound wheel castings suitable for LCF test were received in October and we have accumulated 160,000 cycles on the LCF testing. The LCF testing will continue to failure.

\section{Inventions/Patents}

All inventions, patents and associated publications related to this project are being reviewed for applicability and will be submitted under separate cover. 


\section{PROJECT 3 - ULTRA HIGH PRESSURE TURBOCHARGER for HEAVY-DUTY DIESEL ENGINES}

The objective of this project is to design, develop, procure and test a design of series turbocharger for high pressure ratios required for 2010 emissions regulations packaged on a single shaft, termed the LST. One of the objectives of the LST is to provide the compressor stage performance of a series turbocharger within the packaging of a single turbocharger. Benefits of this turbocharger design include:

- Broad compressor map

- High compressor pressure ratio capability

The LST is designed to provide the charge air system performance of a series turbocharger (i.e., two (2) turbochargers) within the packaging of a single turbocharger, thus providing packaging benefits and lower installed cost. The program technical objectives include:

- Scale the compressor stage from the larger LST55 turbocharger to the HD diesel engine (13 liter engine displacement) LST45 turbocharger

- Integrate a variable nozzle turbine (VNT ${ }^{\mathrm{TM}}$ ) into the LST45V turbocharger design

- Turbocharger Performance Targets:

- 5.60 maximum operating compressor pressure ratio

o $76 \%$ compressor stage efficiency (up to 4.50 compressor pressure ratio)

o 55\% overall turbocharger efficiency @ 4.50 compressor pressure ratio

\section{Background}

Turbocharging is critical for reducing fuel consumption in internal combustion engines. This is true for diesel, gasoline, and alternate fuel engines for passenger cars as well as commercial vehicle applications. In order to adapt and fully utilize the benefit that turbocharging can provide for US applications, further advances are required.

Heavy duty diesel engine emissions in the US are the most stringent in the world. These requirements impose unique demands on turbochargers such as higher pressure ratios and high rates of Exhaust Gas Recirculation (EGR) flow. Research and development is critical to meet these requirements.

\section{Task 3.1 - Procure prototype hardware, assemble and balance the rotating group}

\section{Task 3.1 - Overall Progress Update}

Status: Prior to procuring hardware for the LST45V prototype turbocharger, a design study of the compressor stage hardware was done. Using the experience gained from the LST45V "Progenitor" turbocharger design, a production intent LST45V turbocharger 
design has been done. Rotor-dynamic analysis has been completed for the LST45V prototype turbocharger assembly. The rotor used a larger journal size and the bearing span will be increased such that the turbocharger assembly will not be limited in operation due to rotor-dynamics. The production intent LST45V turbocharger design related detailed engineering drawings and 3D models are released, components ordered, received and tested. Based upon initial testing/qualification of the "Production Intent" LST45V turbocharger design as well as preferences from selected OEM engine manufacturers, the LST45V turbocharger has been focused towards achieving improved mechanical efficiency and overall turbocharger efficiency. The LST45V turbocharger was redesigned to accept an anti-friction rolling element bearing system. Additionally, the turbocharger end seals have been redesigned to reduce blow-by leakage into the engine crankcase. The new turbocharger is designated LST45VR and all the components are ordered and received.

\section{Detailed designs of final LST45VR turbo charger are below}

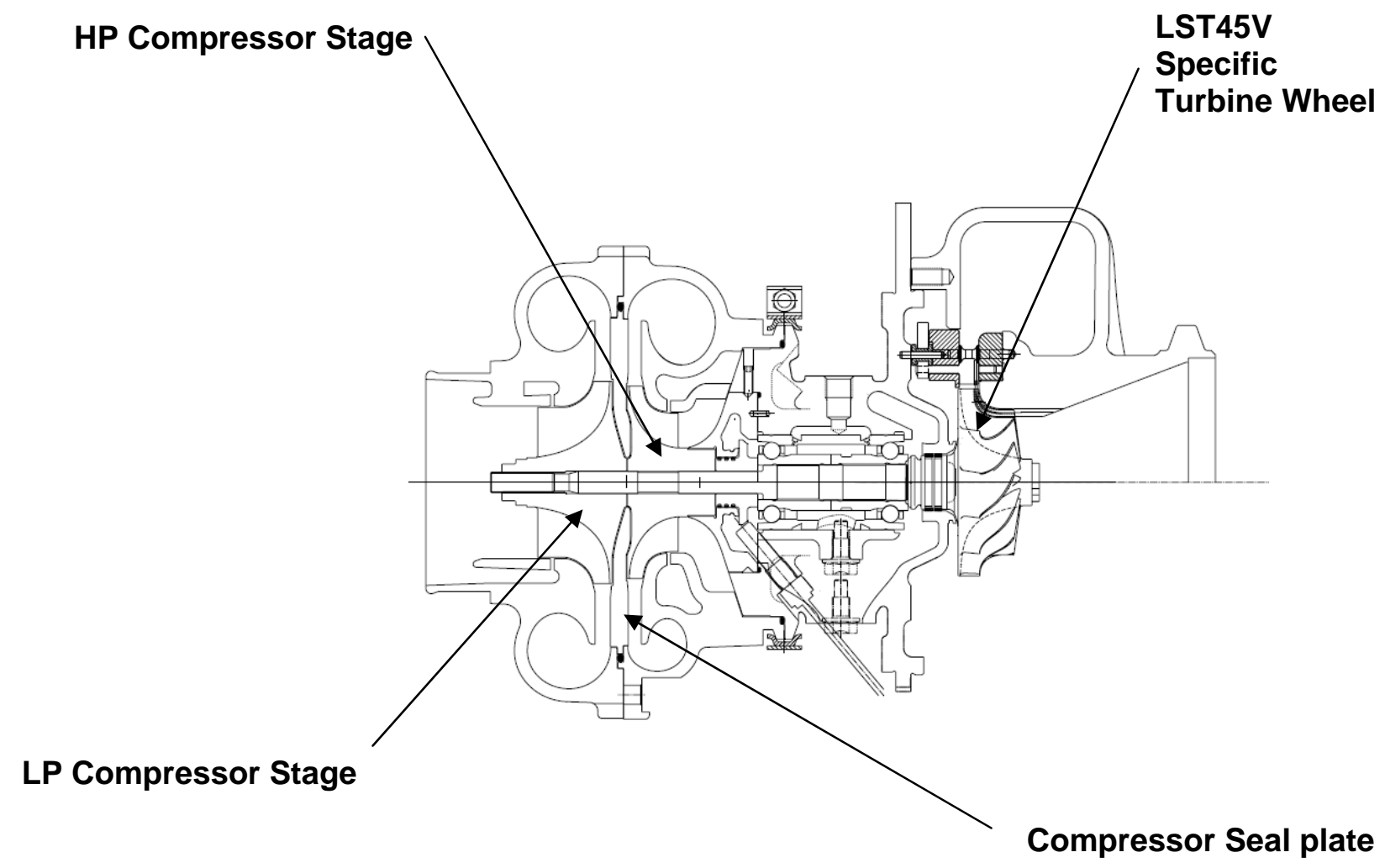

LST45VR Turbocharger Cross-Section

Bearing System: The rolling element bearing system is a $16 \mathrm{~mm}$ cartridge assembly. The bearing cartridge utilizes ceramic balls and silver plated steel cages. The bearing 
cartridge system is capable of resisting thrust loads such that a separate thrust bearing is no longer required.

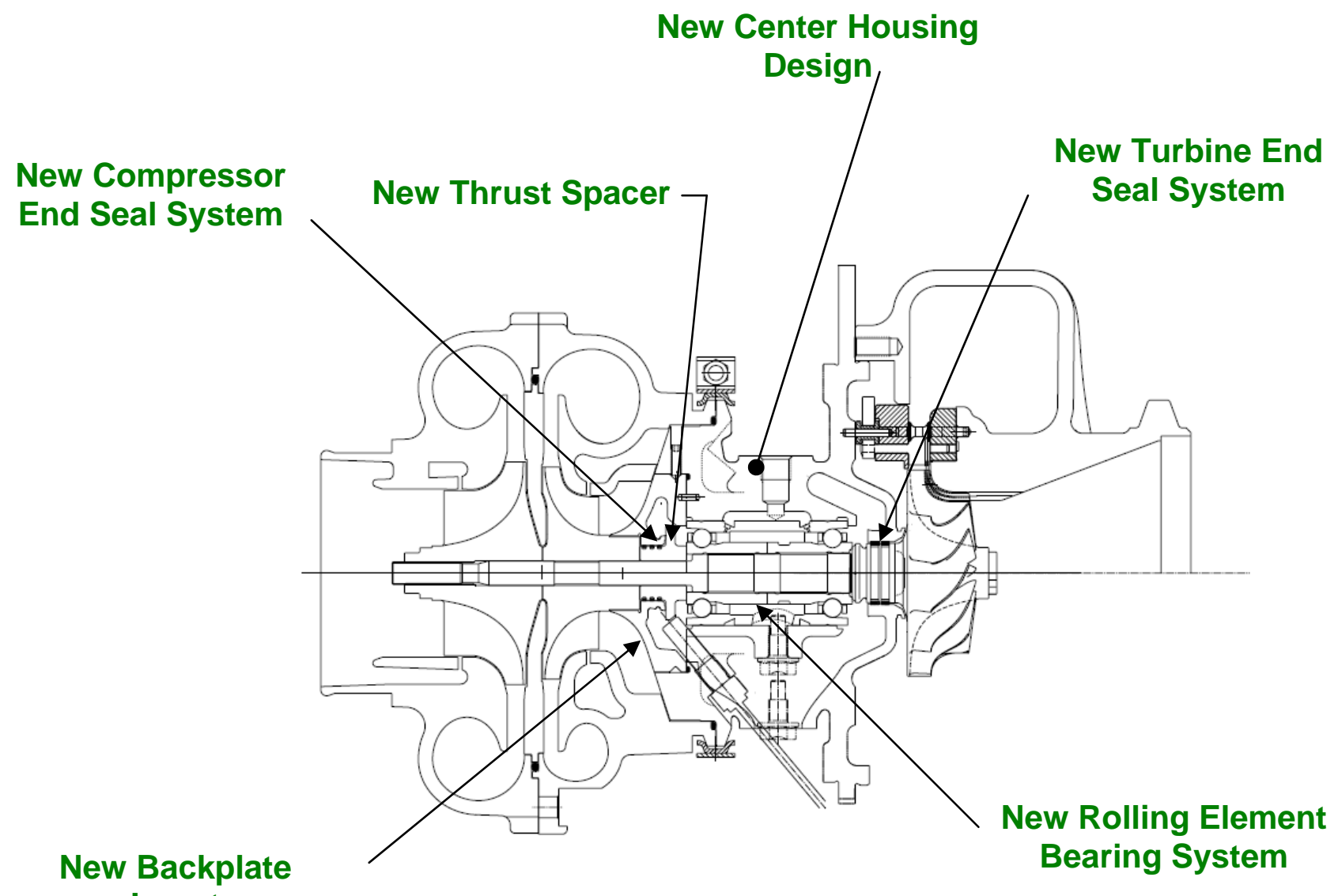

LST45VR Turbocharger - Bearing system 
Below Figure is an enlarged view of the turbine end and compressor end seal systems.

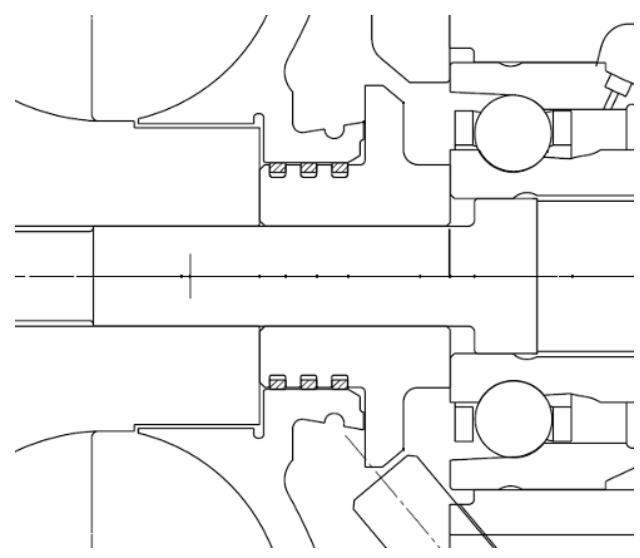

Compressor End Seal System

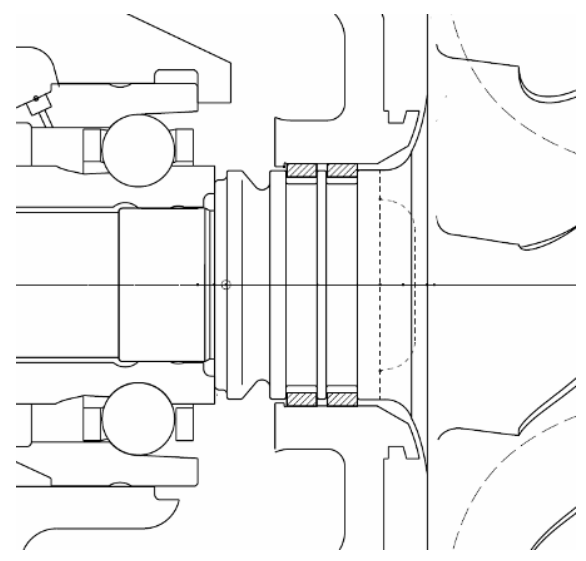

Turbine End Seal System

Compressor End Seal Design: The revised thrust spacer is also shown in the figure. The LST45VR turbocharger compressor end seal design uses three (3) piston rings to seal oil from leaking into the gas passage as well as prevent blow-by gas from entering the center housing drain cavity and engine crankcase.

Turbine End Seal Design: As with the compressor end seal, the LST45VR turbocharger turbine end seal design seals oil from leaking into the gas passage as well as prevent blow-by gas from entering the center housing drain cavity and engine crankcase. The turbine end seal uses two (2) piston rings.

\section{Task 3.2 - Conduct comprehensive performance testing on a gas stand to verify the performance of the design}

\section{Task 3.2 Overall Progress Update}

The final design, LST45VR comprehensively tested on gas stand to verify the performance of the design tested/evaluated over it's full operating range. Data was gathered to produce a more complete LST45VR turbocharger compressor map. Additional LST45VR turbine mapping also completed.

Figure below shows the LST45VR turbocharger compressor performance (non-ported HP compressor stage) over the full operating range. 


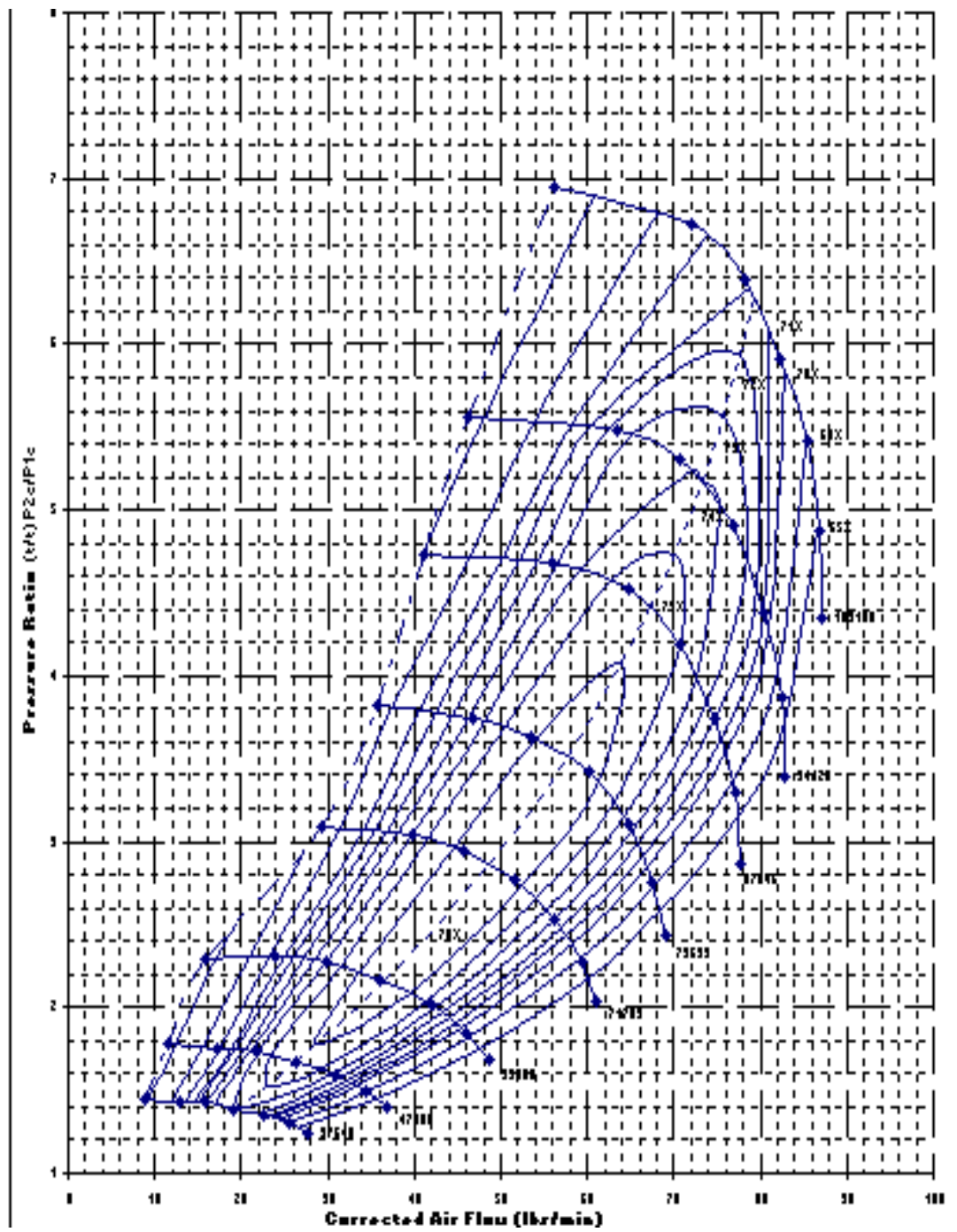

\section{LST45VR Turbocharger Full Operating Range Compressor Map non-ported HP compressor stage $76 \%$ Peak Island}


Figure below shows the LST45VR turbocharger compressor performance (non-ported HP compressor stage) over the full operating range.

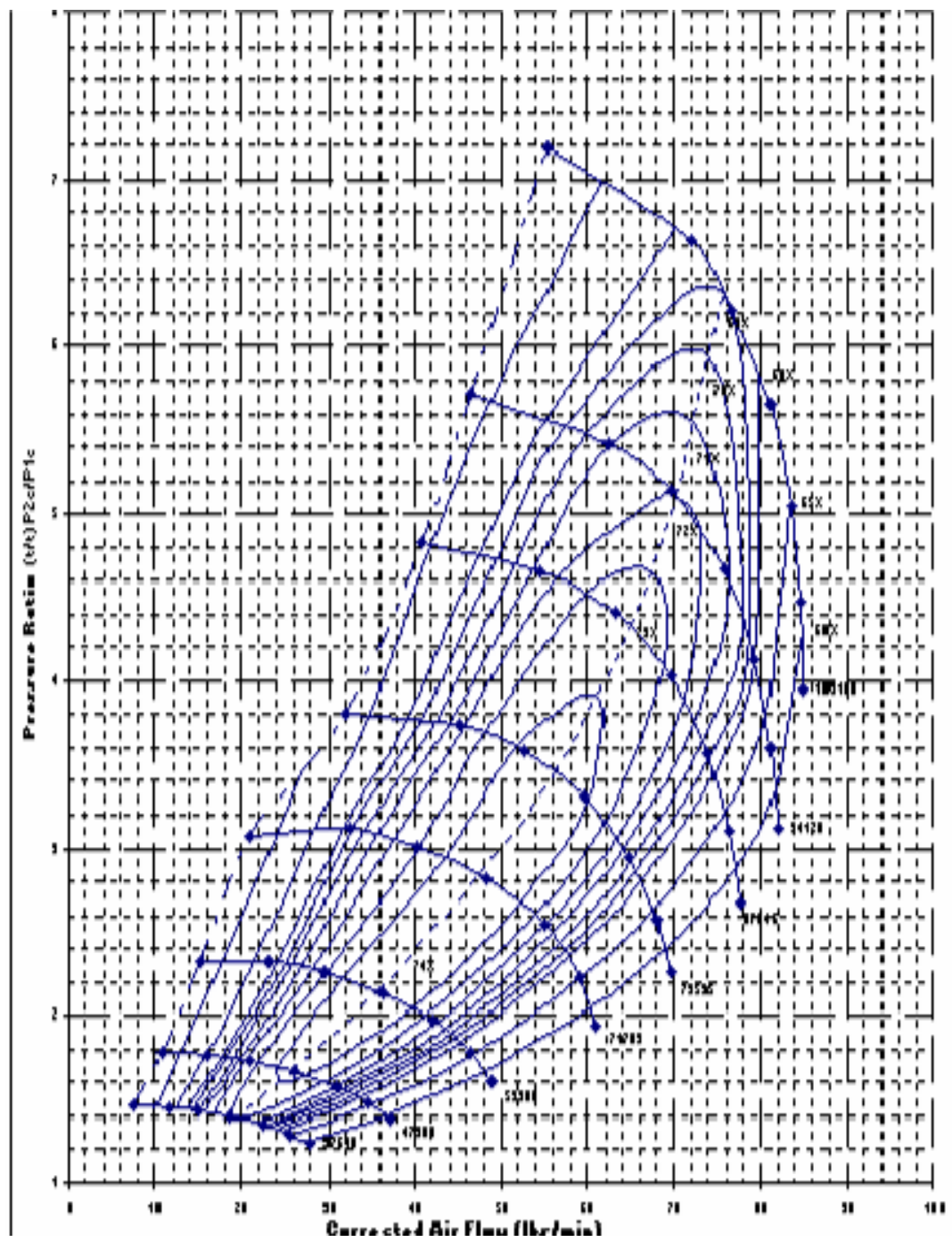

\section{LST45VR Turbocharger Full Operating Range Compressor Map fully ported HP compressor stage 74\% Peak Island}


LST45VR Compressor Performance: The air supply to the laboratory turbocharger test bed was revised to provide higher pressure air supply so that more of the LST45VR turbocharger could be evaluated over the full operating range. The LST45VR turbocharger compressor demonstrated pressure ratios over 7:1

Demonstrated Performance:

- Maximum demonstrated compressor pressure ratio $=7.2: 1$

- $76 \%$ peak compressor efficiency

- 73\% compressor efficiency @ 5.50 compressor pressure ratio

- Overall turbocharger efficiency $=52.5 \%$

- Map width =56.6@ 4.00 compressor pressure ratio

Task 3.3 Complete an endurance test of prototype hardware including a 500 hour cyclic durability test on a gas stand to verify mechanical integrity of the design

\section{Task 3.3 Overall Progress Update}

This task not started with-in the reported period of time.

Task 3.4 - Procure parts, build, test and ship LST45VR performance demonstrators to conduct on engine performance testing at selected engine $\operatorname{OEM}(s)$. Analyze and report engine data

\section{Task 3.4 - Overall Progress Update}

The final turbo charger design, LST45VR turbocharger assemblies were prepared, assembled, and shipped to select OEM Heavy Duty Diesel engine manufacturer's for evaluation of the turbocharger system and comparison to 2 stage (Series) Turbocharging systems. Considerable testing was completed by one OEM with quite satisfying results. 


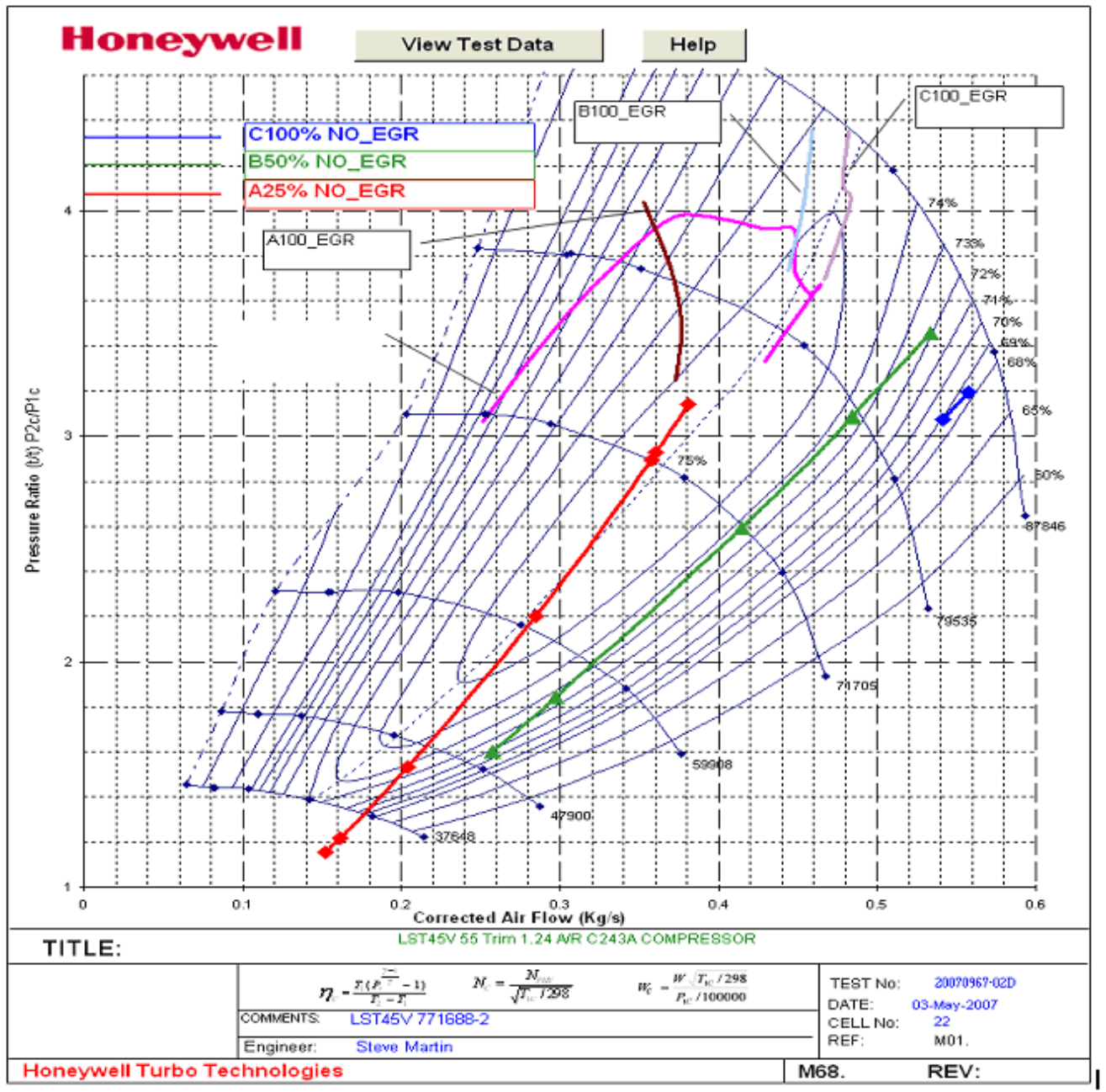

\section{On-Engine Compressor Performance of LST45VR turbocharger}

Figure above shows the compressor match to the engine at various engine operation conditions. The width of the LST45VR compressor map results in a more forgiving turbocharger match compared to a traditional turbocharger compressor. Adequate compressor surge margin is realized as well as relief from a compressor choke condition. 
Figure below shows a comparison of the transient engine performance (2 stage turbochargers vs LST45VR turbocharger). The transient response was measured to be quite comparable to a 2 stage turbocharger system.

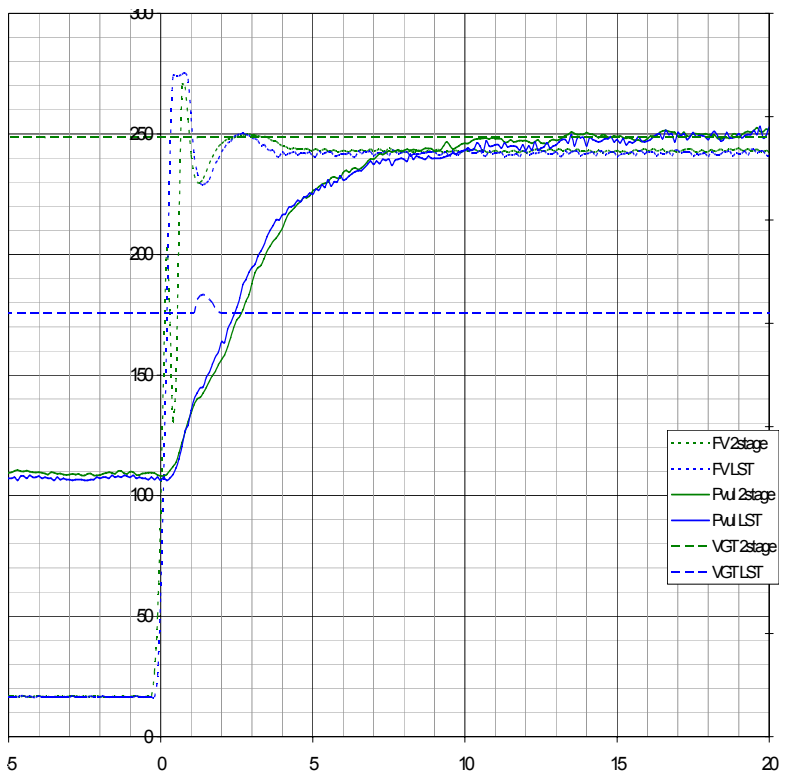

Engine Transient Performance Comparison (2 stage turbochargers vs LST45VR turbocharger)

Task 3.5 - Complete a prototype, producible hardware for engine testing and pre-production qualification. Conduct tests to ensure that hardware meets criteria

\section{Task 3.5 Overall Progress update}

The LST45V pre-production design completed and conducted the tests to meet the criteria and results are as follows.

Turbocharger Shaft Motion Qualification: Shaft motion testing was completed. The measured shaft motion exceeded allowable limits at the higher turbocharger speeds. Below are the results of shaft motion test, measured at extreme of journal bearing system clearances. 
LST45V SHAFT MOTION TEST

Min OD/Min ID Clearance Corner

212 F (100C) 15W-40 Oil Supply

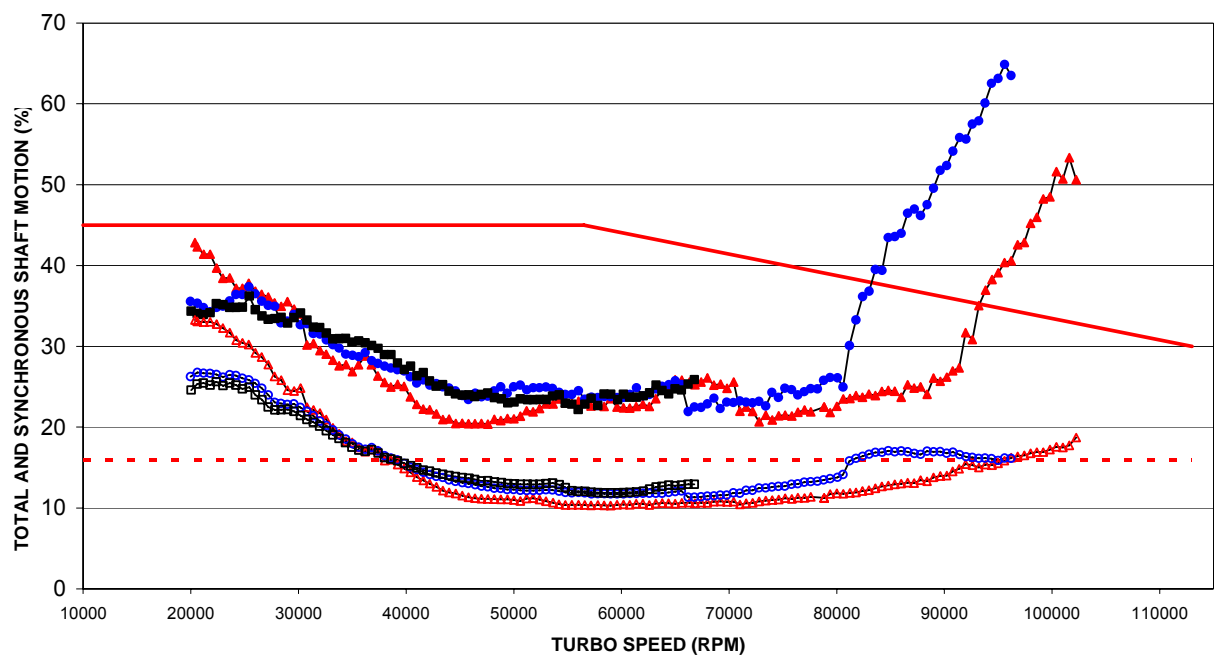

LST45V Shaft Motion Results -Minimum OD/Minimum ID Bearing System Clearance Corner

LST45V SHAFT MOTION TEST

Max OD/Max ID Clearance Corner

212 F (100C) 15W-40 Oil Supply

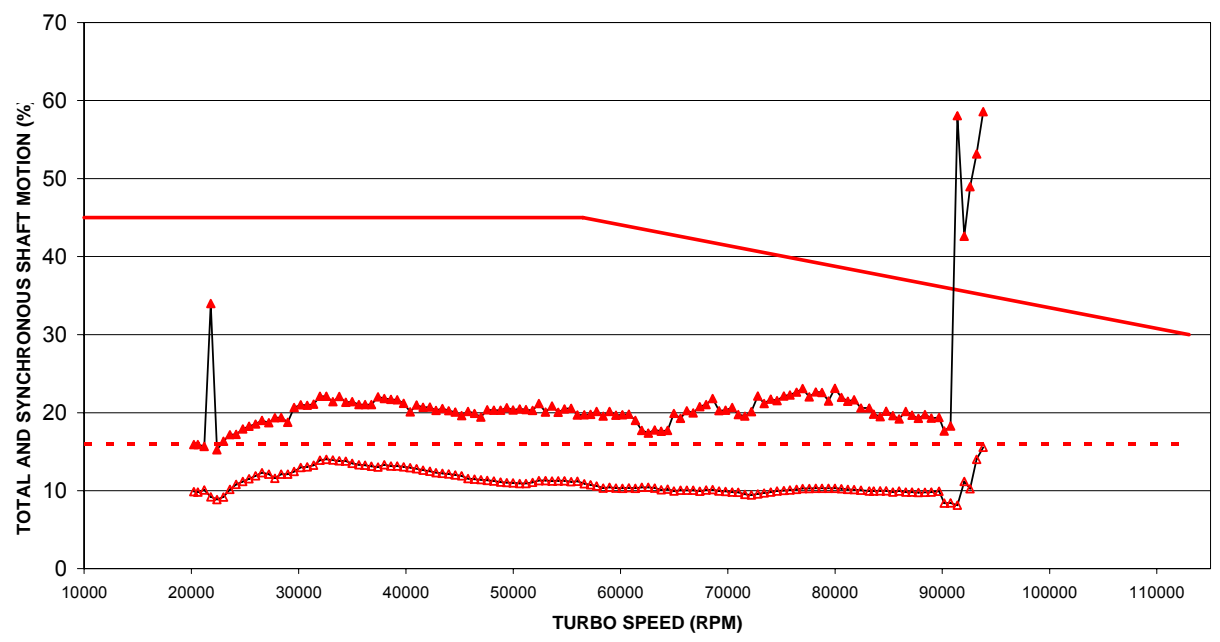

LST45V Shaft Motion Results - Maximum OD/Maximum ID Bearing System Clearance Corner 
LST45V SHAFT MOTION TEST

Min OD/Max ID Clearance Corner 212 F (100C) 15W-40 Oil Supply

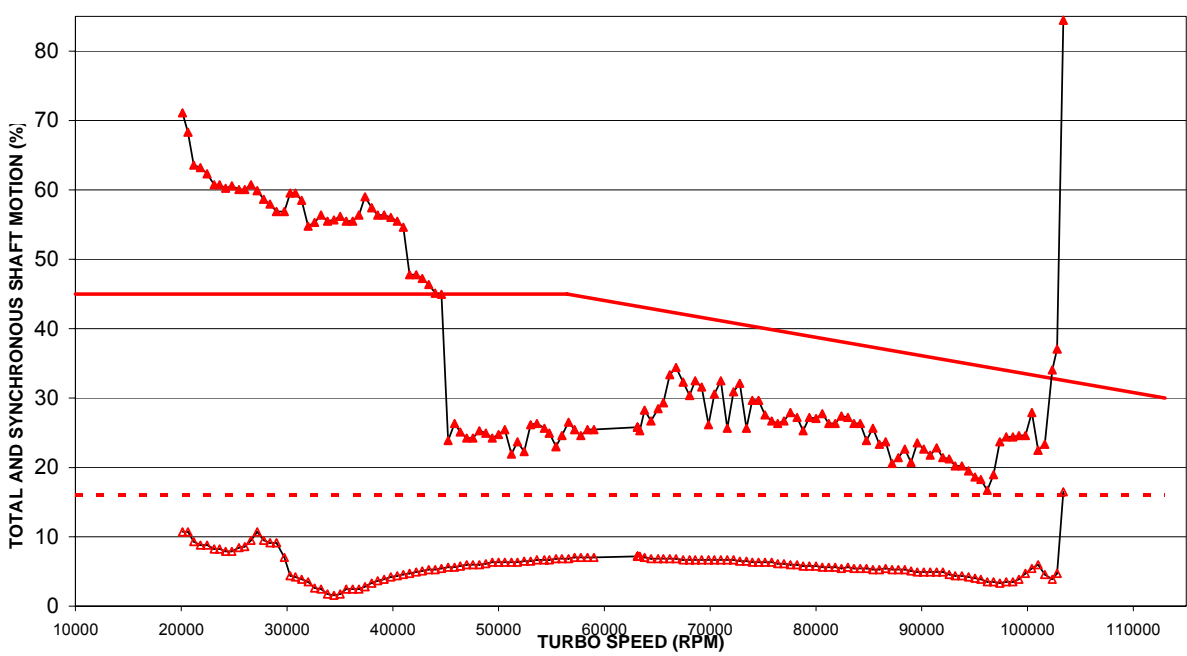

LST45V Shaft Motion Results - Minimum OD/Maximum ID Bearing System Clearance Corner

LST45V SHAFT MOTION TEST Max OD/Min ID Clearance Corner 212 F (100C) 15W-40 Oil Supply

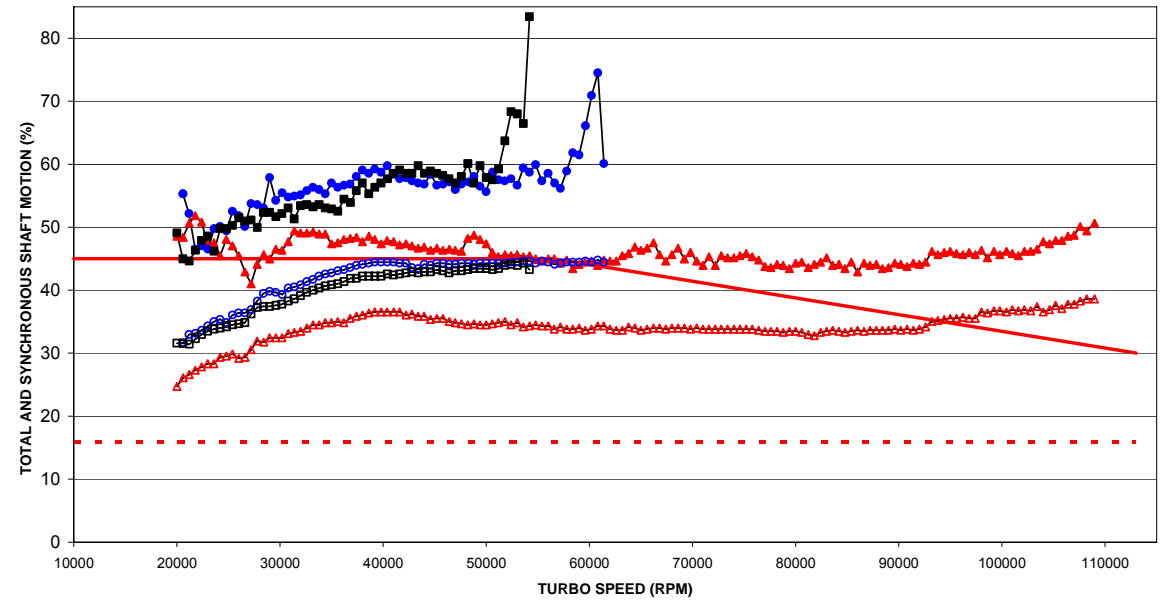

LST45V Shaft Motion Results - Maximum OD/Minimum ID Bearing System Clearance Corner 
Turbocharger Heat Soakback Qualification: Below figure shows the layout of special instrumentation use to evaluate Heat Soakback boundary conditions for the LST45V turbocharger

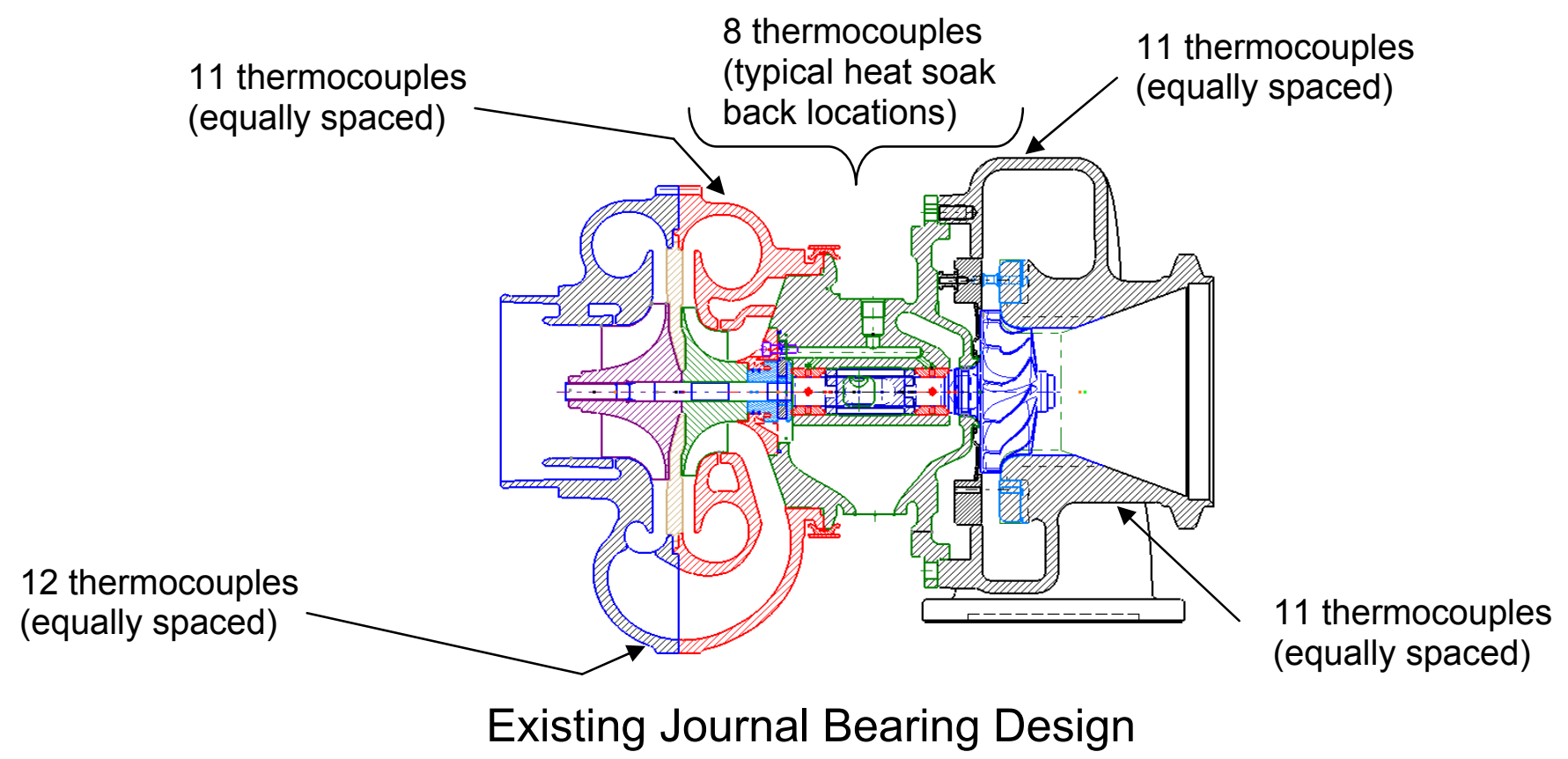

LST45V Turbocharger - Heat Soakback/ Boundary Conditions Instrumentation 
Below figure shows the fully instrumented LST45V turbocharger set-up for heat soakback evaluation.

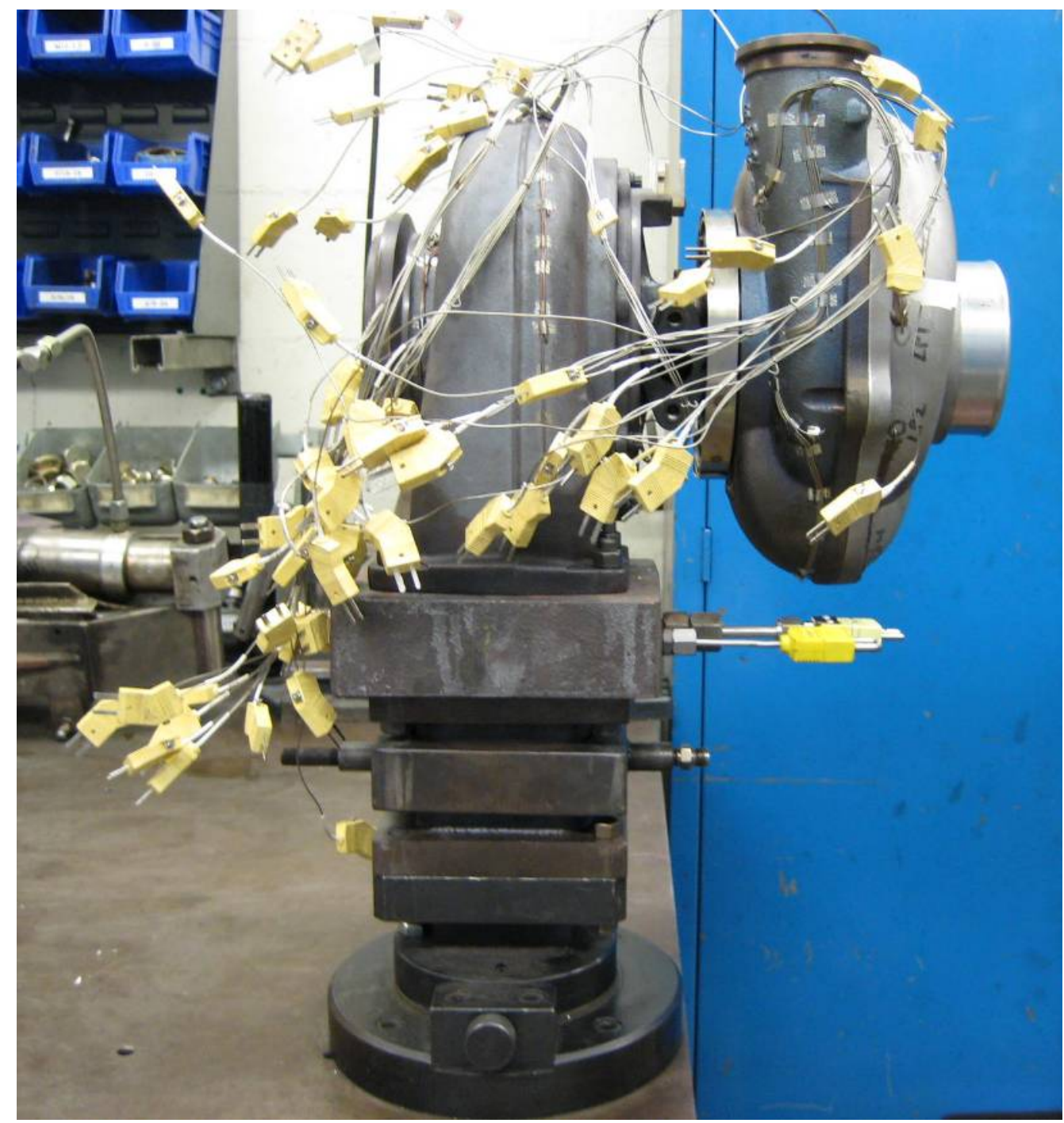

LST45V Turbocharger - Instrumented for Heat soak Back Evaluation and Boundary Conditions 
Turbocharger Heat Soakback boundary conditions measured and recorded. Below Figure shows the results from the heat soakback testing.

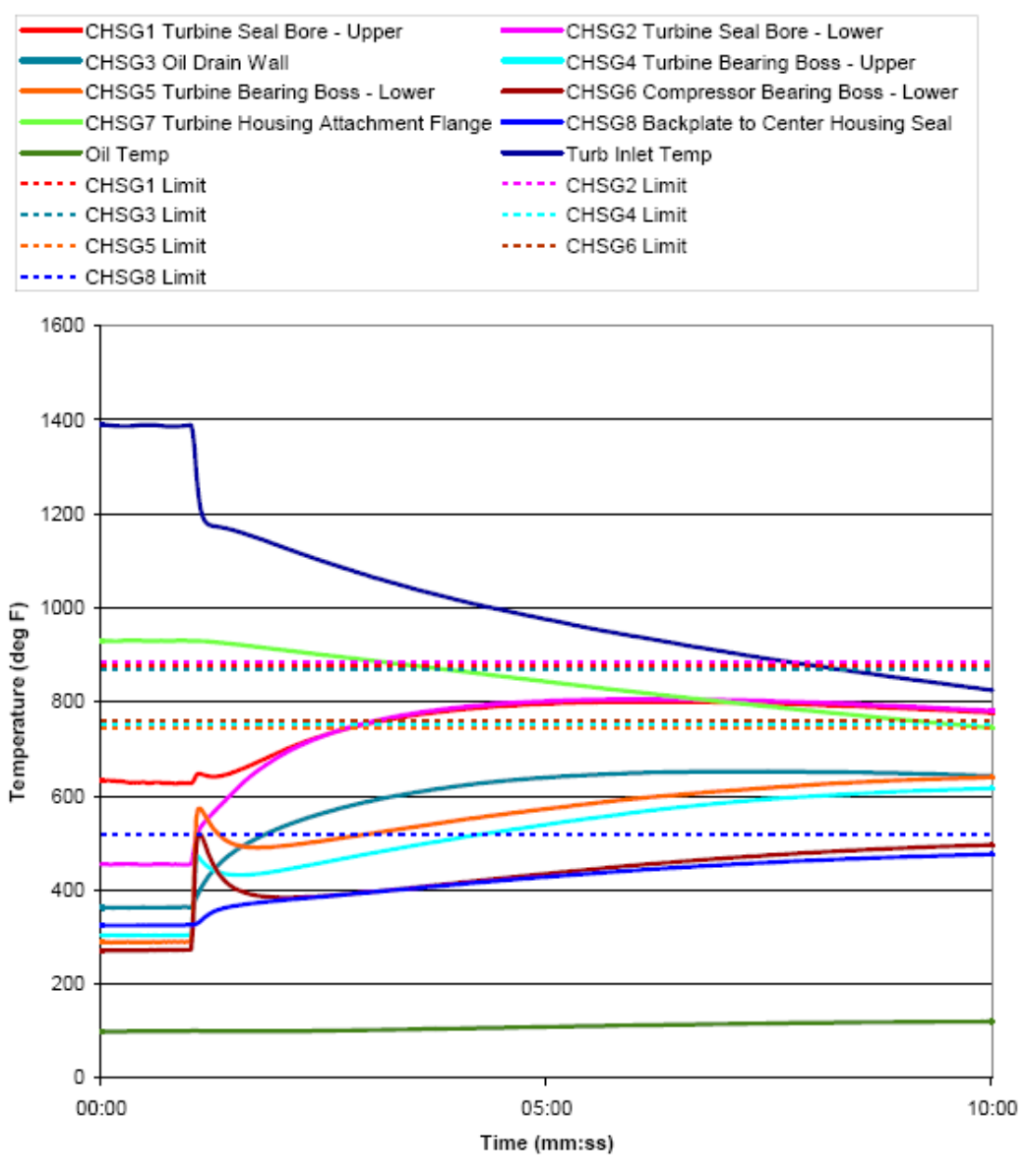

LST45V Turbocharger - Heat Soakback Measurements 
Following the completion of the project "Ultra-High Pressure Turbocharger for HD Diesel Engines", Honeywell Transportation Systems - Turbocharger Technologies - Torrance, California received the remainder of the LST45VR turbocharger components and assembled the first LST45VR turbocharger. Figure below shows the LST45VR turbocharger assembly.

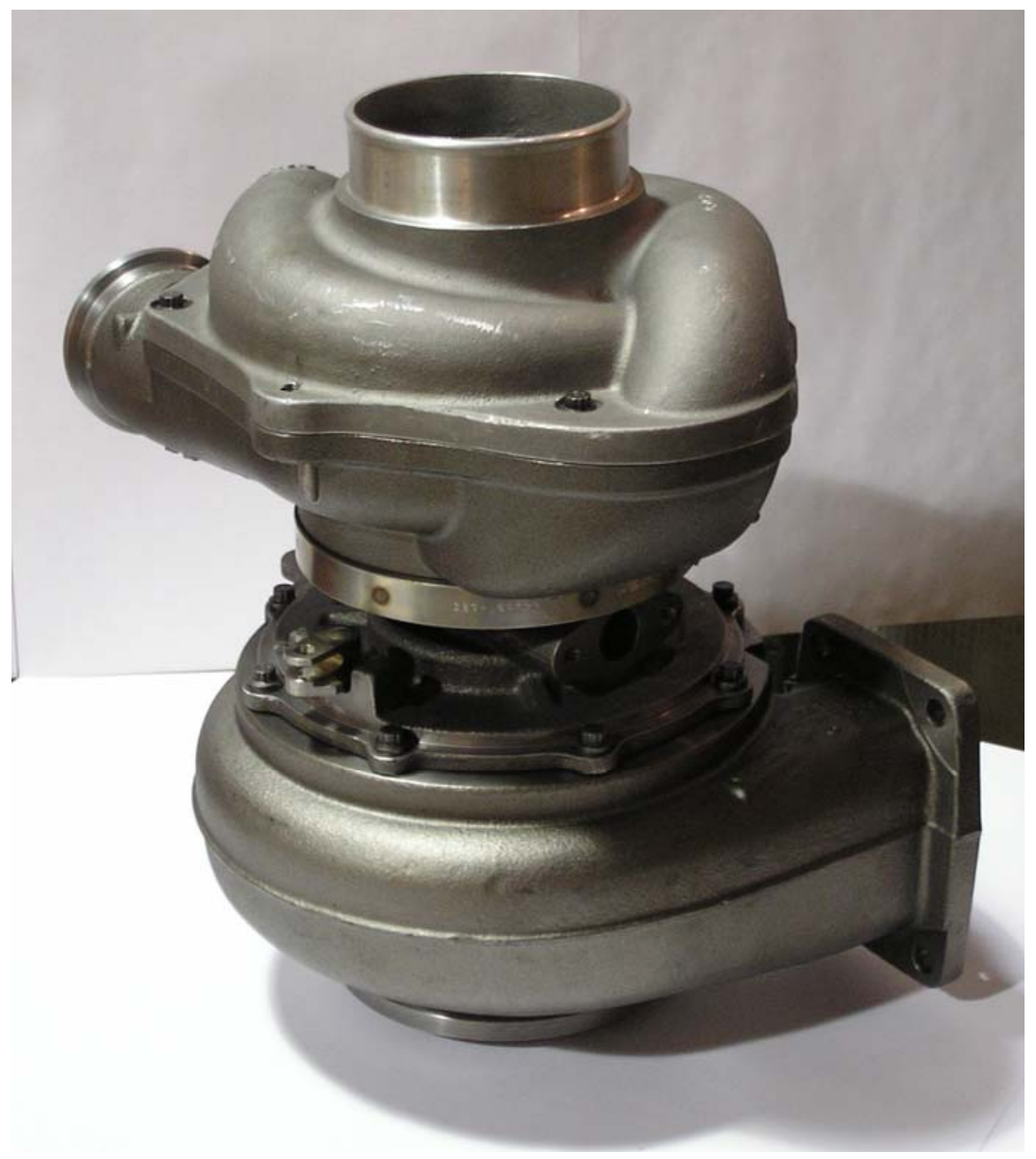

LST45VR Turbocharger 


\section{Inventions/Patents}

All inventions, patents and associated publications related to this project are being reviewed for applicability and will be submitted under separate cover. 


\section{PROJECT 4 - ADVANCED GASOLINE TURBOCHARGER}

The objective of this project is to create a turbo solution to reduce fuel consumption while increasing specific power / torque output on a gasoline engine powered passenger vehicle. In order to compensate for the increase in vehicle weight and the reduction in engine sizes, the OEM's must require overall performance (steady state and transient), of turbo charging. The conventional turbo (fixed geometry, waste-gated) is limited to meet those future market needs. There is a need to design and develop variable geometry turbo charging to operate in the high temperature exhaust of a gasoline engine.

Measurable performance objective is to provide a variable turbine geometry technology that delivers these performances targets:

- $60 \%$ efficiency for an expansion ratio of 1.6 at a corrected mass flow of 0.05

- $40 \%$ efficiency for an expansion ratio of 2.0 at a corrected mass flow of 0.13

These performances will be characterized with prototypes on gas stand and used as inputs to simulate engine performances when boosted with a variable geometry turbine concept.

Several concepts will be compared on the gas stand in order to rank benefits of different technologies.

\section{Background}

Gasoline boosting technology is developing very fast, using waste gate technology as a prime path option. With increasing oil price and stringent emissions reductions requirements, it is needed to increase specific power of gasoline engines to allow significant downsizing. For this purpose, downsizing engines can only be viable if higher performance boosting device is available in order to sustain acceptable transient performances that are critical to customer vehicle drive ability. Standard turbo technology is not able to close low end torque performance gap.

Two stage systems have demonstrated to be able to meet high performances targets but at a higher costs and complexity which is not affordable for mass production passenger vehicles.

How far we can improve this gap with a variable geometry turbine is a key question that is raised and main topic of this development.

\section{Task 4.1 Target Setting and Functional Analysis}

\section{Task 4.1 Overall Progress Update}

Target engines performances have been defined for $1.8 \mathrm{~L}$ and $2.0 \mathrm{~L}$ engines. Engines performance targets have been translated to turbo charger performance to achieve low 
end torque and high end power. Controllability requirements have also been taken into account as part of this task.

\section{Results:}

- Turbocharger optimum size to meet engine performances has been sized to a VGT1752 size.

- Controllability requirements have been set to an accuracy level of $+/-5 \mathrm{~N}$.m on the engine.

- Comparison of VGT technology with baseline waste gate and waste gate with ball bearing technology have been considered in the specifications.

- $1050^{\circ} \mathrm{C}$ and $1000^{\circ} \mathrm{C}$ maximum gas temperature limits have been considered in the material selection and components specifications.

- Electric actuation has been considered as a mandatory option to meet control accuracy targets.

- Low end performance targets have been set to $60 \%$ efficiency for an expansion ratio of 1.6 at a corrected mass flow of 0.05

- High end performance target has been set to $40 \%$ efficiency for an expansion ratio of 2.0 at a corrected mass flow of 0.13

- A detailed functional analysis of the concept has been done as a basis for components and sub assemblies design definitions.

The figure below depicts performance target curves simulated for low end torque and engine delta $\mathrm{P}$

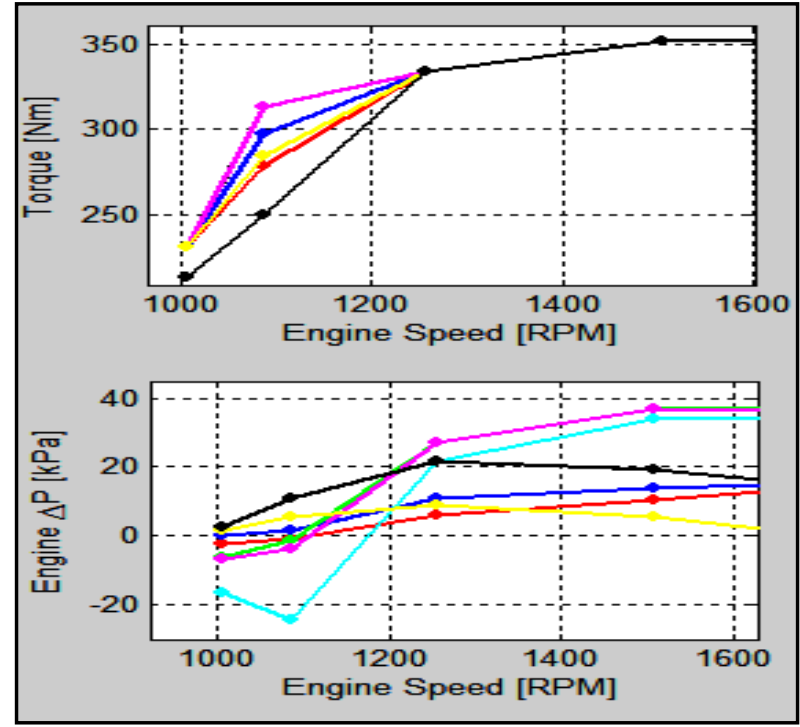

The purpose of these simulations for different turbo chargers technologies on 2.0L gasoline engines was to find optimum targets that balance low end transient performance (torque) and high end power performance. These targets are important as they drive the selection of the turbine technology and dimension of the key components. 
The following is a summary table of performance targets for the turbine stage. Different initial concepts have been evaluated against these targets and show the challenge to achieve both low end and high end targets.

\begin{tabular}{|c|c|c|c|c|}
\hline \multirow{2}{*}{} & \multicolumn{2}{|c|}{ 1100erpm (ER=1.6) } & \multicolumn{2}{c|}{ 6000erpm (ER=2.16) } \\
\cline { 2 - 5 } & Mcorr & ETA & Mcorr & ETA \\
\hline Target & $\mathbf{k g} / \mathbf{s}$ & - & $\mathbf{k g} / \mathbf{s}$ & - \\
\hline Current & 0.048 & $\mathbf{0 . 6 2}$ & $\mathbf{0 . 1 3 6}$ & $\mathbf{0 . 4}$ \\
\hline Proposal \#1 & 0.048 & $\mathbf{0 . 6 2}$ & $\mathbf{0 . 1 2 4}$ & $\mathbf{0 . 4}$ \\
\hline Proposal \#2 & 0.048 & $\mathbf{0 . 5 6}$ & 0.136 & 0.46 \\
\hline Proposal \#3 & 0.048 & $\mathbf{0 . 5 9}$ & 0.136 & 0.48 \\
\hline Proposal \#4 & 0.048 & $\mathbf{0 . 5 9}$ & 0.136 & 0.54 \\
\hline
\end{tabular}

The diagram below defines the principal schematic of the VGT integration

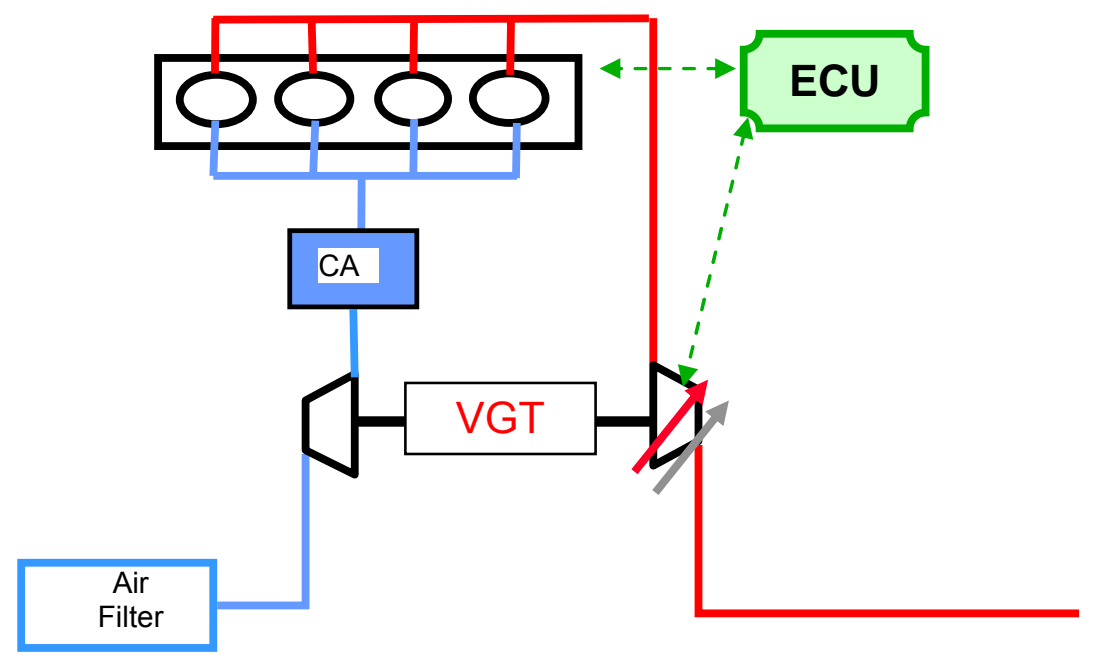

\section{Task 4.2 - Initial Concept Design}

\section{Task 4.2 Overall Progress Update}

A first concept design has been completed to evaluate an axial type of variable geometry. This concept design is taking into account the optimum trade-off in performances as shown in table $\mathrm{n}^{\circ} 1$. 
Results: 3D models and detailed drawings of all the components of the variable geometry turbine have been completed. First FEA analysis has been done to assess potential failure risks in high temperature conditions. The design is using a specific turbine wheel optimized for maximum efficiency in the low end. Specific nozzle and variable piston mechanism compatible with an electric actuator have been designed.

Materials selected for this concept evaluation are targeted at $1000^{\circ} \mathrm{C}$ with an upgrade option to $1050^{\circ} \mathrm{C}$. All designs have been completed in a rapid-prototype environment and don't address mass production feasibility issues.

The figure below depicts the concept design of gasoline variable geometry turbine, showing the principal of a fixed vane nozzle and sliding piston that adjusts the boost level per engine control requirements.

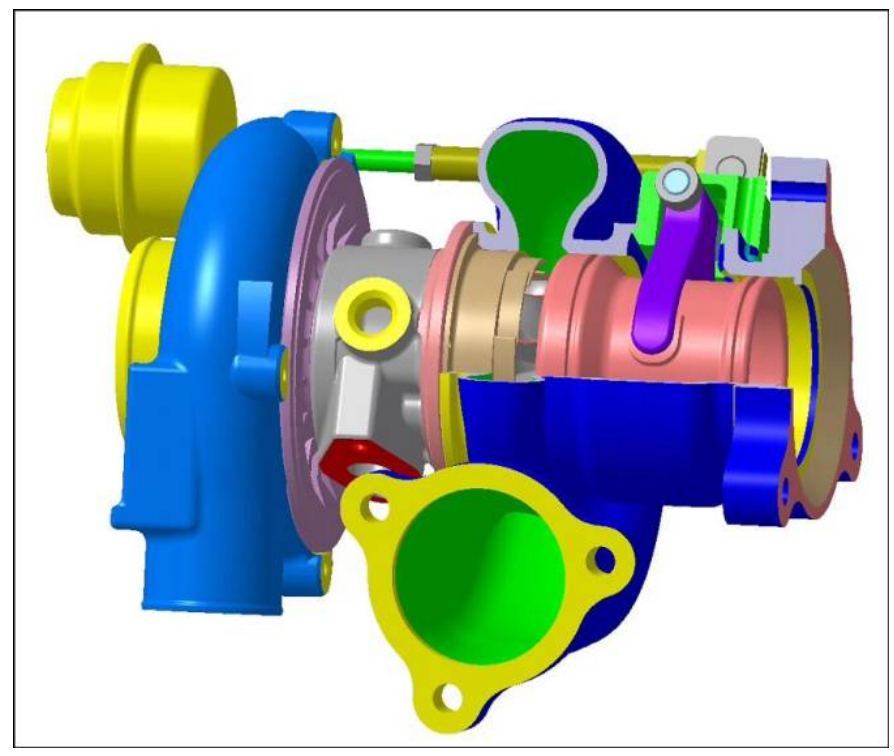

Task 4.3 - Technical Risk Assessment

\section{Task 4.3 Overall Progress Update}

A detailed technical risk assessment has been conducted by several experts for the concept shown above. The experts identified key technical challenges must be overcome to succeed with a variable geometry turbine that achieves an optimum performance trade off. Key reliability risks were also identified and initially considered in the concept design.

Summary Table of Technical Risks

\begin{tabular}{|l|l|l|}
\hline Risks statement & Failure mode & Risk level \\
\hline $\begin{array}{l}\text { Turbine performances not at } \\
\text { target }\end{array}$ & $\begin{array}{l}\text { Not able to meet low end \& high end } \\
\text { performances }\end{array}$ & high \\
\hline Controllability not acceptable & Accuracy of control of flow is not sufficient & high \\
\hline $\begin{array}{l}\text { Compressor flow range } \\
\text { insufficient }\end{array}$ & $\begin{array}{l}\text { Compressor not able to meet low end \& } \\
\text { high end performances }\end{array}$ & high \\
\hline
\end{tabular}




\begin{tabular}{|l|l|l|}
$\begin{array}{l}\text { Product performances } \\
\text { dispersions }\end{array}$ & $\begin{array}{l}\text { Dispersion in nozzle parts could lead to min } \\
\text { flow variations }\end{array}$ & medium \\
\hline $\begin{array}{l}\text { Turbine housing thermo } \\
\text { mechanical failures }\end{array}$ & $\begin{array}{l}\text { Turbine housing cracking under high thermo } \\
\text { mechanical loads }\end{array}$ & medium \\
\hline $\begin{array}{l}\text { Nozzle component distortions } \\
\text { and cracks }\end{array}$ & $\begin{array}{l}\text { Nozzle distortions lead to internal leakages } \\
\text { impacting performances and controllability }\end{array}$ & high \\
\hline Piston sticking & $\begin{array}{l}\text { Nozzle failure due to thermo mechanical } \\
\text { stresses }\end{array}$ & high \\
\hline Internal leakages & $\begin{array}{l}\text { Piston sticks under high thermo mechanical } \\
\text { loads that lead to product failure }\end{array}$ & medium \\
\hline $\begin{array}{l}\text { Actuation mechanism is not } \\
\text { reliable }\end{array}$ & $\begin{array}{l}\text { High internal leakages due to components } \\
\text { distortions }\end{array}$ & $\begin{array}{l}\text { Mechanism is either failing or distorting or } \\
\text { sticking, position variations .... }\end{array}$ \\
\hline $\begin{array}{l}\text { Electric actuator need specific } \\
\text { features }\end{array}$ & $\begin{array}{l}\text { Hard stop functionality + force capabilities + } \\
\text { reduced internal clearance }\end{array}$ \\
\hline
\end{tabular}

\section{Task 4.4 - Simulations CFD}

\section{Task 4.4 Overall Progress Update}

A CFD model of the complete turbine stage has been completed for baseline nozzle, piston and turbine wheel design. The aim of this model is to iterate on different aerodynamic optimizations to find the best design parameters for each component in order to achieve target performance. The first simulations conducted proved the quality of the model and its ability to predict performance levels for different geometries. Initial results have been used to identify losses breakdown in each component of the turbine stage.

\section{Examples of Flow Simulations}

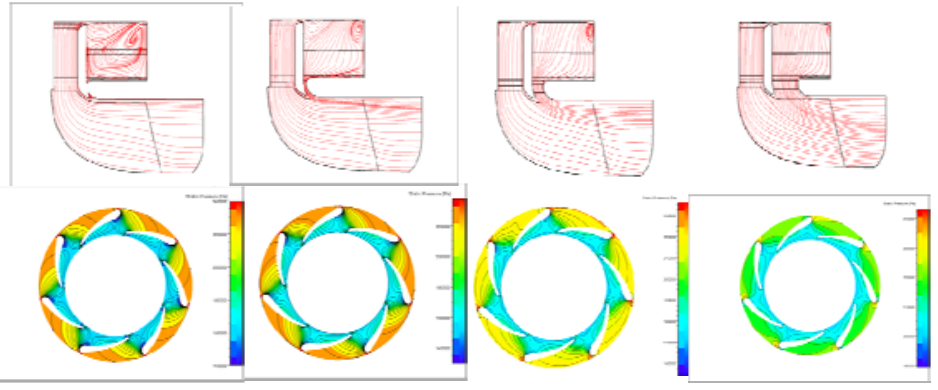




\section{Task 4.5 - Prototypes and CFD models validation}

\section{Task 4.5 Overall Progress Update}

Prototypes have been built in order to validate the CFD model. These prototypes have been tested on a gas stand, covering various flow ranges from expansion ration 1.6 to 2.0. Different configurations of variable geometry have been tested. Accuracy of CFD model has been estimated and its ability to predict real performances has been challenged for future design optimization.

CFD model is available, has been calibrated and can be used to run analytical DOE for components geometry optimization and overall turbine stage performances prediction. A detailed examination of the flow structures inside the nozzle vanes and turbine wheel can be performed; weak design areas can be identified and improved.

\section{CFD Model - Mesh structure}

- Fine mesh used throughout:

- Volute: $1.3 \mathrm{~m}$ nodes

- Vane 1: $1.9 \mathrm{~m}$ nodes

- Vane 2: $1.8 \mathrm{~m}$ nodes

- Wheel: $1.3 \mathrm{~m}$ nodes

- Spalart Almaras low-Re turbulence model

- $2^{\text {nd }}$-order accurate in space and time

- Near-wall mesh size for precise boundary layer modelling

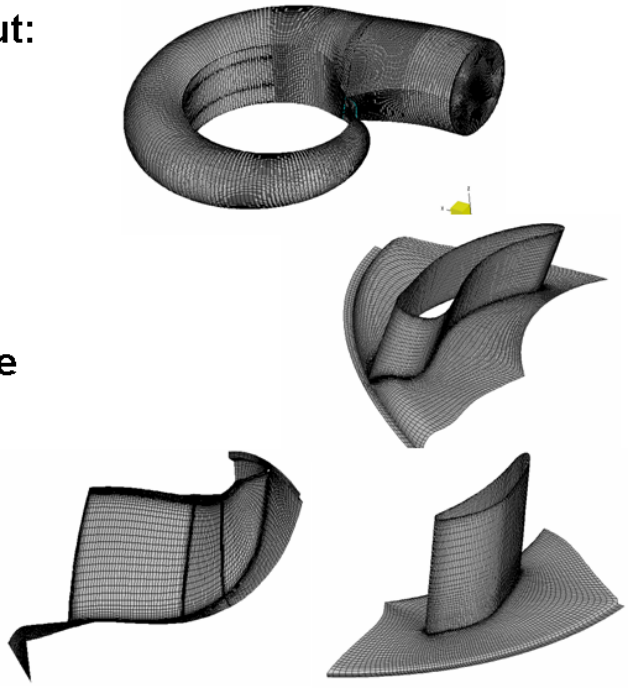

\section{CFD Model - Gas Stand Validation}

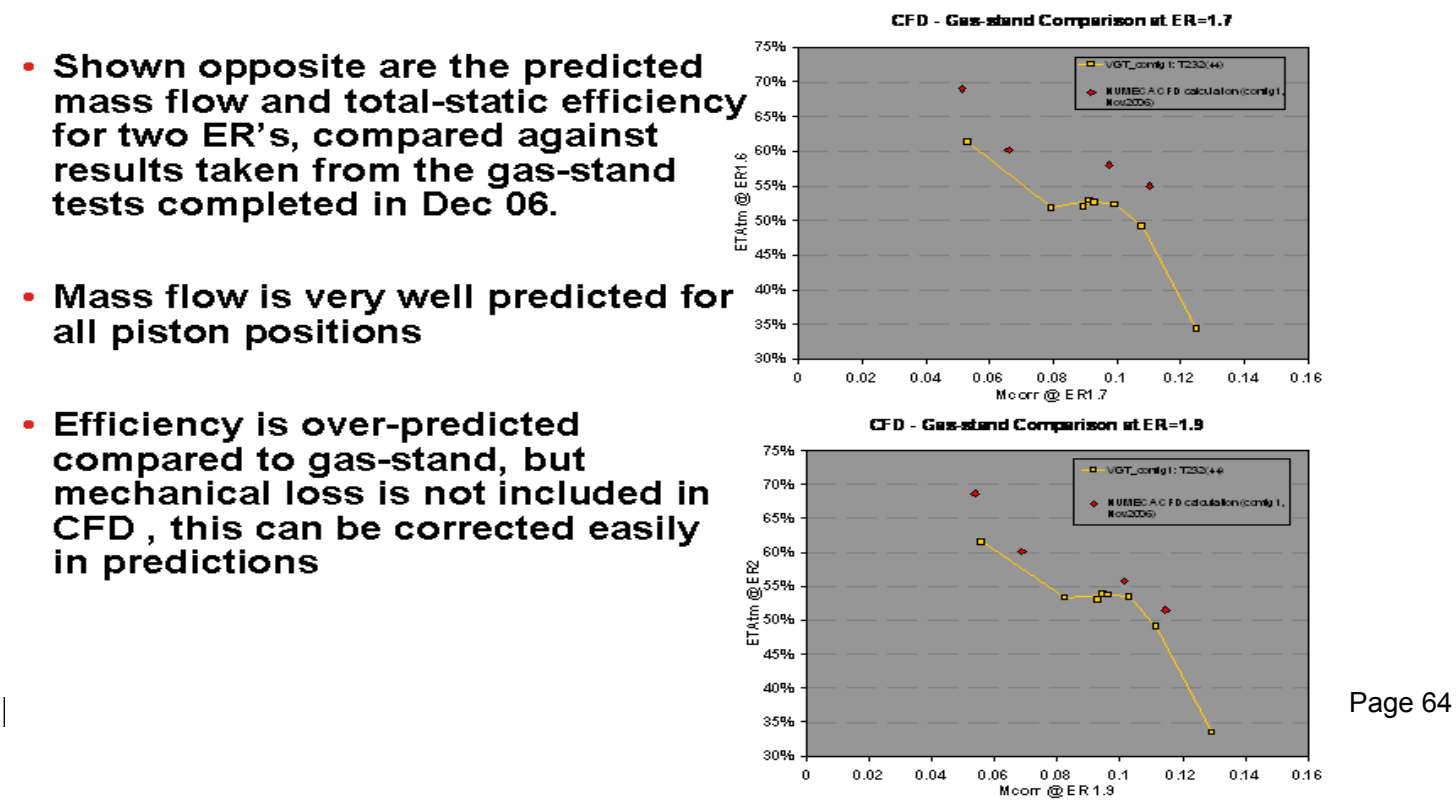




\section{Task 4.6 - Gas Stand Performances Testing}

\section{Task 4.6 Overall Progress Update}

Gas stand performances have been conducted for different configurations. Measurements have been assessing efficiency, flow range and controllability features of VGT technology. These initial tests give the basis of comparison with CFD models predictions. Turbine maps derived will be used to start engine calibrations and performances evaluations.

Gas stand tests have shown good low end efficiency performances, lack of flow and efficiency for high expansion ratios. An important drawback has been highlighted by these tests regarding the controllability. The progressivity of control of the variable geometry mechanism is not good enough for on engine application. An important efficiency drop is obtained for a very small change in the flow on the first steps of control.

CFD models will be used to improve the geometry in order to close the gap on both high end and controllability targets.

\section{Prototype tested}

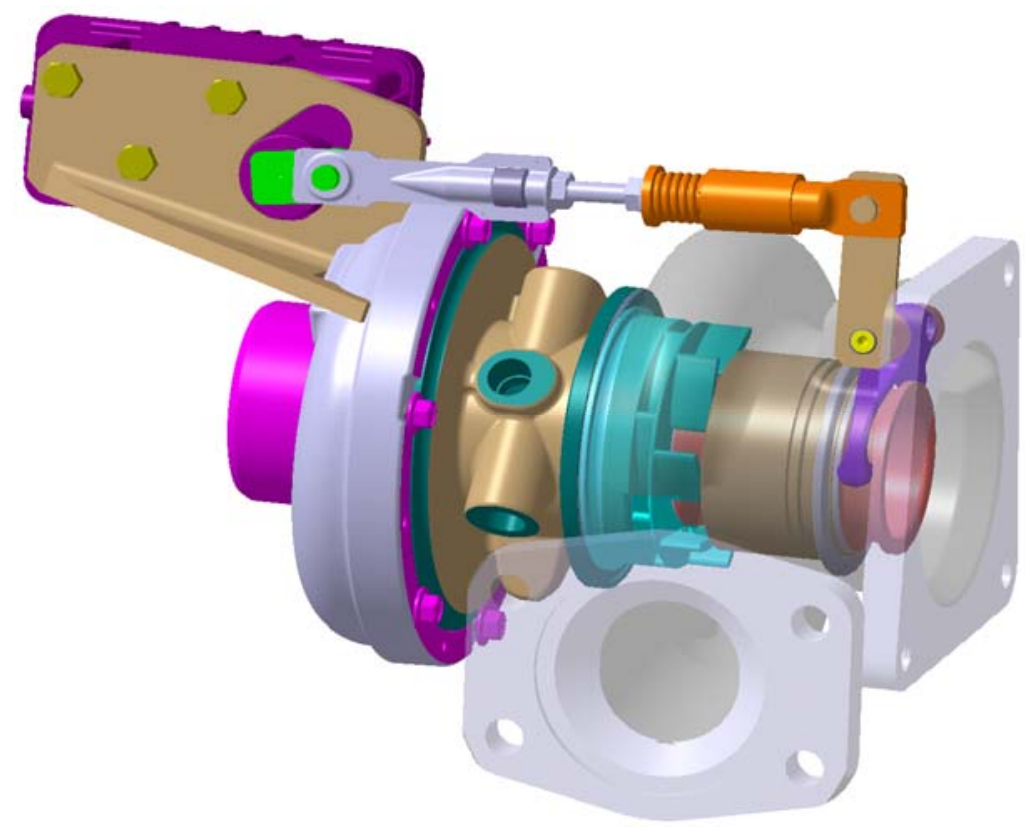


Gas Stand Tests Results
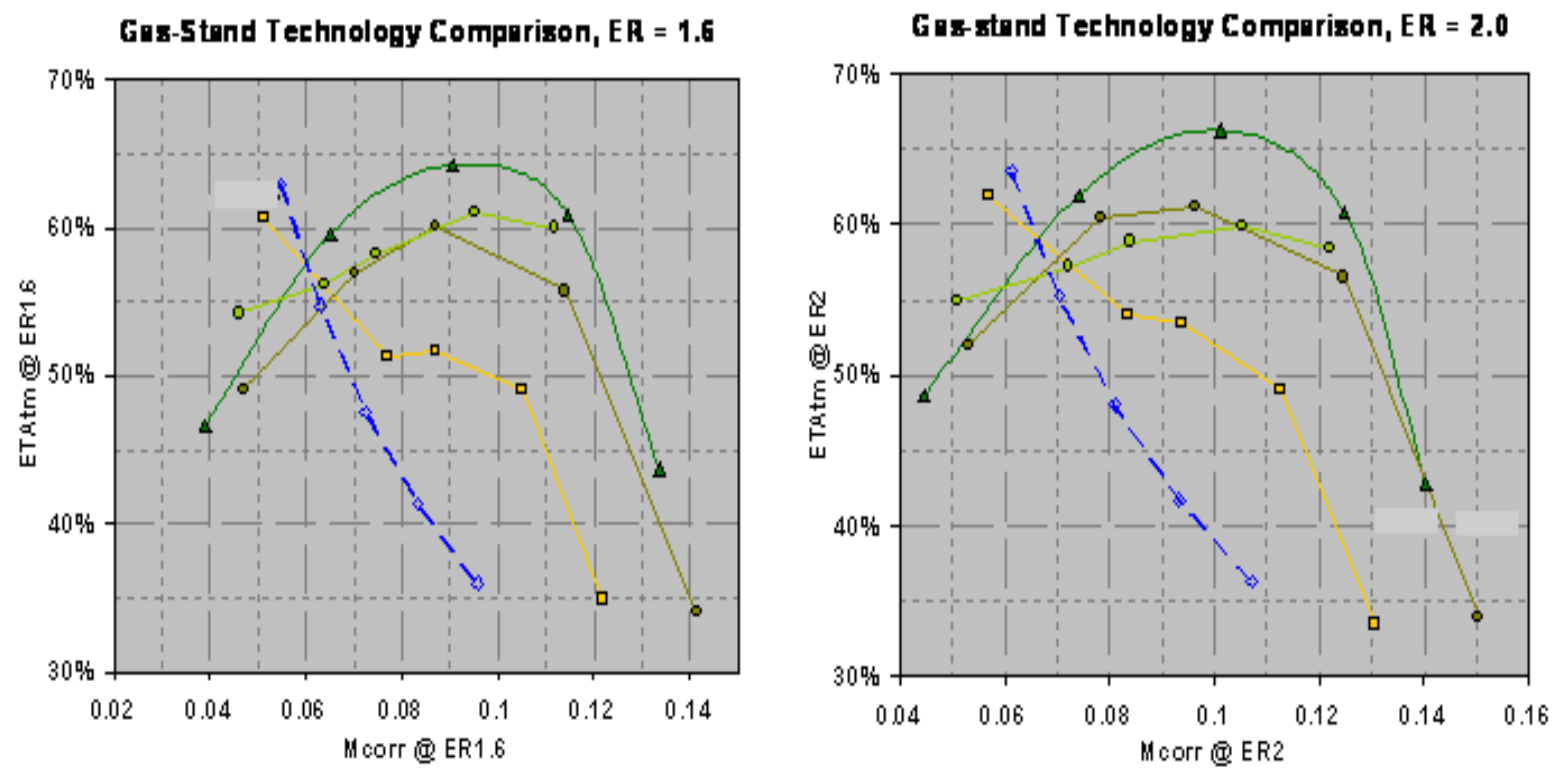

Task 4.7 - Engine Performance and Control Testing

\section{Task 4.7 Overall Progress Update}

Status: Engine performances have been conducted to assess transient capabilities, maximum power capabilities and controllability. Steady state torque curves and time to torque performances have been measured for different nozzle and turbine wheels definitions.

Results: Engine tests have shown capability of VGT to reach high levels of torque and excellent low end transient performances. Enhancement of engine torque is improved by $10 \%$ per first measurements done on a gasoline engine. Time to reach maximum torque has been improved by approximately $80 \%$. Initial control testing have shown challenges to reach a progressive control acceptable for a real life application. Poor control performance would be a barrier to apply this technology as vehicle drivability could be negatively impacted. Modern engine control systems can compensate some of the control gasp from the device to be controlled, but with some limits. Key element of improvement will be controllability of product via optimization of power versus flow variation as shown in the figures below. 


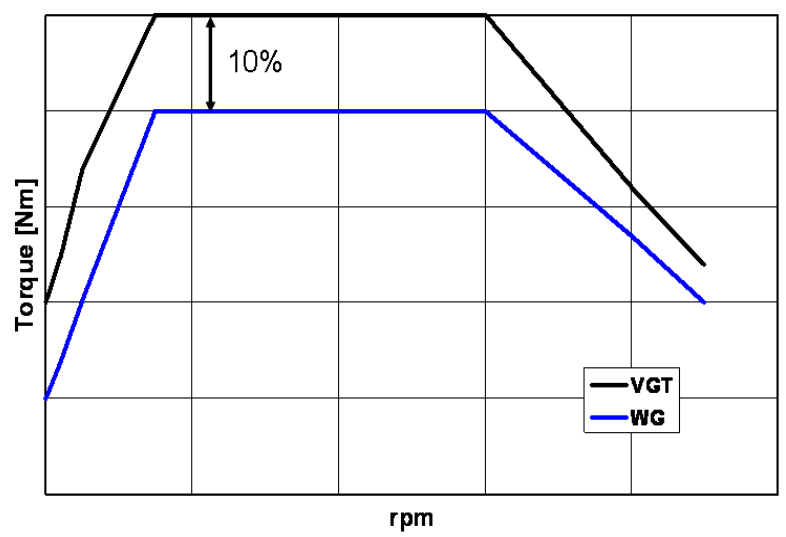

Engine torque tests

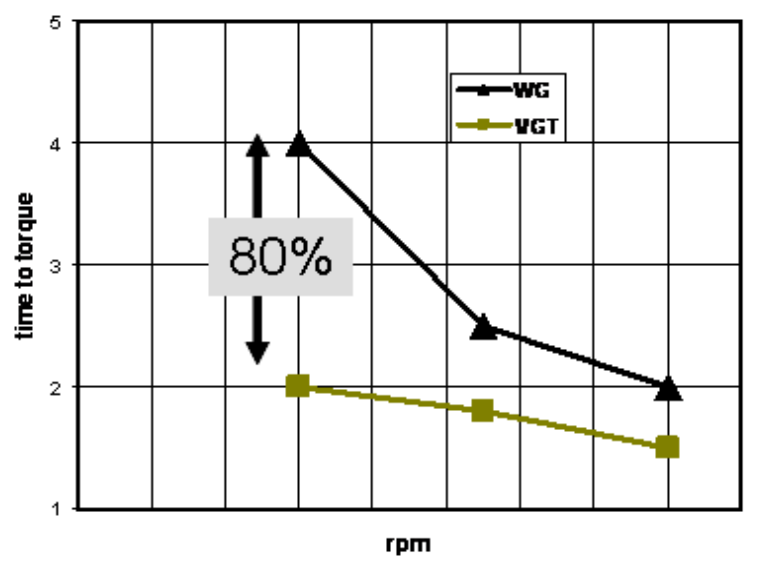

Time to torque tests

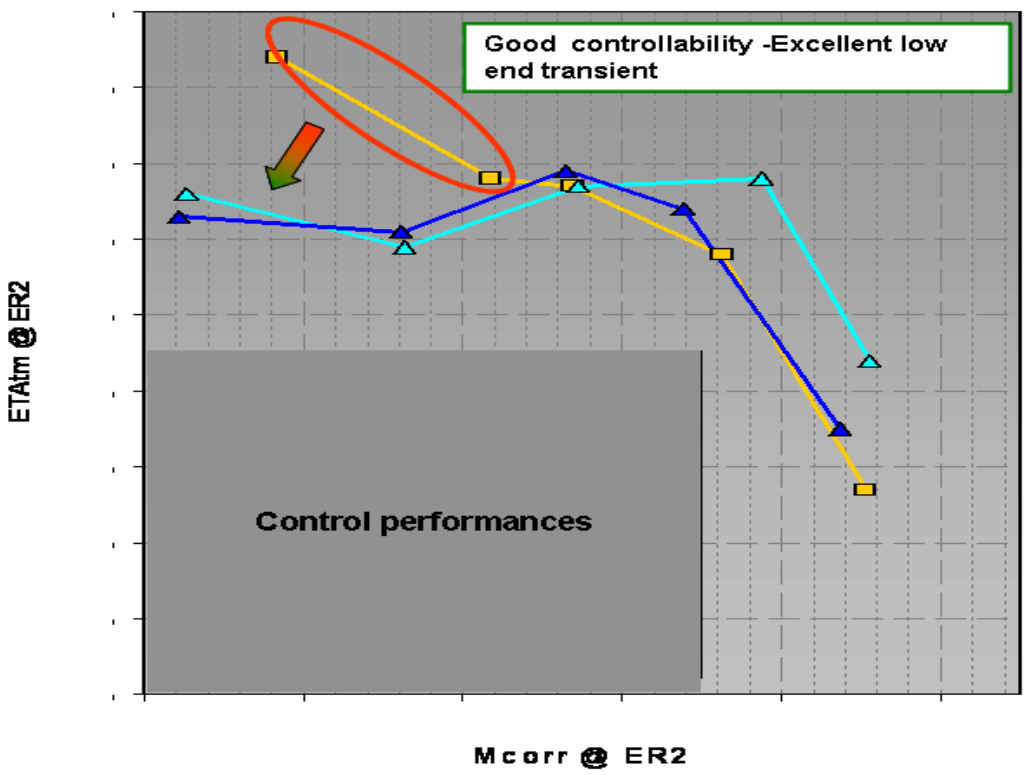




\section{Control optimization tests}

\section{Task 4.8 - Design Optimization for Durability}

\section{Task 4.8 Overall Progress Update}

Status: Design of our VGT has been optimized in order to address failure modes that can occur during various end user duty cycles. Key failure modes have been identified using DFMEA methodology. These failure modes will be replicated later on gas stand and engine to assess durability of design. In order to prevent failures and design for maximum durability extensive FEA analysis has been conducted on the overall turbine stage and for each component of the variable geometry mechanism. Top risks have been considered in these design optimizations. Most of them focus on thermal transfers and thermo mechanical analyses. High stresses areas in components and excessive deformations of components in critical areas have been studied in detail.

Results: Top durability failure modes are summarized in table below.

\begin{tabular}{|c|c|}
\hline Component & Failure mode \\
\hline Piston & $\begin{array}{l}\text { Piston sticking in Insert } \\
\text { Piston vanes cracks }\end{array}$ \\
\hline Nozzle & $\begin{array}{l}\text { Nozzle radial \& axial deformations } \\
\text { Nozzle cracks }\end{array}$ \\
\hline Turbine & $\begin{array}{l}\text { Turbine cracks } \\
\text { Turbine deformations }\end{array}$ \\
\hline Turbine wheel & LCF ( IOw cycle fatigue ) \\
\hline $\begin{array}{l}\text { Piston - Nozzle } \\
\text { interface }\end{array}$ & Gas leakage when piston is closed \\
\hline Piston ring & Piston ring collapse under hot conditions \\
\hline Fork & Fork deformations - Fork cracks \\
\hline Fork axle & $\begin{array}{l}\text { Fordk axle sticking } \\
\text { Fork axle failure }\end{array}$ \\
\hline Insert & Insert gets loose in hot conditions \\
\hline Kinematics & Deformations of kinematic components \\
\hline
\end{tabular}

Several FEA analyses have been conducted on each component and assemblies. Thermal boundary conditions have been defined based on engine measurements under different load conditions. FEA models intend to represent the worst case conditions that the product could see during its life cycle if applied on a vehicle.

For this purpose a cycle has been defined to consider both steady state and transient thermal phenomena in our calculations. The cycle used is represented on figure below. 


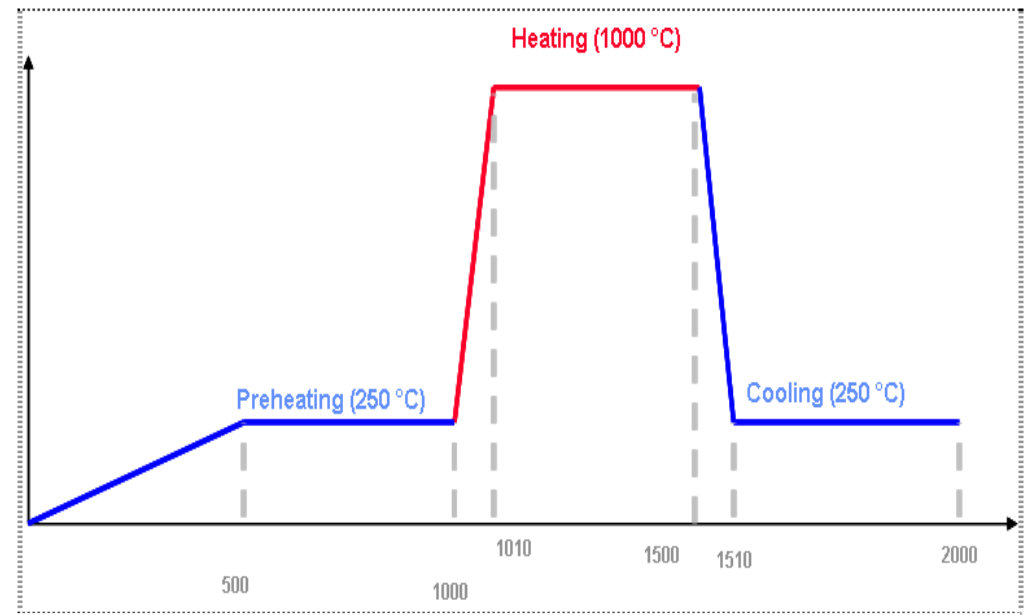

Thermal cycle used for FEA analysis

This cycle is made of 3 phases:

- Phase-1 is pre- heating simulating a transient heating up from the gases.

- Phase-2 is steady state at maximum gas temperature $1000^{\circ} \mathrm{C}$, phase 3 is transient cooling down simulating engine thermal shocks conditions.

All calculations are conducted in elastoplastic domain.

Fig below shows an example of turbine housing model.

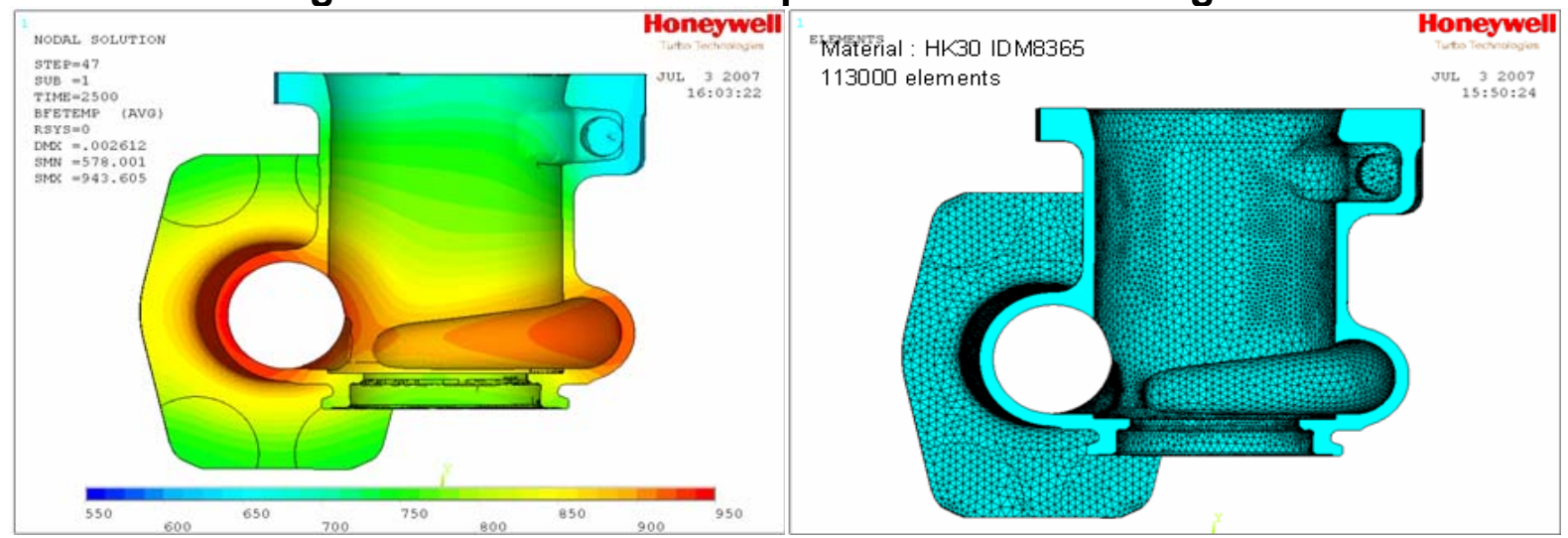

\section{Turbine model, thermal gradients}

First thermal models show a progressive distribution of temperatures in VGT. Temperature gradients are very important in turbine with maximum temperatures in volute and a drop of $200^{\circ} \mathrm{C}$ from volute to turbine outlet. This temperature gradient can be responsible for turbine distortions that can lead to high local stresses and variable geometry deformations.

Fig below shows local plastic deformations that can occur at the tongue and in other areas. Optimization of the turbine design minimizes these plastic strains and reduces cracks risks in critical areas. This will be confirmed by first thermal shocks tests run on engine in next project phase. 


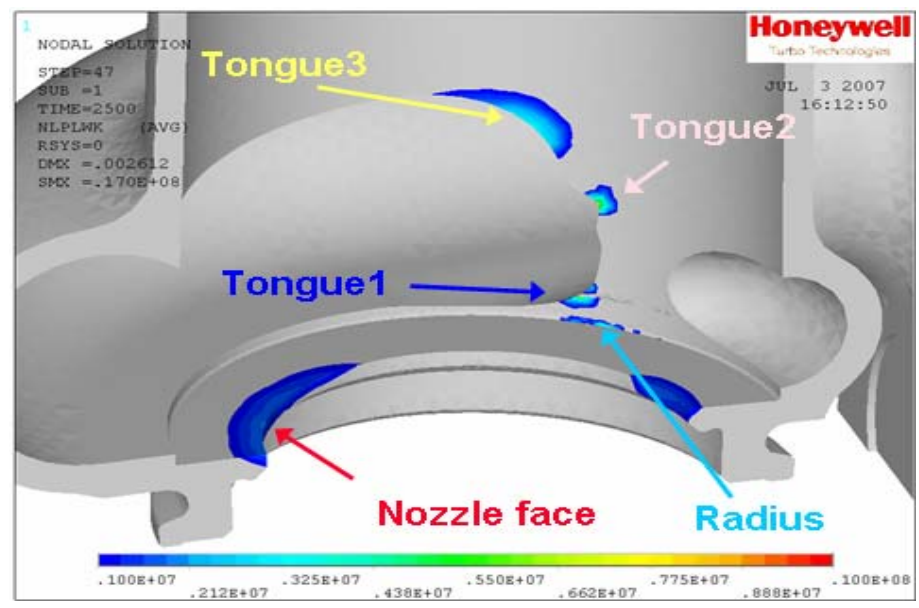

Turbine local plastic deformations

Similar analysis has been conducted on the crank mechanism and nozzle components. Fig below shows reduction of maximum local stresses in fork under actuation and gas loading in steady state condition, at high gas temperature. We can see that stress level has been reduced by $100 \%$, target to safety factor 2 has been largely exceeded.

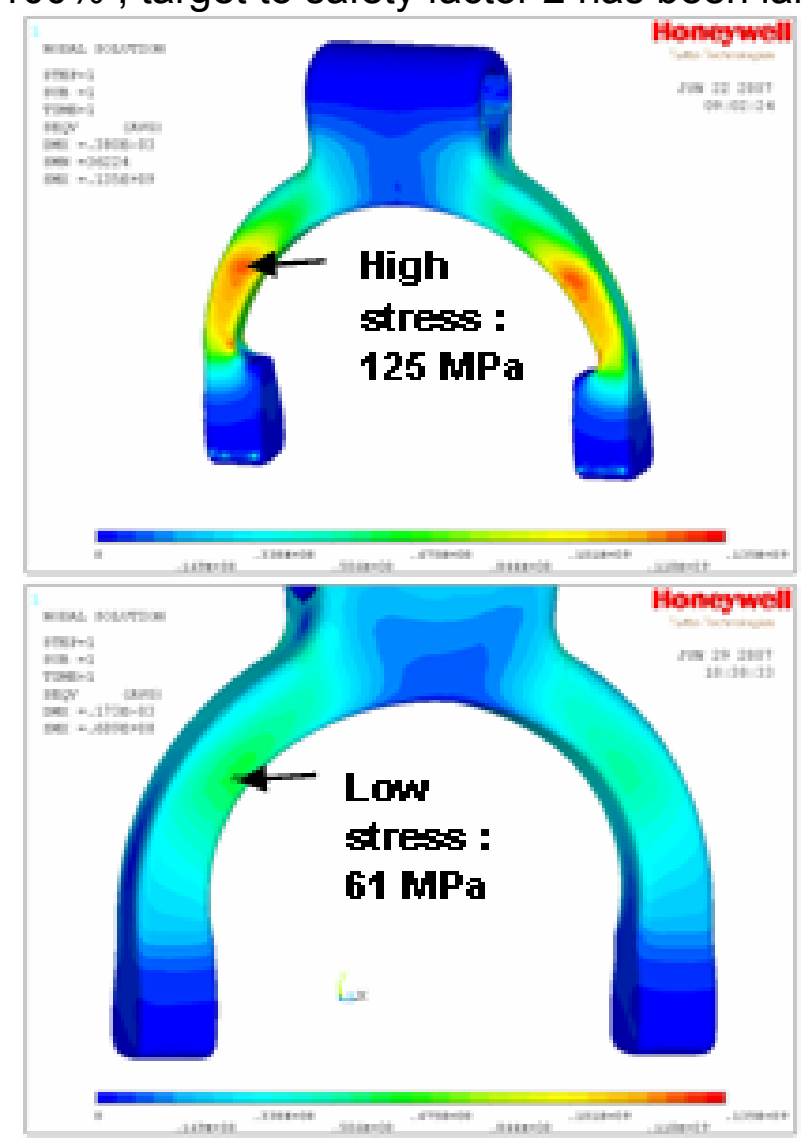

Peak stresses in fork - optimum design

Same approach has been followed to reduce local peak stresses in nozzle component. Figures below show a distribution of stresses in nozzle. Optimum definition of radius in different high stress areas have allowed to define a safe design that will pass thermal shocks durability tests. 


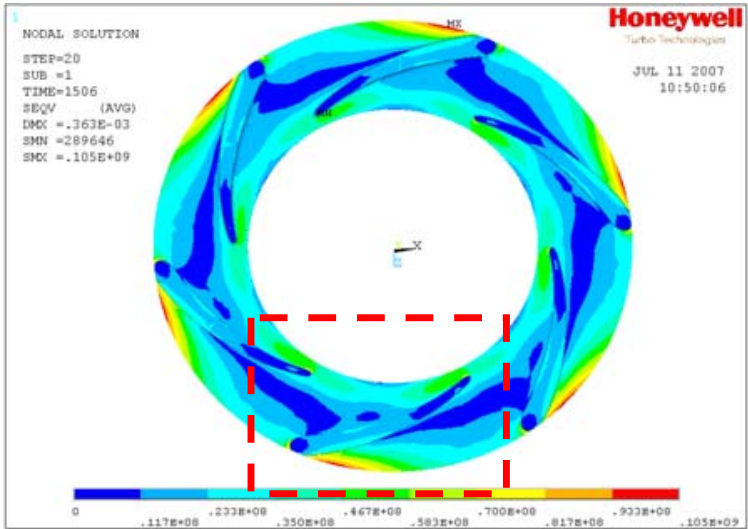

Stress distribution in nozzle

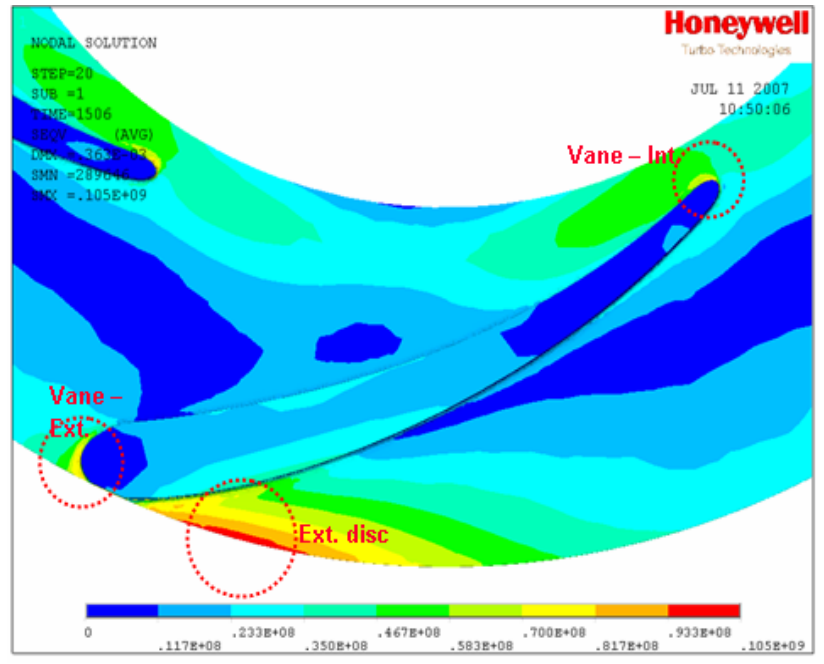

Local nozzle design optimization

Distortions of the different components have been analyzed for different transient thermal cycles, with the objective to prevent failures by defining a robust design.

Below figures show the radial deformation of turbine and the axial elongation of turbine.
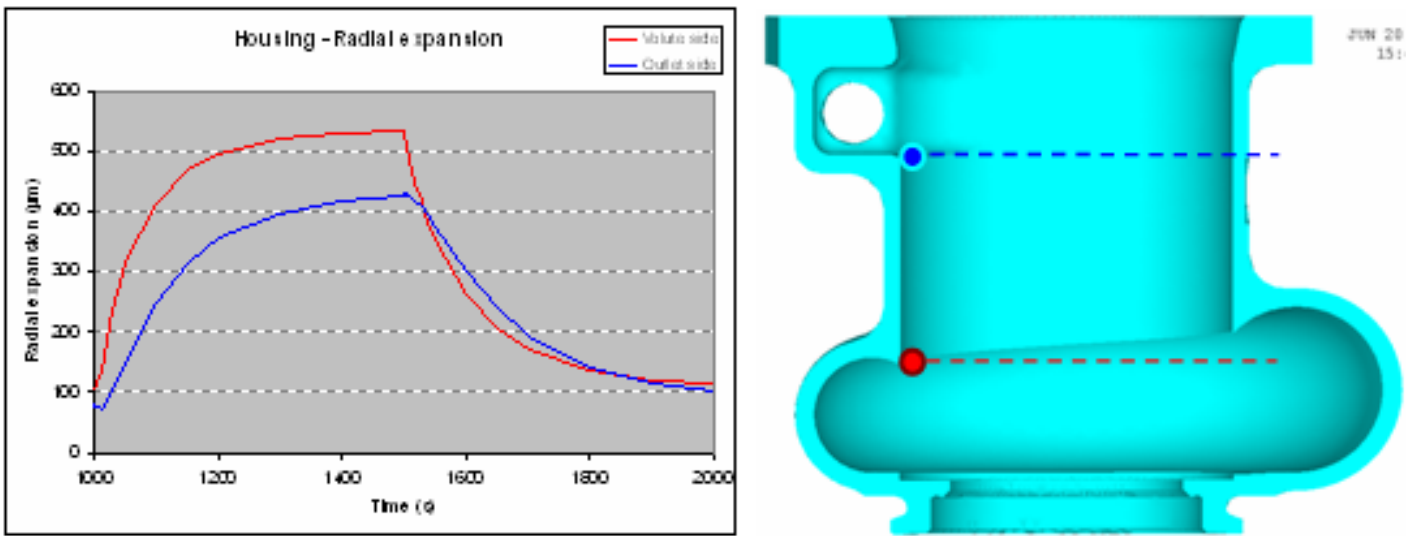

Radial deformation of turbine 


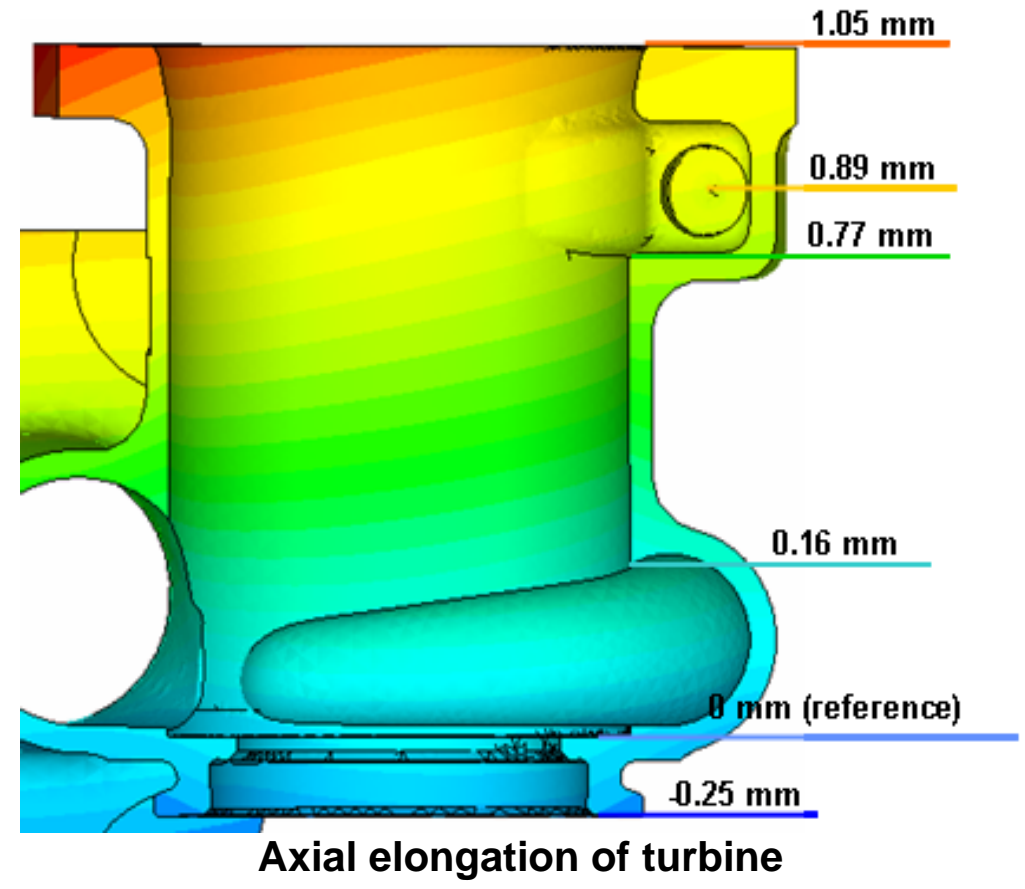

These deformations are due to thermal gradients in the turbine housing during thermal cycles. We can see that radial deformation of turbine is larger on volute side than on outlet side. This effect is a potential cause of piston sticking as the piston is sliding in the turbine cylindrical part. Design of piston and turbine housing must consider this effect in order to prevent this failure mode. Axial elongation of the turbine is reaching $1 \mathrm{~mm}$, that can contribute to a poor controllability as it can affect piston position during transient phase. In order to mitigate this risk specific crank design and turbine shape definition have been used.

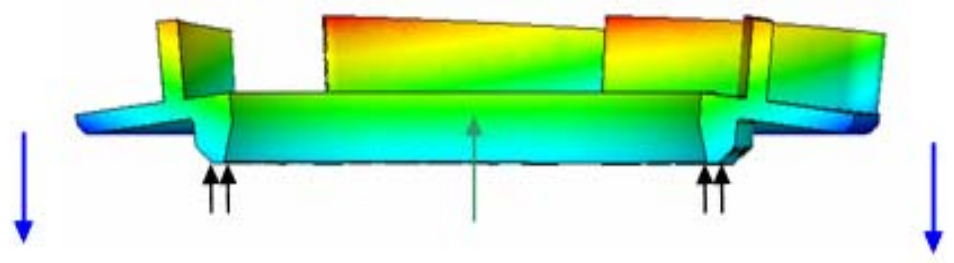

Nozzle disc undergoes bending

\section{Axial deformation of nozzle}

Fig above is describing a typical axial deformation of the nozzle. This is considered in the assembly of nozzle with turbine to allow a free movement during transient thermal conditions. This type of assembly will prevent high stresses and plastic deformations of the component.

One of the major functional risks is related to piston sticking in the turbine housing. This has been studied as shown on figure below. 

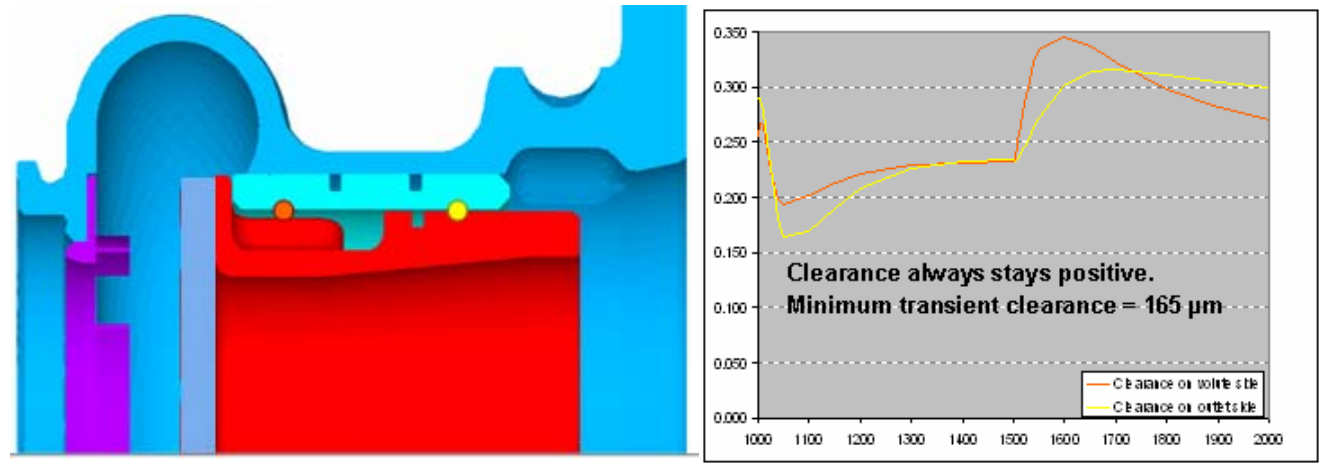

Radial clearance piston-turbine

Clearance evolution at different axial positions between piston and turbine housing is studied at different temperatures. We can see that if piston and turbine housings geometry and materials are defined properly we can always keep a positive clearance which is the minimum condition to prevent any sticking failure mode.

As an overall conclusion we can say that extensive FEA analysis has been conducted to model thermal and thermo mechanical phenomena that can occur during product life cycle. Initial calibration of these models with gas stand and engine tests have been done, that give a good confidence level in simulation results. More robust design could be defined that will accelerate real life testing and reliability level.

\section{Task 4.9 Pre-Durability Tests}

\section{Task 4.9 Overall Progress Update}

Status: Latest design prototypes have been built to run different types of durability tests. These tests target key failure modes under high thermo mechanical stresses and transient thermal conditions.

Different tests cycles have been defined for testing on engine and on components benches such as gas stand and oven. Temperature, expansion ratio and actuation forces are the key parameters that were studied during this pre durability phase. Post test analysis has been conducted that highlighted critical points in the product design.

Results: Several prototypes samples have been built using production intent design and processes and best optimized designs after previous optimization phase. Key elements of reliability on these samples have been identified as turbine housing cracks, piston and nozzle vanes cracks, piston sticking, and piston wear.

Figure below shows prototypes that have been used for engine and gas stand durability tests. Before starting durability cycles, an analysis protocol has been defined. 


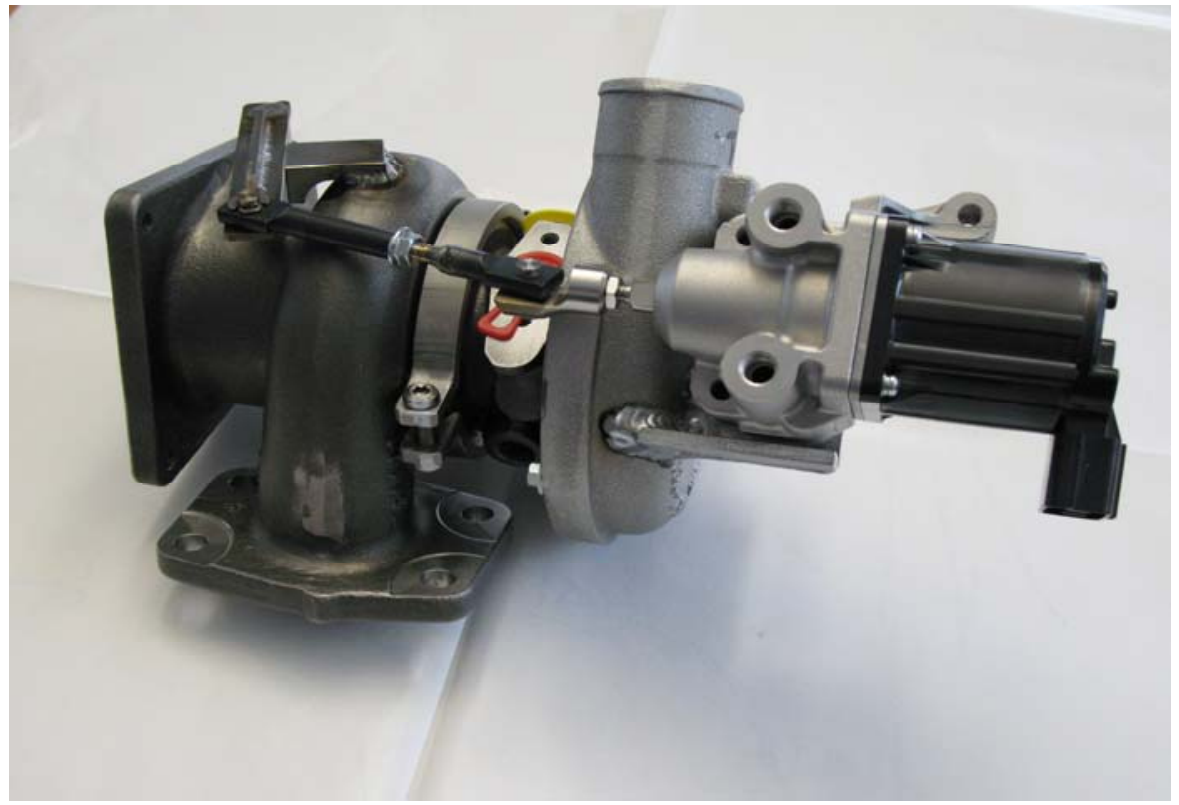

Prototype VGT17 for durability

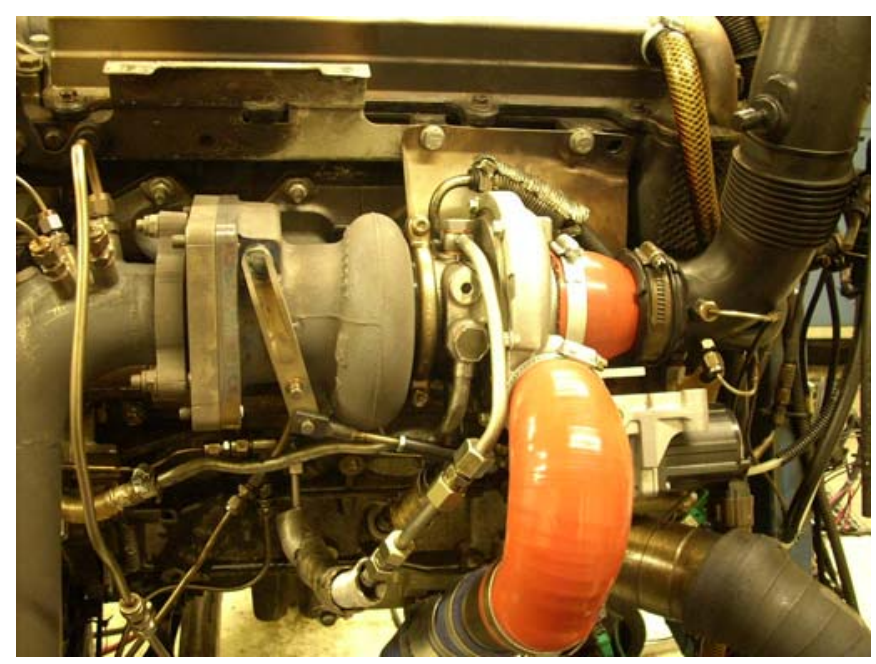

\section{Prototype VGT17 installed on the engine}

Figure below shows the critical areas that are main focus of analysis during pre durability phase. 
DE-FC26-06NT42873

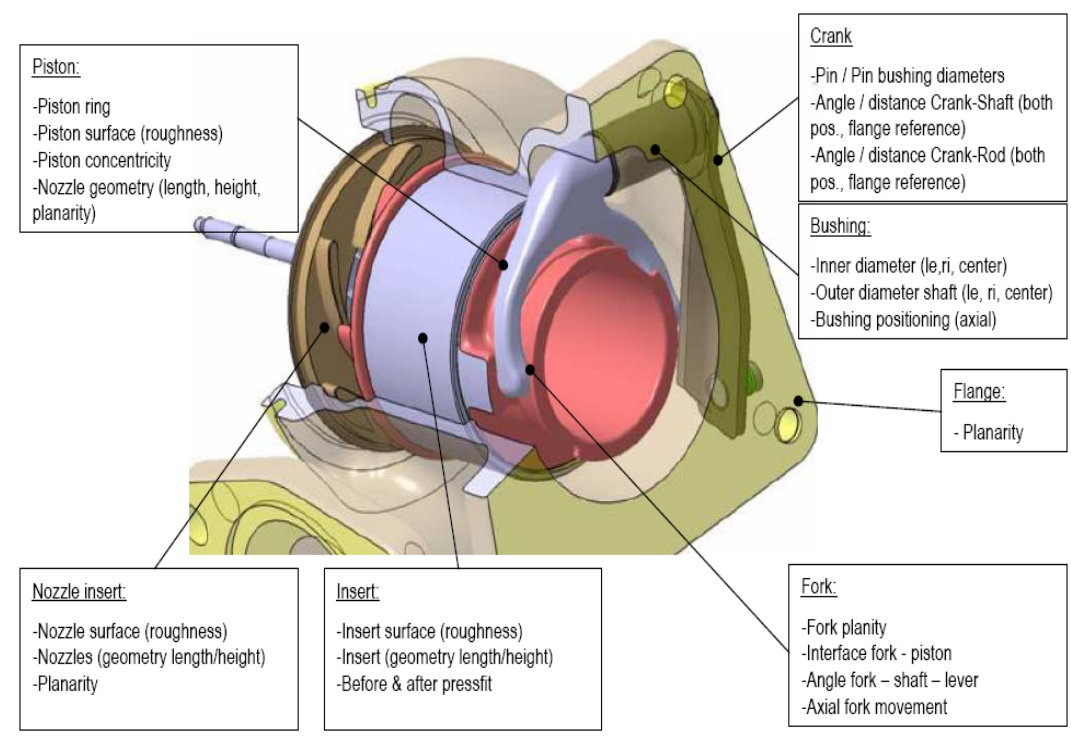

Key areas of analysis

Each prototype is completely measured before assembly and data are recorded in a database as shown on one example table below. After durability cycles the prototypes are functionally tested (leakage, mass flow, efficiency) and component geometries are measured again. Comparison of as new characteristics and after test data allow us to estimate level of damage for a given test cycle.

\begin{tabular}{|c|c|c|c|}
\hline Turbine housing & Drawing value & at protoshop & after tests \\
\hline Bushing length outside of Thsg & $2 \mathrm{~mm}$ & $2,1 \mathrm{~mm}$ & \\
\hline Int. diam of Thsg (insert location) on nozzle side; on middle; on outlet side & $58 \mathrm{~mm}$ & I/I & I/I \\
\hline Internal diameter on Thsg for bushing; on cranck side & $15,967 \mathrm{~mm}$ & & \\
\hline Internal diameter on Thsg for bushing; on middle side & $15,967 \mathrm{~mm}$ & & \\
\hline Internal diameter on Thsg for bushing; on piston side & $15,967 \mathrm{~mm}$ & & \\
\hline Internal diameter of bushing; on cranck side & $11,580 \mathrm{~mm}$ & & \\
\hline Internal diameter of bushing; on middle side & $11,580 \mathrm{~mm}$ & & \\
\hline Internal diameter of bushing; on piston side & $11,580 \mathrm{~mm}$ & & \\
\hline external diameter of bushing; on cranck side & $16,006 \mathrm{~mm}$ & & \\
\hline external diameter of bushing; on middle side & $16,006 \mathrm{~mm}$ & & \\
\hline external diameter of bushing; on piston side & $16,006 \mathrm{~mm}$ & & \\
\hline Clearance between piston \& TW & $0,50 \mathrm{~mm}$ & & \\
\hline Nozzle & dawing value & at protoshop & after tests \\
\hline Visual aspect of nozzle & \multicolumn{2}{|c|}{ cracks; deposits; erosion; FOD } & \\
\hline external diameter (19 quotation) & $65,8 \mathrm{~mm}$ & & \\
\hline \multicolumn{4}{|l|}{ internal diameter at end of vanes } \\
\hline internal diameter & $45 \mathrm{~mm}$ & & \\
\hline vane height & $6 \mathrm{~mm}$ & & \\
\hline Throat & $? ? \mathrm{~mm}^{2}$ & & \\
\hline planeity of vanes & $0,10 \mathrm{~mm}$ & & \\
\hline Insert & dawing value & at protoshop & after tests \\
\hline Internal diameter on nozzle side / in middle / on outlet side & $53,3 \mathrm{~mm}$ & /// & /// \\
\hline External diameter on nozzle side / in middle / on outlet side & $58 \mathrm{~mm}$ & I/II & I/I \\
\hline \multirow{2}{*}{\multicolumn{4}{|c|}{$\begin{array}{l}\text { Circularity at internal diameter on nozzle side / in middle / on outlet side } \\
\text { Circularity at external diameter on nozzle side / in middle / on outlet side }\end{array}$}} \\
\hline & & & \\
\hline Diameter of antirotating pin hole & $6,2 \mathrm{~mm}$ & & \\
\hline \multicolumn{4}{|l|}{ Ra insert } \\
\hline Piston & dawing value & at protoshop & after tests \\
\hline Diameter of bolt anti rotating of piston & $6 \mathrm{~mm}$ & & \\
\hline External diameter on piston ring & $53,25 \mathrm{~mm}$ & & \\
\hline Gap on piston ring & $\mathrm{mm} ?$ & & \\
\hline groove width of piston ring on piston & $6,5 \mathrm{~mm}$ & & \\
\hline external diameter of piston (on sliding contact) & $52,9 \mathrm{~mm}$ & $52,9 \mathrm{~mm}$ & \\
\hline External diamter on collerette & $60,8 \mathrm{~mm}$ & $61,16 \mathrm{~mm}$ & \\
\hline Diameter of leading edge on piston & & $60,9 \mathrm{~mm}$ & \\
\hline distance between pads on piston for fork & \multicolumn{2}{|c|}{$\mathrm{mm}$ (but not directly quoted) } & \\
\hline External diamter of piston on fork area & $45,6 \mathrm{~mm}$ & $6 \mathrm{~mm}$ before recti & \\
\hline Internal diameter of piston & $40,5 \mathrm{~mm}$ & $40,44 \mathrm{~mm}$ & \\
\hline Visual aspect of piston (on sliding contact) & $\begin{array}{c}\text { micro-welding; stripes; } \\
\text { corrosion; particles }\end{array}$ & & \\
\hline Visual aspect of piston (on fork contact) & & & \\
\hline Throat & $? ? \mathrm{~mm}^{2}$ & & \\
\hline planeity of vanes & $0,10 \mathrm{~mm}$ & & \\
\hline
\end{tabular}




\section{Metrology matrix}

Several tests cycles have been defined with intention to represent different product life cycle situations. These tests cycles are representative of end use most severe duty cycles that oure VGT product will have to survive before release for mass production.

Table below represents the most important cycles that are replicated during pre durability phase.

\begin{tabular}{|l|l|l|}
\hline \multicolumn{1}{|c|}{ Test type } & End user driving type & \multicolumn{1}{|c|}{ Damage types } \\
\hline $\begin{array}{l}\text { Thermal schocks } 1000^{\circ} \mathrm{c}-300^{\circ} \mathrm{c} \text { on engine } \\
\text { Thermal schocks } 1000^{\circ} \mathrm{c}-300^{\circ} \mathrm{c} \text { on gas stand }\end{array}$ & $\begin{array}{l}\text { Heavy load variations } \\
\text { Big torque cycling }\end{array}$ & $\begin{array}{l}\text { Cracks in materials } \\
\text { High thermo mechanical stresses } \\
\text { Turbine and nozzle deformations(creep) }\end{array}$ \\
\hline \hline Piston cycling combined with thermal cycling & $\begin{array}{l}\text { Motorway with load variations } \\
\text { City driving intensiv }\end{array}$ & $\begin{array}{l}\text { Wear in variable geometry } \\
\text { Transient thermal deformations( sticking) } \\
\text { Durability of control mechanism }\end{array}$ \\
\hline \hline Load steps cycling & $\begin{array}{l}\text { Mountain drive } \\
\text { Frequent gear and load } \\
\text { changes }\end{array}$ & $\begin{array}{l}\text { Piston sticking } \\
\text { Piston wear } \\
\text { Variable geometry actuation durability }\end{array}$ \\
\hline \hline Poly cycle & $\begin{array}{l}\text { Combination of different } \\
\text { driving profiles }\end{array}$ & $\begin{array}{l}\text { Components wear } \\
\text { Performances evolution } \\
\text { Sticking and erratic events } \\
\text {-urban } \\
\text {-motorway }\end{array}$ \\
\hline
\end{tabular}

Tests cycles summary

One example of test cycle pattern is represented graph below, mainly focused on material creep and components thermo mechanical fatigue and cracks. This type of pattern is repeated for 200 hours on gas stand or on engine. Cracks occurrence and propagation are monitored during test; full component damage analysis is completed after end of test.

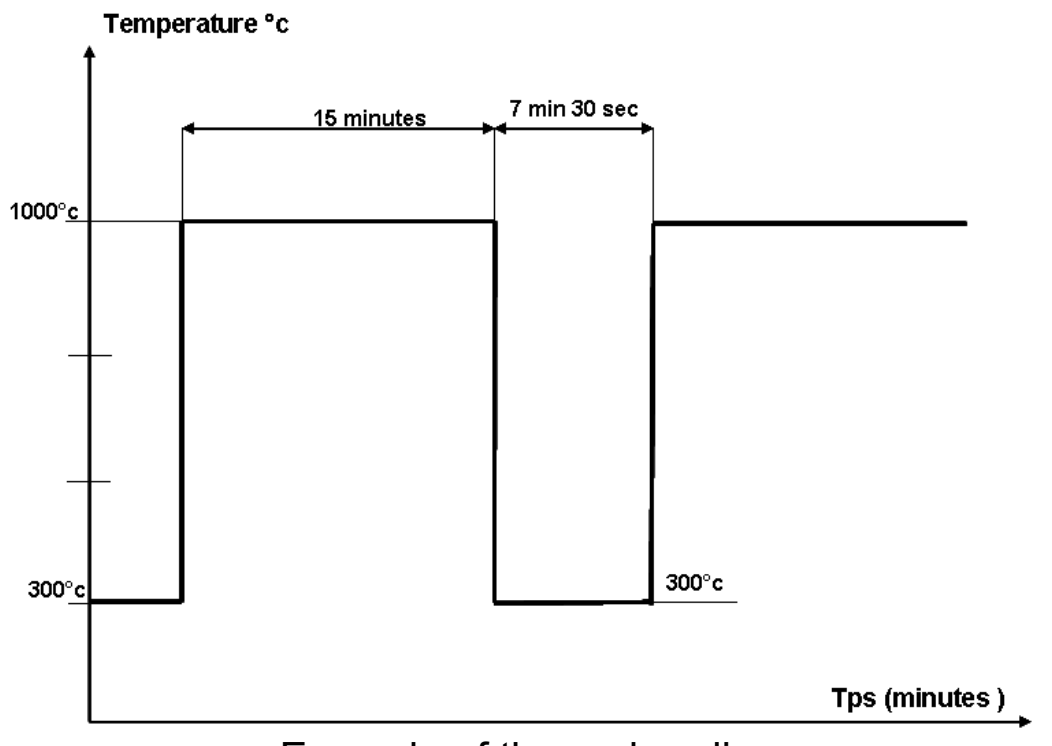

Example of thermal cycling 
Figure below shows an example of poly cycle pattern that represents a worst case condition of an end user driving cycle. This type of test is implemented on engine bench and equivalent components cycles are defined to be run on component bench. Advantage of component specific test is to address one specific failure mode at a time, therefore more accurate damage predictions.

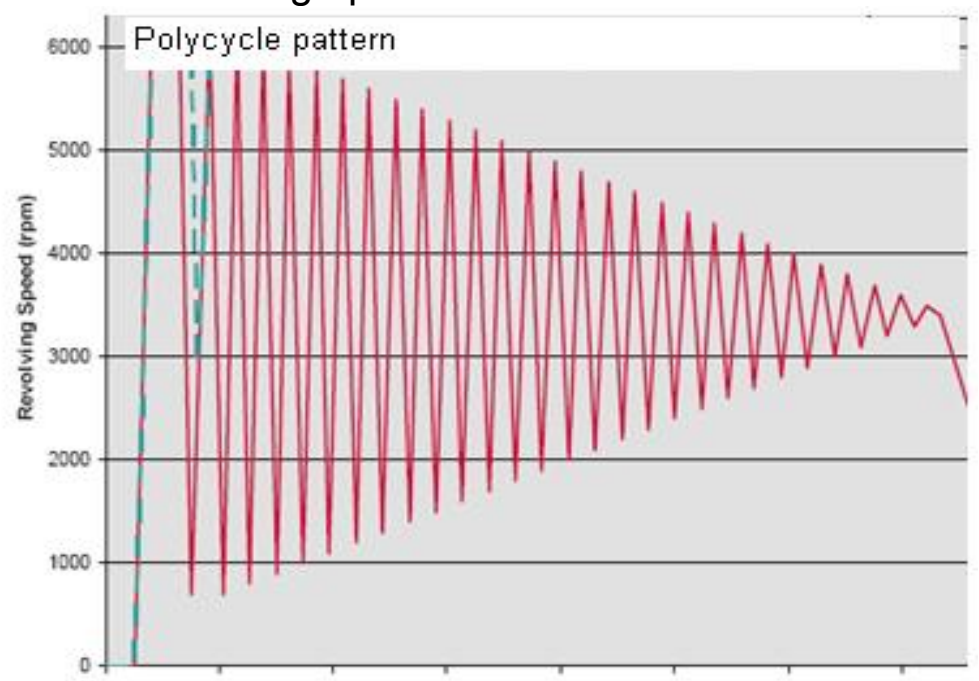

Example of poly-cycle pattern

Key results obtained during these first pre durability tests have generated damages in expected areas as predicted by our FEA analysis.

Piston and nozzle: Looking at the piston we can see cracks occurred at the base of the vanes at the inducer end. These cracks are limited in length and don't propagate across the component, therefore not leading to a mechanical failure. We could expect these cracks obtained by thermo mechanical fatigue during thermal shocks after 400 hours. See the figures below.

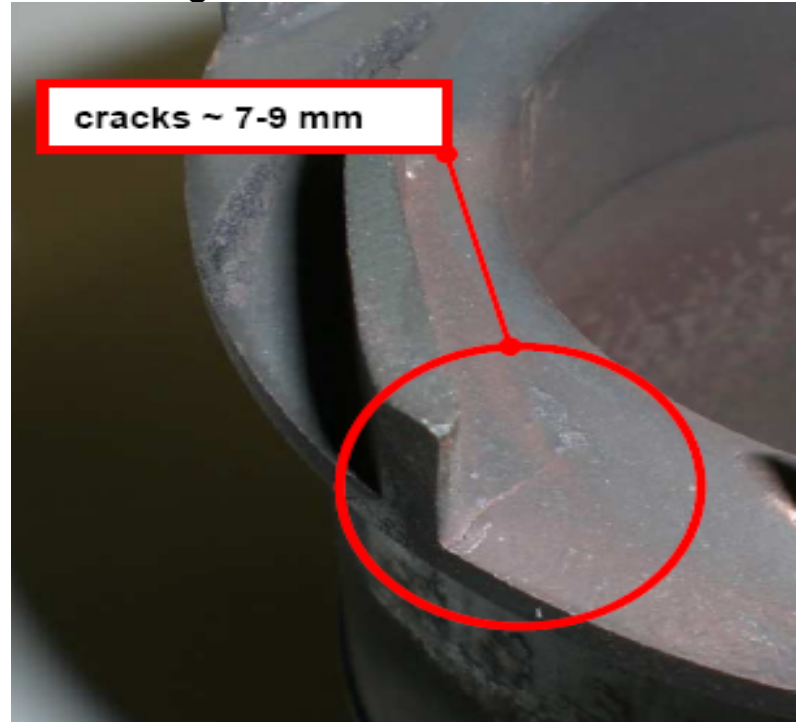

Piston damage : vanes cracks

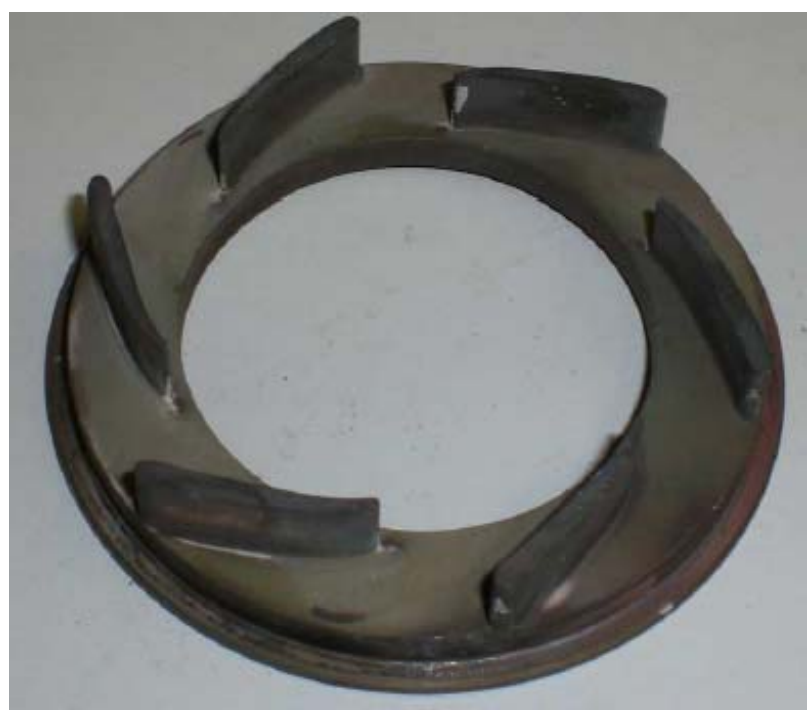

Nozzle damage: surface corrosion 
We see that nozzle is mechanically intact, no crack occurred at vanes base. Some hot corrosion evidence can be seen, unexplained at this stage of the project. We pursue our investigation with chemical analysis to understand what could generate this phenomenon.

The good thing is that there is no performance impact for our turbo charger and no mechanical functional disturbance. Considering severity of this test, we can say that it is a very positive result for our nozzle concept. These first results are used to calibrate our FEA model and optimize the vanes to minimize cracks occurrences.

Another important failure mode investigated during piston cycling tests was wear and sticking. Figure below shows piston wear after 200000 cycles. Visual appearance shows important scratch at piston surface, but metrology data show only few microns abrasive wear. We also see some material transfer from turbine insert to piston that could be a warning with respect to piston sticking.

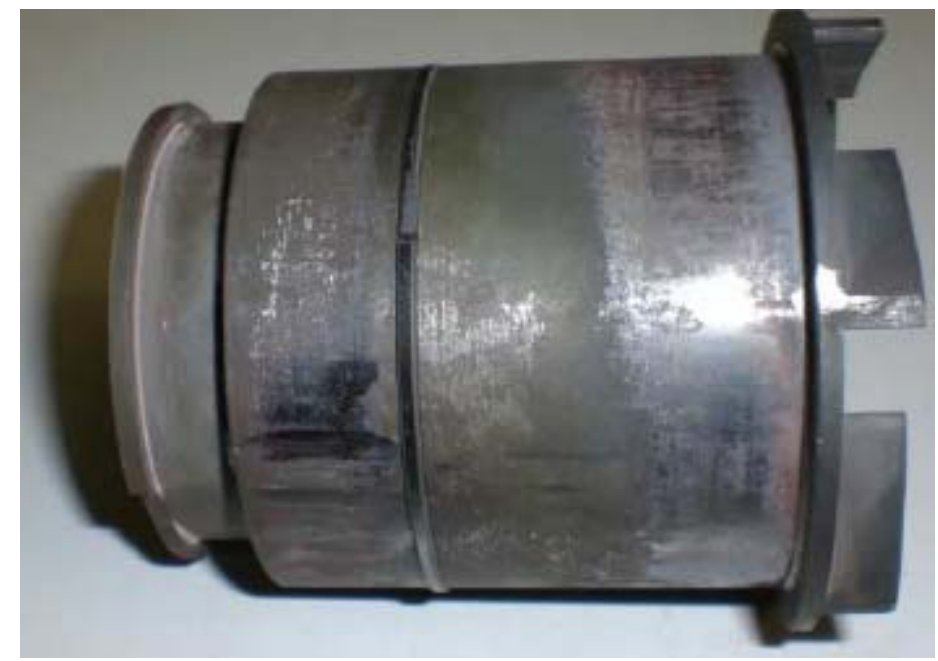

Piston wear - piston ring functional

From these results we reconsider piston - insert clearance and materials compatibility from a mechanical contact standpoint. Good thing about this is that piston is still fully functional as well as the piston ring which ensures appropriate level of gas leakage. There was no piston ring collapse even after severe thermal shocks. This confirms that piston ring material upgrade to withstand higher temperatures was the right decision.

Turbine housing - insert: Major damage observed on the turbine housing is symmetrical cracks at the angles of the tongue. Please see the figure below. These cracks could be dangerous in a way that they could go through the turbine and generate either gas leakage of complete turbine housing mechanical failure. This test results is very useful to calibrate our FEA model and optimize the machining of the tongue: transforming sharp machining angle to nice filet will minimize stress concentrations and delay crack occurrence during thermal shocks. 


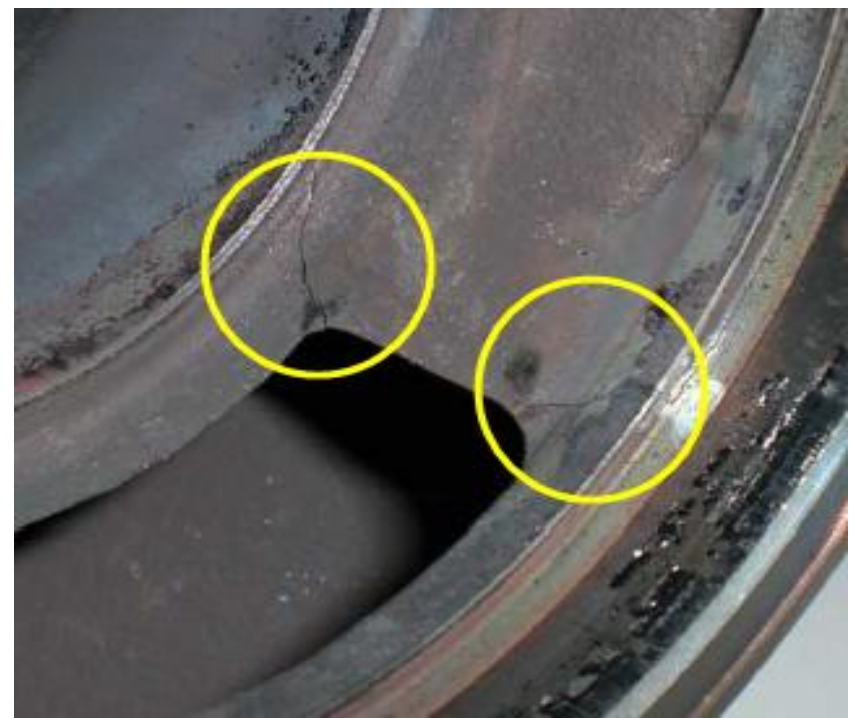

Turbine damage: cracks in tongue

Other areas of the turbines (flange, volute, piston cylindrical area) have shown no major deformation. We can say that creep is limited in the turbine housing itself which is consistent with the high material yield stress limit (HK30 stainless steel) in the $1000^{\circ} \mathrm{C}$ temperature range.

But we can see that insert could suffer high plastic deformations due to the fact that piston and insert expands much faster than turbine housing. As a results high stress applied to the insert which has a lower yield stress limit has generated plastic deformations that we could reproduce in an oven test. During gas stand tests we could observe sticking problems as summarized in table below. These sticking have been caused by loss of clearance between piston and insert because insert was press fit in turbine and has been plastically deformed during thermal transients.

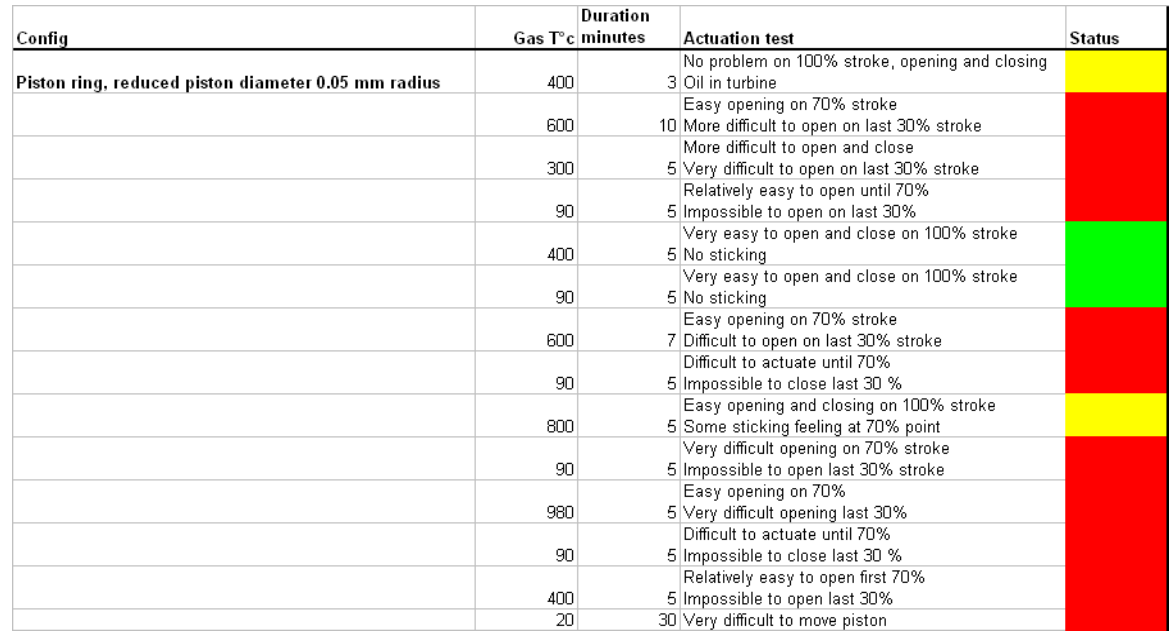

Sticking phenomenon - gas stand tests observations

Creep phenomena could be reproduced in oven as shown figure below. As all components are at the same temperature, sticking phenomenon is not observed during 
this test which confirms our understanding of this failure mode. All these experimental observations have been predicted quite accurately by FEA analysis.

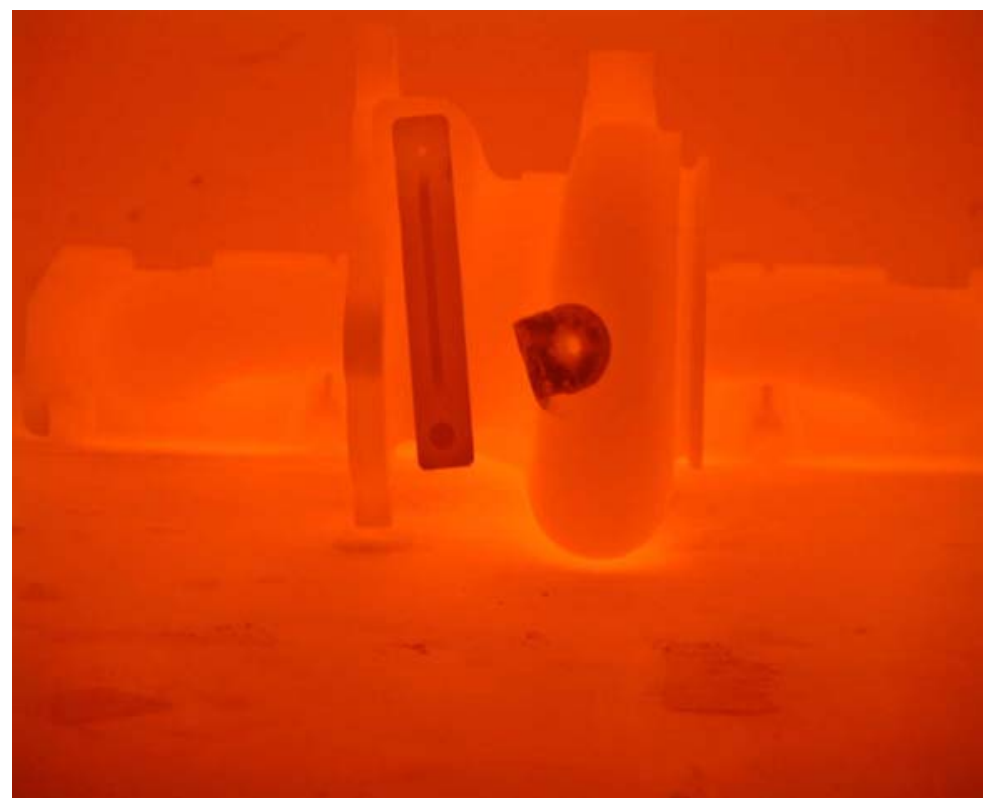

Creep and sticking phenomenon - oven tests

Fork: Fork is the key force transmission component between actuator and piston. A good contact quality and durable between fork and piston must be ensured. Main observation (shown in figure below) is a non symmetric wear of fork contacts with piston. 2 important consequences are excessive axial clearance that will impact controllability and non symmetrical guiding of the piston. This last consequence is more severe as it can cause piston sticking either in cold or hot conditions. Immediate remedy will be new fork design and reduce fork axis clearance in order to minimize non symmetrical force. A possible next step would be to have a double bushing rotational guiding for the fork.

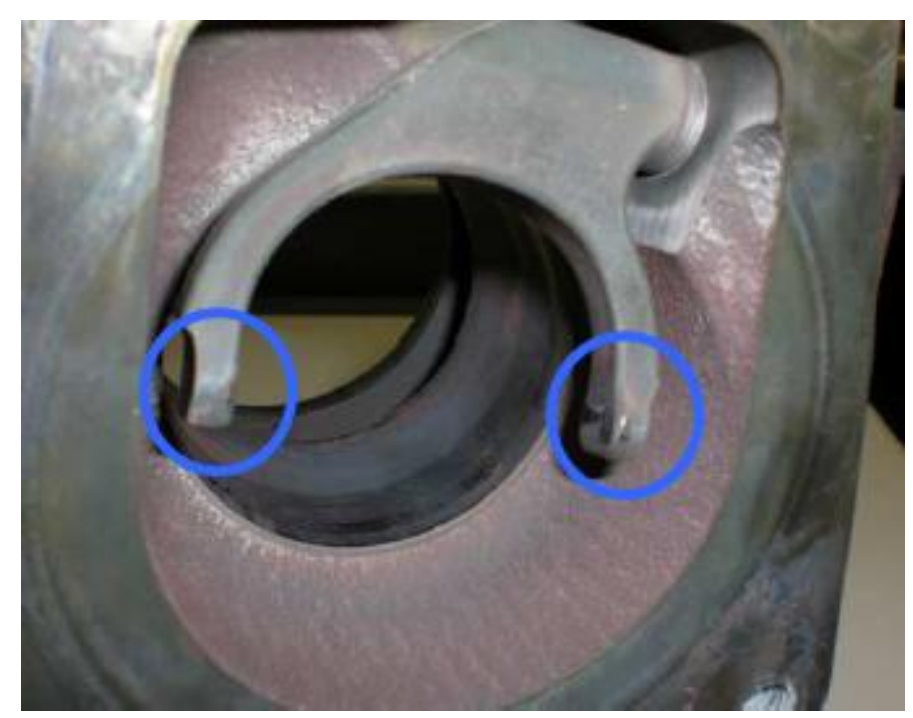

Fork damage: asymmetric wear 


\section{Overall durability status:}

Several failure modes have been reproduced during these preliminary pre durability tests. Engine and gas stand tests correlate very well with predicted weaknesses from FEA simulations and DFMEA analysis.

Next important steps will be:

- $\quad$ Continue pre durability tests to cover more product life cycle situations

- Optimize design for final durability

- Conduct final endurance before releasing design for production

\section{Task 4.10 - Final Durability Tests}

This activity has not been able to complete in the reported time period

\section{Inventions/Patents}

All inventions, patents and associated publications related to this project are being reviewed for applicability and will be submitted under separate cover. 


\section{PROJECT 5 - MODULAR HYBRID BOOSTING}

The objective of the Modular Hybrid Boost (MHB) concept is to meet air demand requirements of future engine strategies whose air system performance cannot be satisfied with state of the art turbocharger systems. These engine concepts include $\mathrm{HCCl}$ engines, or other "Multi-Mode Combustion" compression ignition engines, or high efficiency, dilute gasoline engines. The MHB system comprises a turbine driven generator, a motor driven compressor, and various other components in different configurations. These other components could include ultra-capacitors, motor/generator drives coupled to the engine crankshaft, power electronics and advanced multi-variable controls.

The Modular Hybrid Boost program objective is to assess the feasibility of the concept through an initial trade study including component modeling and performance analysis, then to progress to concept demonstration with an initial design. Figure 1 shows the basic system block diagram.

This report covers the Phase 1 of this program which was completed in the $4^{\text {th }}$ quarter of 2006.

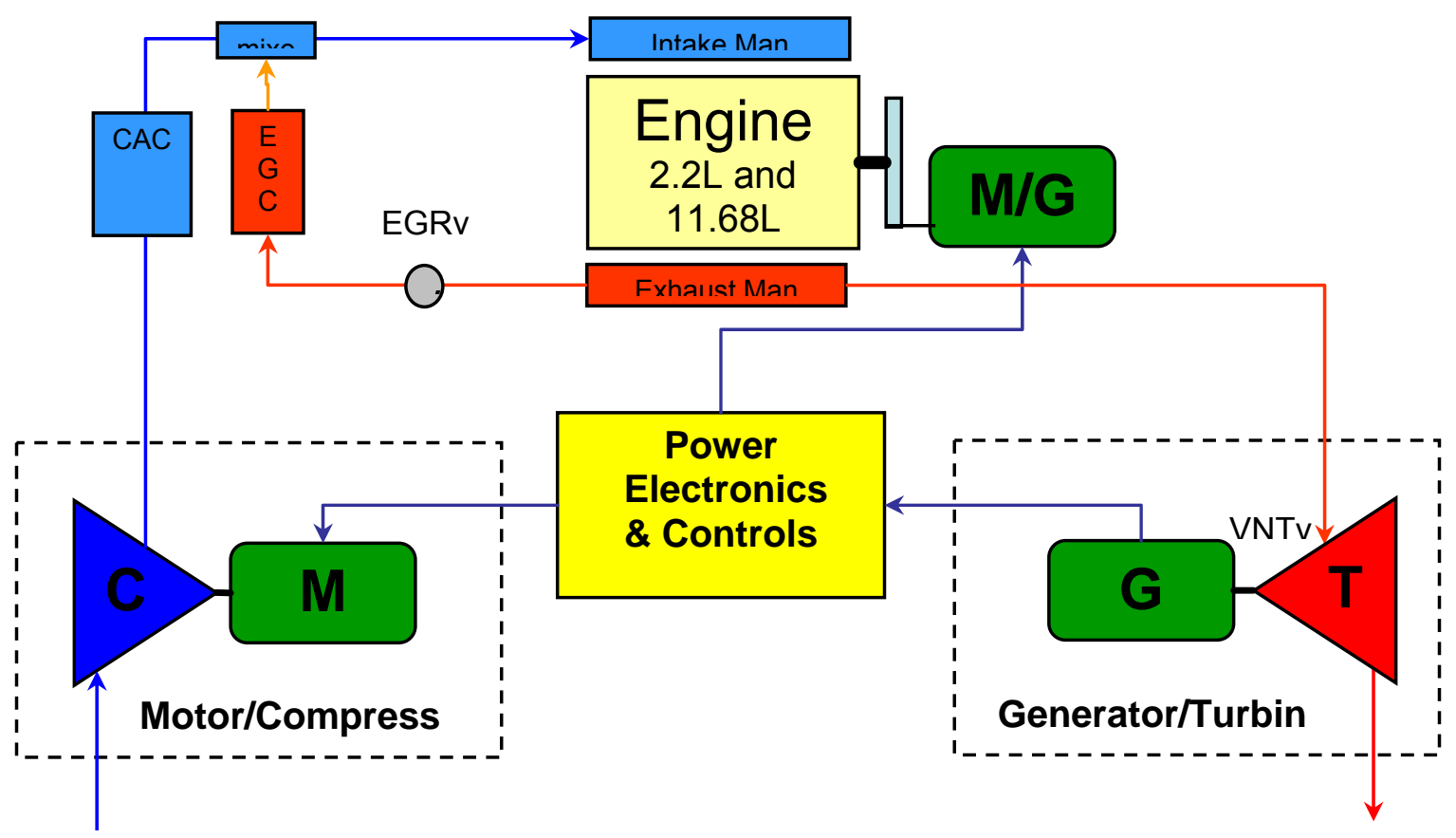

MHB System Block Diagram

\section{Task 5.1 - Feasibility Study}

Phase 1 of the project entails a two part feasibility study involving boosting requirements analysis and performance simulations. Boosting requirements will be used to size 
system components including motors \& generators. Performance simulations will compare MHB against baseline configurations and will help develop control methodologies.

Phase 1 of the project is complete. Requirements analysis used to determine component specifications and suppliers found with capability to meet these requirements. Performance simulations found MHB has key benefits over state of the art boosting technology.

Results: Turbine and compressor power/speed requirements were established for 3 engine sizes. These were used for a design study of the generators and motors. Permanent Magnet Brushless DC architecture can provide the power density and speed requirements for the range. Size and weight are reasonably matched for the turbines and compressors they mate to. No fundamental problems were found to preclude successful implementation of the design. Efficiency should be greater than $90 \%$ over most of the operating range for all configurations and over $95 \%$ for the larger systems. See Figure 2 for an example of compressor motor power requirements.

Two sources are being researched to supply motors \& generators; Calnetix \& Honeywell Aerospace. Calnetix participated in the initial study. See report "MHB Motor \& Generator Design Study" for motor \& generator details

Identified areas of high risk for the motor and generator designs are rotor dynamics and thermal management. These areas will get special attention in the design phase.

\section{Task 5.2 - Performance Simulations}

Performance simulations were run using GT Power engine simulation tool. These show significant benefits of MHB system over current boosting technologies. This is especially true for advanced combustion techniques where EGR rates exceed the capability of traditional systems.

For 2.2 liter engine, MHB enabled:

- Higher EGR rates at part load (supercharging)

- Improved fuel economy at full load \& high engine speed

- Higher turbine efficiency operation over wider range

- Turbo compounding at high power

For an 11.6 liter engine, MHB enabled:

- Higher EGR rates at part load and full load

- Higher turbine efficiency operation over wider range

- Improved fuel economy at part load and full load

At identical operating points (EGR level and AFR), the MHB system has an inherent challenge in achieving fuel economy due to the power losses of the motor and generator (compared to a solid shaft). Despite this handicap, the MHB system showed comparable efficiency at part load operation. The opportunity exists to further optimize 
the turbine and compressor operating points and achieve both higher EGR rates as well as better fuel efficiency.

See report "MHB Performance Simulation Summary of Results" for details.

\section{Overall Progress Update}

Several important design decisions were made in the final design. The transmission technology has been selected as well as what bearing types will be used. All fundamental components and design features are defined. The motor-generator hardware was delivered ready for final grinding and assembly. With this progress, some significant hurdles still remain.

The transmission selection was driven by bearing considerations. The traction drive normal load requirement drove bearing life far below acceptable levels. This constraint is the primary drawback to traction drive implementation. The alternative transmission is helical gears. The bearing loads are well within limits and material costs may be acceptable. Other problems with gears include alignment, thrust loads and noise. The tooth pitch combined with the gear speed may keep gear noise above audible frequencies. Thrust washers are being included in the design and alignment tolerance is being analyzed.

The gear design utilizes a standard gear tooth pitch. This will keep manufacturing cost down as well as keeping prototype schedule reasonable. Gear face profiling may be needed to reduce noise but will not be included on initial prototypes so worst case can be evaluated. Pitch line velocities are quite high but within limits used in aerospace applications allowing use of standard gear steels.

The bearing selection was straight forward once the transmission was selected. The HP shaft will have 2 angular contact ball bearings, the LP shaft will have 1 angular contact (or possibly deep groove) ball bearing between the gear and rotor and an air bearing by the compressor wheel. The idler gear will employ a journal bearing integrated into the hub with the hub side faces acting as the thrust bearing.

Rotordynamics analysis of the new system is quite complex. Gear meshing introduces rotor instability while providing some damping. Dynamic coupling between shafts may be quite high but is difficult to quantify. Our existing rotordynamics software does not support this analysis. Alternate approaches are being investigated as well as modifying the existing code. We do not have a good projection of the time or results of this analysis.

Cooling and lubrication requirements have been quantified and flow paths have been chosen. Plumbing is being integrated into the housings as much as possible to keep complexity and cost down. The stator will be liquid cooled with engine coolant but it may need a separate cooler to drop fluid temperature for high load cases. This is undesirable for production so better winding material may be needed. The rotor gap will be cooled with fresh air that will also provide flow for the air bearing. A separate fan and clean air source may be needed for this cooling air to keep the air bearing from fouling. This will be an issue if diesel engines start using mass air flow sensors. If air bearing contamination can be addressed, bleed air will be used for cooling flow. 
The compressor wheels and turbine can use existing designs. The flow/speed and efficiency requirements fall within the capability of existing designs. The turbine will use a double axle VNT designed for heavy duty diesel application. This will significantly reduce development times for the wheels and housings for the components. These designs are also already qualified for this application so commercialization should be less problematic.

Stackup, thermal and manufacturability analysis is beginning. Center housing thermal distortion affecting gear alignment is a significant concern. Thermal gradients are quite high and areas are large. Parting lines, materials \& attachments of the various housings are also being analyzed for best candidate solution.

Motor-generator hardware was received in December. The rotors are ready for grinding when design is complete. The stators are complete and ready to fit into the housings. Power electronics with controllers are scheduled for delivery in March 2008. The turbo motor-generator will be powered from a grid interface using 480V 3 phase power. This interface is bi-directional so bench and gas stand testing can include both supercharging and turbo-compounding. The engine coupled motor-generator is in development, scheduled for delivery in Q2 '08. The base engine for testing is scheduled for delivery in January ' 08 .

The high EGR requirements to meet US2010 emissions standards can be achieved without supercharging. The need for supplemental compressor power was a fundamental assumption at the early stages of the program. Simulation results have also shown very low benefit from turbo-compounding. Using a massive EGR schedule for US2010 emissions (without SCR), results showed negative benefit for most points and never above $1 / 2 \%$ BSFC reduction. In light of this result, simulations were run using a Euro6 EGR schedule with SCR after treatment. This approach requires significantly less EGR but has slightly higher exhaust backpressure. Figure below shows simulation results for BSFC improvement for varying turbo efficiency and conversion efficiency at the Euro 6 EGR rates. 


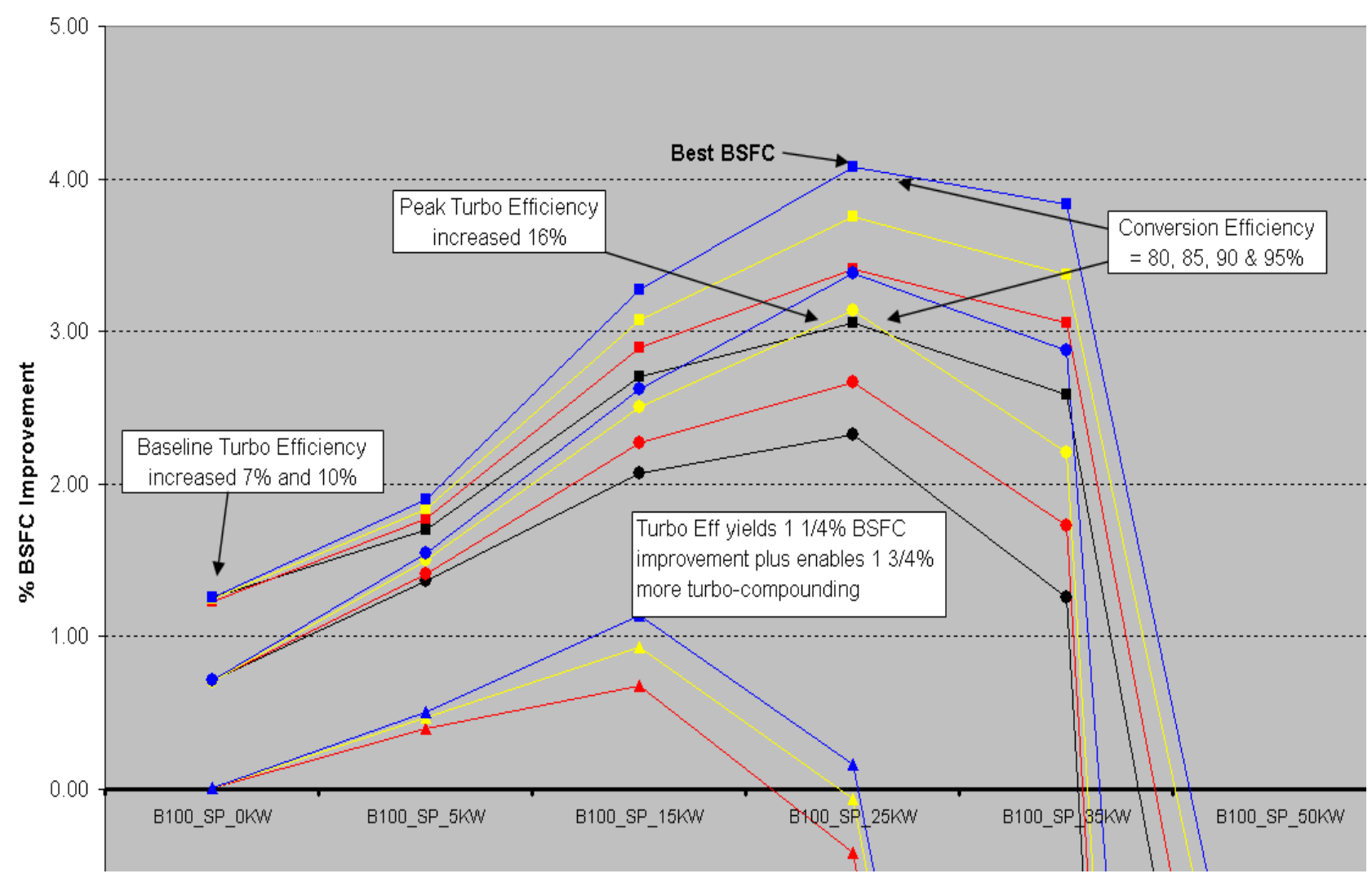

BSFC Change from Turbo-Compounding

With typical turbo efficiencies, the fuel economy benefit from turbo-compounding was less than $1.5 \%$. With higher turbo efficiencies, the benefit is as much as $3 \%$ (plus $1.5 \%$ for the improved turbo efficiency). This is for an engine operating point where high turbo-compounding benefit could be found. The "conversion efficiency" is the total efficiency from turbo shaft to crank shaft. This was varied from $80 \%$ to $95 \%$ to compare our efficiency estimates to other published data. Turbo efficiency was also varied to compare to published systems.

These results are still below the published data. Typical values for turbo-compounding benefit range from $4-7 \%$ with some as high as $10 \%$. With the increased efficiencies, we were able to match the lower range of claims, but we could not approach the higher end. Some other potential sources of variability are EGR \& A/F rates. In an effort to bottom this out, we met with a major OEM supplier of engines with turbo-compounding systems. Data was exchanged and discrepancies between results are understood. We are confident our performance simulations are accurate.

This discussion is critical to the project since the very foundation of the concept rests on the need for supplemental compressor power and the benefit of turbo-compounding. The last remaining benefit of the motor-generator would be transient response. This aspect is the next area of investigation to determine the concepts validity. Without significant demand or benefit, the cost and complexity of an electric machine coupled to the turbo would not be marketable. 
In light of the low projected benefits and high system cost and complexity, the project has been suspended.

\section{Inventions/Patents}

All inventions, patents and associated publications related to this project are being reviewed for applicability and will be submitted under separate cover. 


\section{PROJECT 6 - TITANIUM COMPRESSOR WHEEL DEVELOPMENT FOR PASSENGER VEHICLE SIZE TURBOCHARGERS}

The objective of this project is to design, procure, test, develop and qualify a series of passenger vehicle size turbochargers (GT20 - GT27 sizes) which are capable of withstanding the rigors and duty cycle associated with high specific output medium duty (MD) applications. These applications are more severe than typical passenger vehicle applications. The compressor wheel will be designed in titanium to resist low cycle fatigue (LCF) failures and the compressor housing will be designed in cast iron for containment purposes. Additionally, the center housing (bearing housing) must be redesigned structurally to support a larger mass compressor housing and the center housing also accommodates a completely new bearing system. The new bearing system is required to control a new rotating group with a higher mass compressor wheel (titanium vs. aluminum) and must span from a GT20 to a GT27 rotating group.

\section{Background}

Titanium compressor wheels are being designed for turbocharger sizes used on high output, medium duty (MD) applications. These applications tend to have severe duty cycles, requiring titanium wheels in place of traditional aluminum wheels due to low cycle fatigue (LCF) life requirements. Many high output MD application air systems utilize two turbochargers in series configuration, with the smaller, high pressure stage (HP) turbocharger being subjected to high compressor inlet pressure and temperature. These conditions also lead to migration from aluminum wheels to titanium in order to combat material creep and LCF failure. Lastly, MD air systems using long route EGR systems require titanium compressor wheels because the sulfuric acid content in the recirculated exhaust gas corrodes aluminum wheels, again resulting in reduced LCF life.

\section{Task 6.1 - Compressor Wheel/Rotating Group Design and Analysis}

Conduct aerodynamic analysis on wheel design, wheel scaling, and stress analysis for the titanium wheel rotating group. Complete rotor dynamic simulation for bearing system selection. Create \& select bearing system, rotating group geometry and associated internal components. Determine compressor wheel bore stress limits and design the compressor wheel accordingly.

\section{Task 6.1 Milestones}

Design and analysis of:

- Titanium Compressor Wheel

- Rotating Group (Turbine Wheel and Shaft Assembly, Bearings, Thrust Collar Components, and Compressor Wheel)

- Bearing System 


\section{Task 6.1 Overall Progress Update}

\section{Compressor Wheel}

Wheel castability studies have been initiated with tooling suppliers. Preliminary results suggest that some design changes may be needed in order to cast the wheels without damaging them.

\section{Bearing System Analysis}

Further analysis of the rotating groups has lead to fundamental understanding of the cause of the high-speed rotor dynamic instabilities witnessed during testing. The figure below on the left shows the most recent test results, including the high-speed instabilities. The figure on the right shows the newest analytical results, with the previous design (red) and a new modified design (blue). Analysis shows that the new design removes the high-speed instabilities for the smaller wheel sizes. Continued analysis has shown that the larger wheel sizes with the new design changes still show some high-speed instability, although greatly reduced. Hardware with the new design changes has been ordered to validate recent analysis.

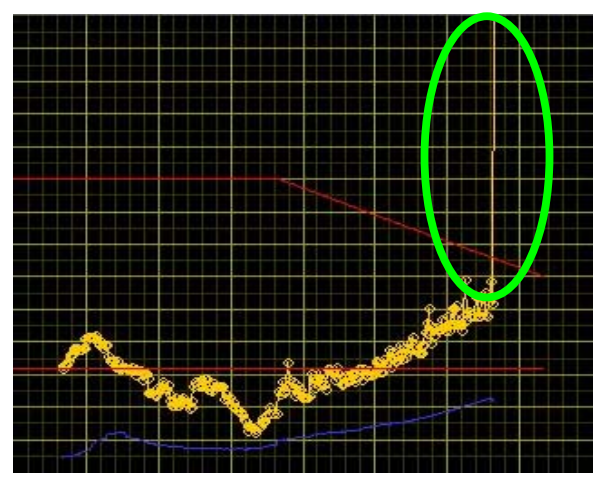

Test results with previous design

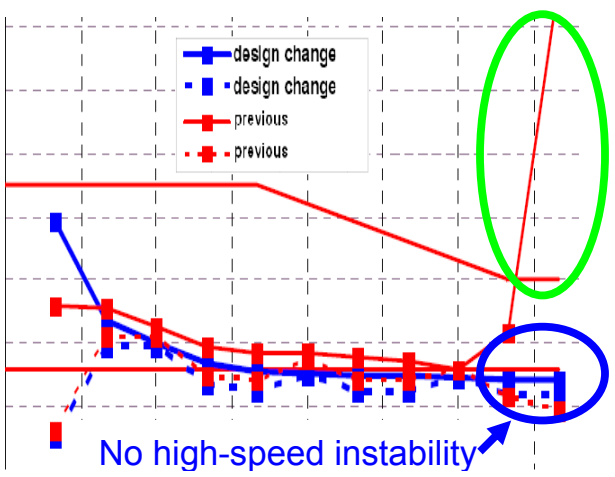

Analysis of new deisgn vs previous

New bearing system analysis compared with actual test results

\section{Task 6.2 - Compressor, Turbine, and Bearing Housing Design and Analysis}

Design several compressor housings, several turbine housings and one new center (bearing) housing. Conduct stress analysis on all components and TMF on turbine housing. Create 3D models and 2D drawings.

\section{Task 6.2 Milestones}

Design of compressor housings, turbine housings and center housings. Complete 3D models and 2D drawings.

Task 6.2 Overall Progress Update 


\section{Compressor and Center (Bearing) Housing Design}

A new center housing was designed to house the newly created rotating group. The center housing attachment flanges must accommodate turbine and compressor housings of all sizes that will be used for the new rotating group. Titanium compressor wheels require cast iron compressor housings to ensure containment in case of wheel burst. The use of cast iron in lieu of an aluminum compressor housing lead to the need for a newly designed compressor housing-to-center housing attachment flange. A Vbanded flange was selected and incorporated into the design.

The new cast iron compressor housing was initially based on an existing aluminum housing in order to maintain known performance characteristics. The new attachment flange was designed in conjunction with the center housing flange.

Housing 3D models were rapid prototyped in-house to ensure ease of assembly. An existing turbine housing design is currently being utilized for the smallest rotating group sizes in order to reduce potential qualification steps and failure mode risk.
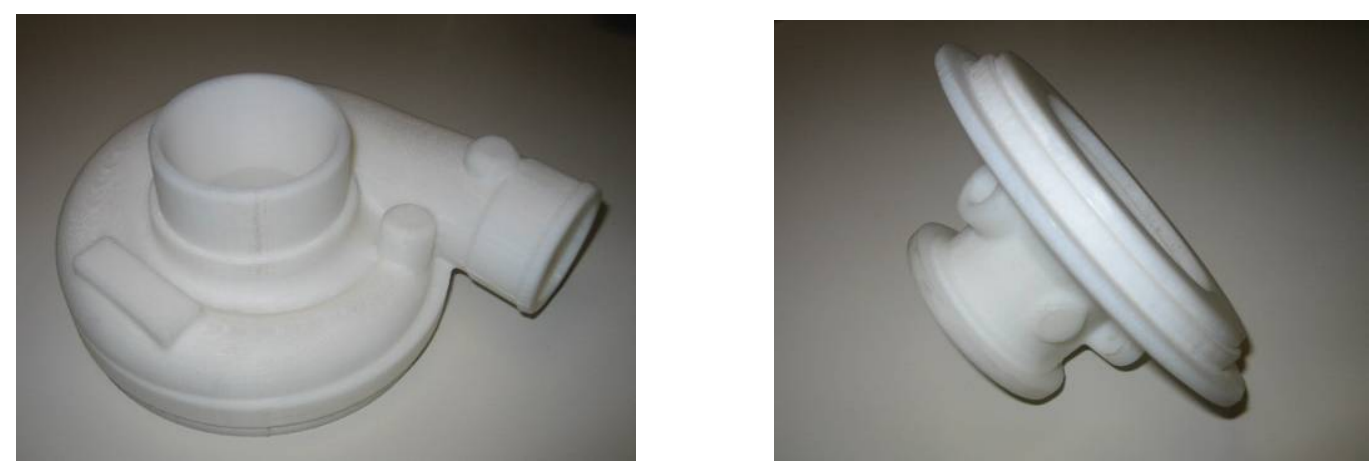

Rapid prototype models of new compressor and center housings

\section{Housing Analysis}

Stress analysis was conducted on the assembly of compressor, center, and turbine housings. With the added mass of the new cast iron compressor housing, structural stiffness was a concern. Analysis showed that the assembly of current housing designs is robust enough to withstand vibratory input and added mass loading. 

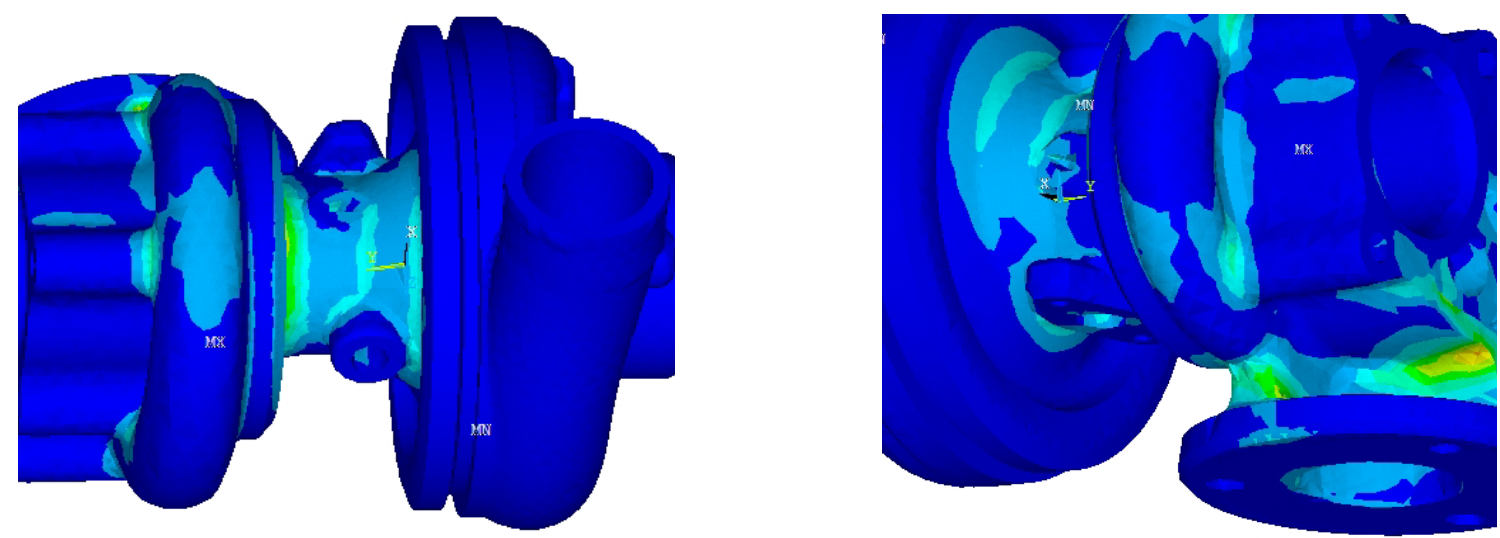

FEA results for compressor, center, and turbine housing assembly

\section{Compressor and Center (Bearing) Housing Design}

After successful performance testing of the first titanium wheel and cast iron compressor housing combination, the remaining wheel/housing combinations are being designed.

\section{Housing Analysis}

As the remaining wheel housing combinations are designed, the assembly of center housing, turbine housing, and new compressor housing will have to be analyzed for structural rigidity.

\section{Task 6.3 - Prototype Part Tooling, Procurement, and Assembly}

Order multiple compressor housing tools, one turbine housing tool, multiple compressor wheel tools, one turbine wheel tool and one center housing tool. These will be used to construct prototypes. Procure prototype hardware. Assemble prototypes in preparation for testing.

\section{Task 6.3 Milestones}

Prototype tooling and prototype hardware.

\section{Task 6.3 Overall Progress Update}

\section{Tooling}

Upon design completion, tooling was ordered for the new compressor housing, center housing, and center housing seal plate. Due to the use of an existing turbine housing for the currently designed rotating group sizes, new turbine housing tooling will not be ordered until large wheel designs are complete. Compressor wheel tooling has not yet been ordered. The first new titanium wheels were cast using machined investment wax models. When performance and durability validation is complete tooling will be ordered for new titanium wheel designs. 


\section{Prototype Procurement}

Prototype hardware was ordered to build first performance and durability test units. New hardware includes:

- Titanium compressor wheels

- Center housings

- Seal plates

- Journal beaings

- Thrust collars

- Shafts for turbine wheel-shaft assemblies

- Cast iron compressor housings

New turbocharger prototype units have been built and will be tested for aerodynamic performance and durability requirements.

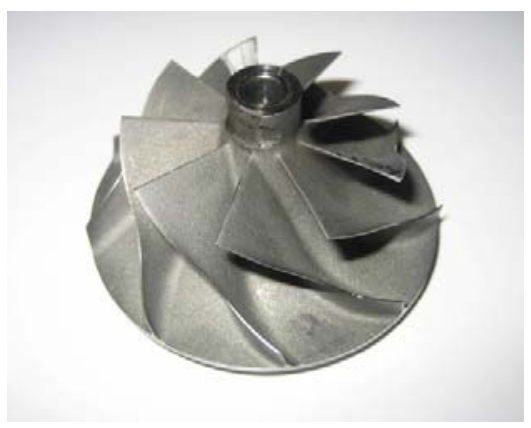

New titanium compressor wheel
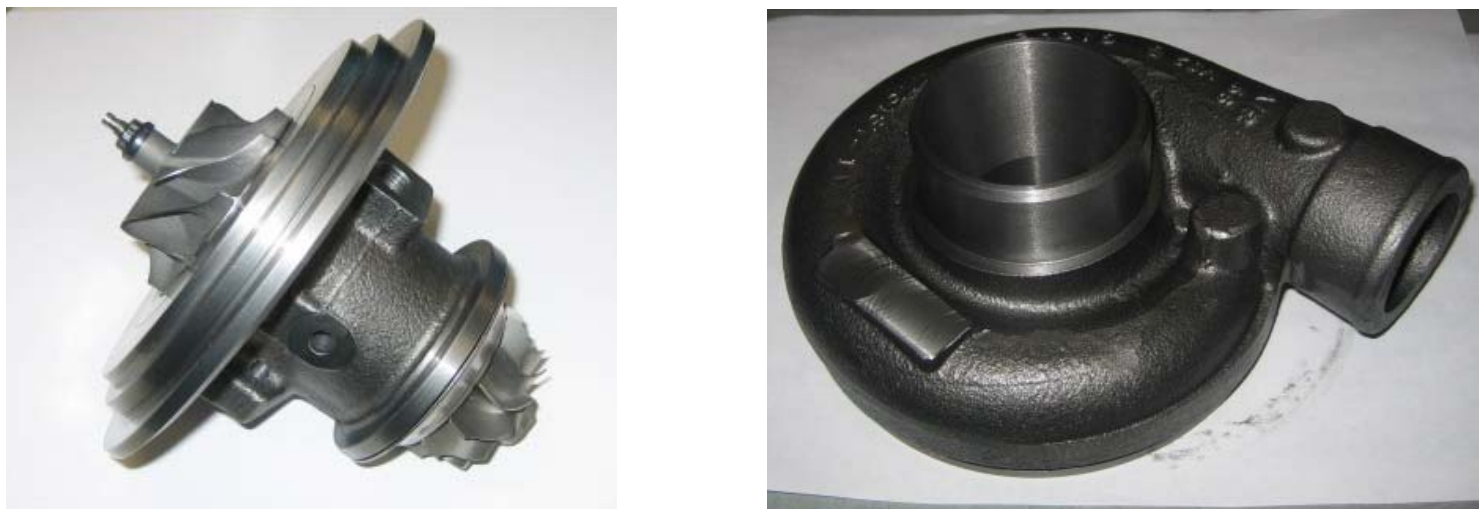

New Center Housing Rotating Assembly (CHRA) and cast iron compressor housing

\section{Task 6.4 - Shaft Motion (Bearing System Rotor dynamics) Testing/Validation}

Conduct comprehensive shaft motion testing on a gas stand to verify the rotor dynamics of the bearing system design.

\section{Task 6.4 Milestones}

Verify that the rotor dynamics are acceptable per Honeywell standards 


\section{Task 6.4 Overall Progress Update}

The first shaft motion tests were conducted on a GT2056 with titanium C230a compressor wheel. The four bearing clearance extremes were tested.
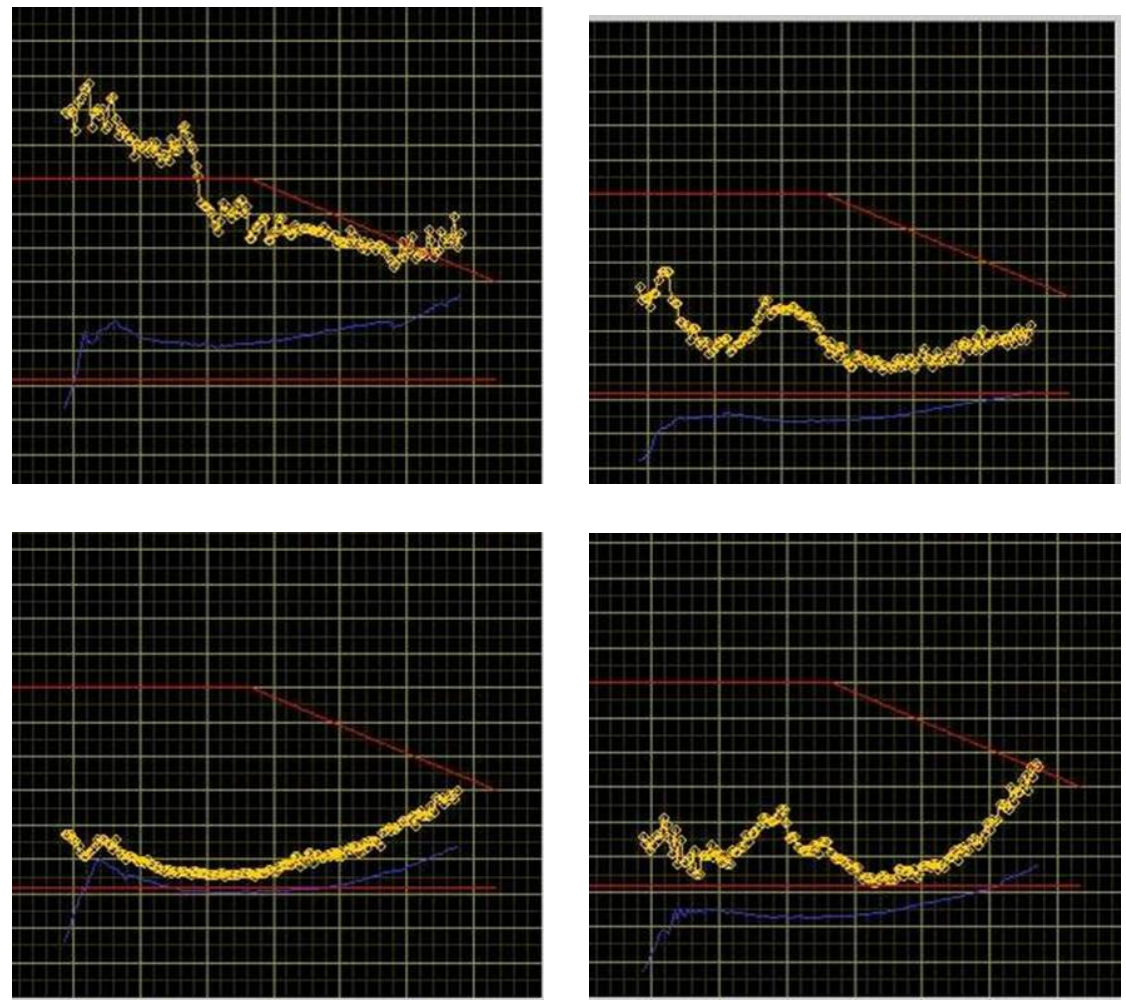

GT2056 titanium shaft motion test results

The results show minor violations of Honeywell limits. New hardware has been ordered to test the newest design changes based on recent bearing system optimization work.

Task 6.5 - Turbocharger Endurance and Performance Testing/Validation

Complete endurance and qualification testing including but not limited to compressor and turbine seal leak testing, hot shut down testing, thermal cycle testing, vibration endurance testing, bearing system capacity testing, on-engine endurance testing, joint durability testing, etc. Also conduct gas stand and on-engine performance testing.

\section{Task 6.5 Milestones}

Final design and technical reports documenting a fully qualified product line (GT20GT27) of turbochargers acceptable for MD applications

\section{Task 6.5 Overall Progress Update}


Testing: Performance testing was completed for the 56mm C230a compressor wheel. A sample compressor map is shown below.

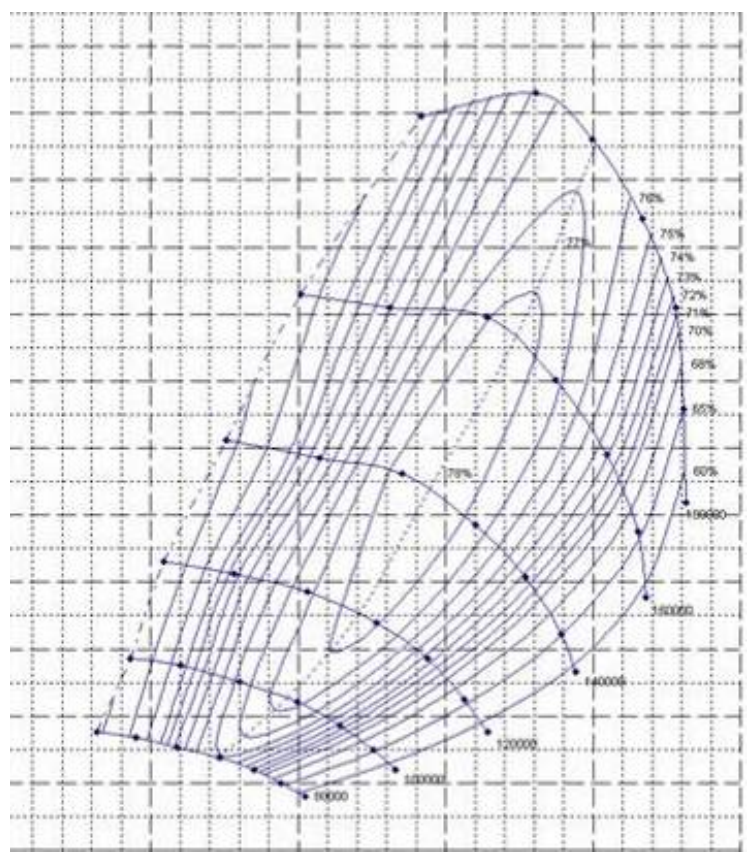

56mm C230a compressor map

Endurance testing is in progress: a sample cycle is shown below.

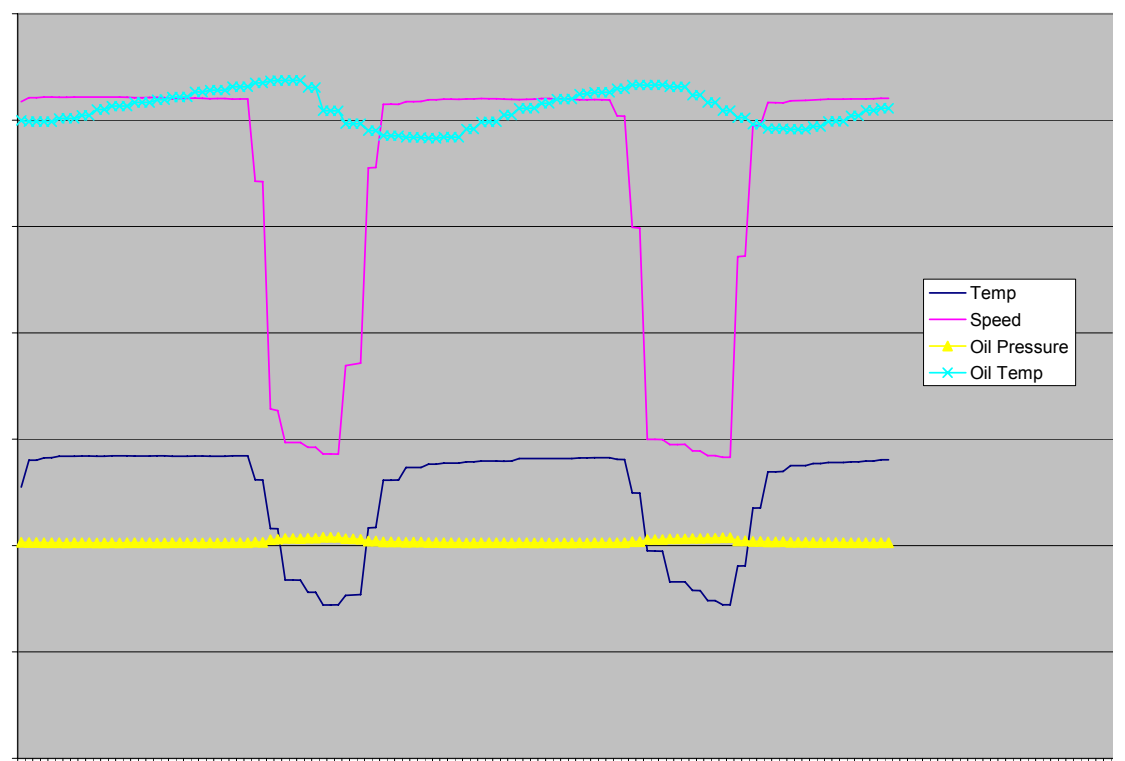

Endurance testing data snapshot 
Instrumented hardware for hot shutdown testing is ready and is waiting for test cell availability.

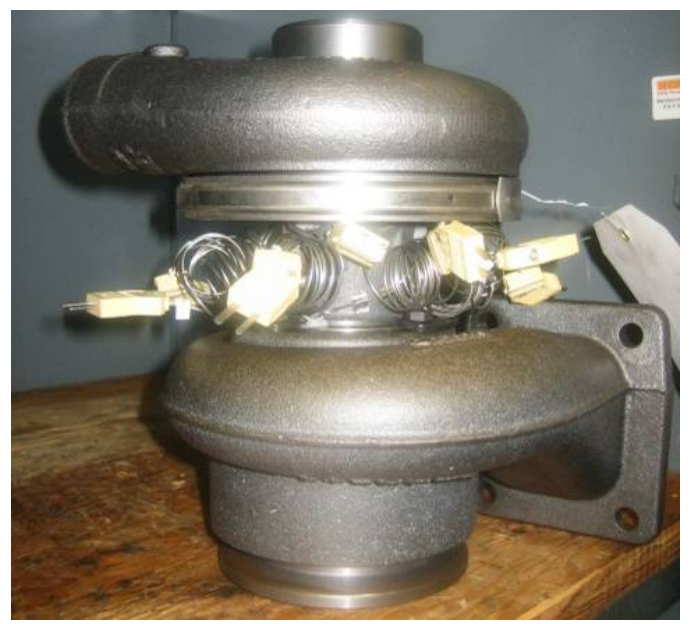

Instrumented hot shutdown unit

Several endurance/validation tests have been completed: hot shutdown testing, compressor and turbine seal testing, turbocharger cyclic endurance testing, and vibration endurance testing.

Hot shutdown testing was completed and passed Honeywell requirements. Temperature results vs. Honeywell limits are shown below.

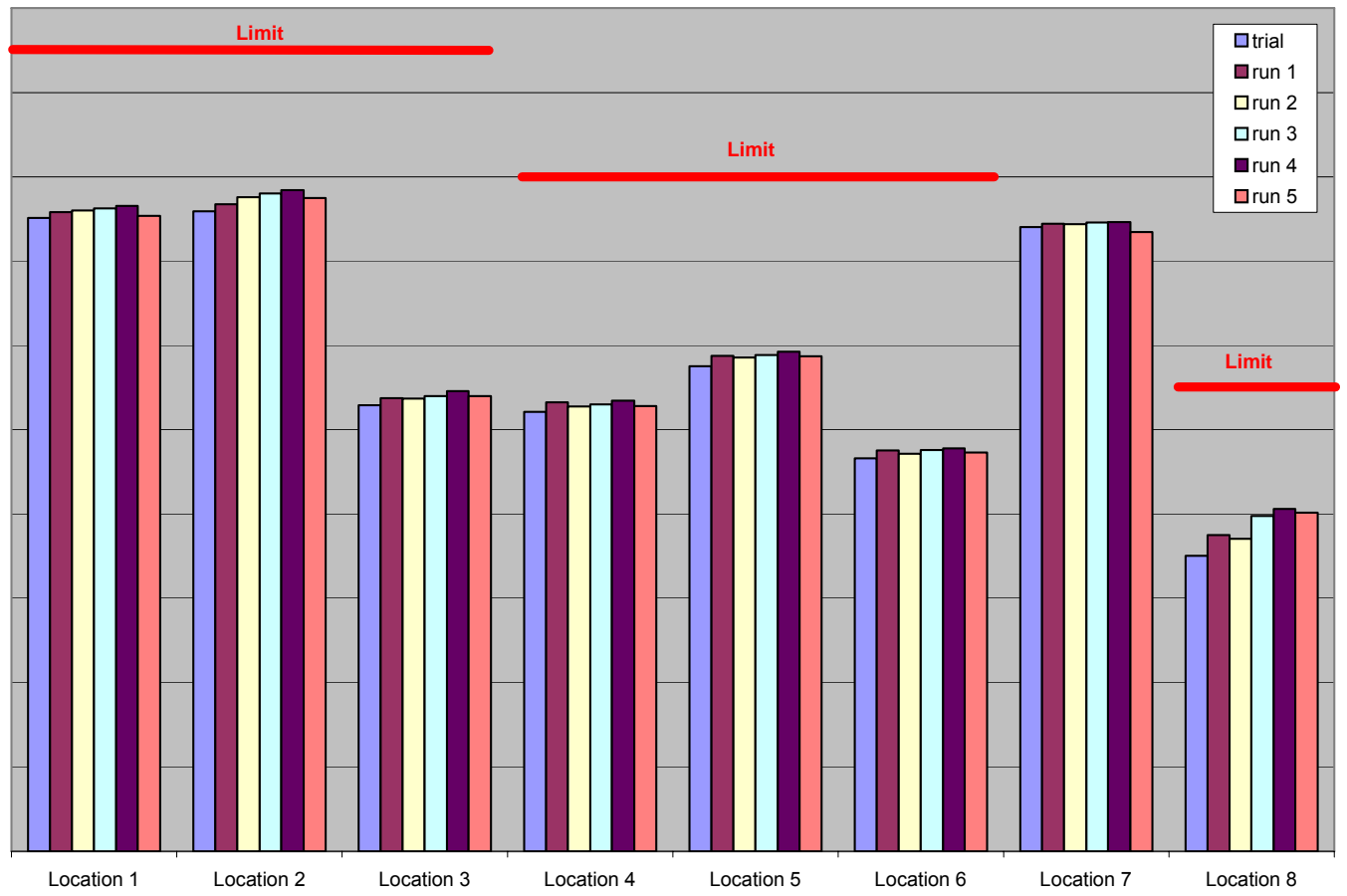

Hot shutdown testing results 
Compressor and turbine seal tests were run on-engine. All tests passed, meaning that under all operating conditions, no oil was allowed to pass from the bearing housing into either the compressor or turbine housing. Cyclic endurance and vibration endurance testing met Honeywell requirements as well.

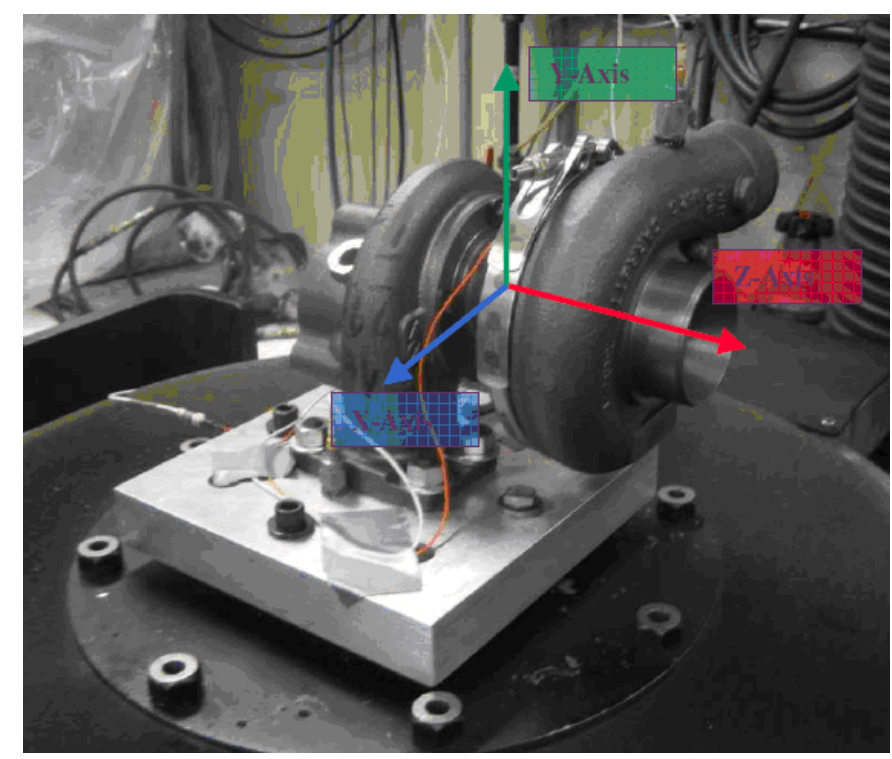

Vibration endurance test rig

\section{Inventions/Patents}

All inventions, patents and associated publications related to this project are being reviewed for applicability and will be submitted under separate cover. 